\title{
Clinical application of video image processing in cardiac angiology
}

Citation for published version (APA):

Janssen, J. H. A. (1989). Clinical application of video image processing in cardiac angiology. [Doctoral Thesis, Maastricht University]. Van Gorcum. https://doi.org/10.26481/dis.19890922jj

Document status and date:

Published: 01/01/1989

DOI:

10.26481/dis.19890922jj

Document Version:

Publisher's PDF, also known as Version of record

\section{Please check the document version of this publication:}

- A submitted manuscript is the version of the article upon submission and before peer-review. There can be important differences between the submitted version and the official published version of record.

People interested in the research are advised to contact the author for the final version of the publication, or visit the DOI to the publisher's website.

- The final author version and the galley proof are versions of the publication after peer review.

- The final published version features the final layout of the paper including the volume, issue and page numbers.

Link to publication

\footnotetext{
General rights rights.

- You may freely distribute the URL identifying the publication in the public portal. please follow below link for the End User Agreement:

www.umlib.nl/taverne-license

Take down policy

If you believe that this document breaches copyright please contact us at:

repository@maastrichtuniversity.nl

providing details and we will investigate your claim.
}

Copyright and moral rights for the publications made accessible in the public portal are retained by the authors and/or other copyright owners and it is a condition of accessing publications that users recognise and abide by the legal requirements associated with these

- Users may download and print one copy of any publication from the public portal for the purpose of private study or research.

- You may not further distribute the material or use it for any profit-making activity or commercial gain

If the publication is distributed under the terms of Article $25 \mathrm{fa}$ of the Dutch Copyright Act, indicated by the "Taverne" license above, 
clinical application of video

image processing in cardiac angiology 
To My parents, Ellen and Peter,

Loes, Siri, Johan Jr. and Mickey 


\section{Clinical application of video image processing in cardiac angiology}

\section{Proefschrift}

ter verkrijging van de graad van doctor aan de Rijksuniversiteit Limburg te Maastricht, op gezag van de Rector Magnificus,

Prof.Dr. F.I.M. Bonke, volgens het besluit van het College van Dekanen, in het openbaar te verdedigen op

vrijdag, 22 september 1989 om 12.00 uur

$$
\text { door }
$$

Johannes Hendrikus Antonius Janssen geboren te Geleen in 1954 
Promotores:

Prof.dr. H.J.J. Wellens

Prof.dr. T. van der Werf, Katholieke Universiteit Nijmegen

Beoordelingscommissie:

Prof.dr. R.S. Reneman, voorzitter

Prof.dr.ir. A. Hasman

Prof.dr. B.K. Janevski

Prof.dr. O.C.K.M. Penn

Dr.ir. J.H.C. Reiber, Erasmus Universiteit Rotterdam 


\section{Contents}

Introduction 1

Chapter 1 Historical notes 3

Chapter 2 Digital subtraction angiography: technology, equipment and techniques 20

Chapter 3 The use of an automatic cine film marker for optimal quantitative assessment of coronary artery dimensions 49

Chapter 4 Radiation reduction during cardiac fluoroscopy using a video image processor 59

Chapter 5 Radiation reduction during cardiac cineangiographic procedures using a video image processor 68

Chapter 6 Detection of acute pulmonary embolism using a portable video image processor 73

Chapter 7 Low dose ventriculography using a video image processor and fluoroscopic exposure levels 83

Chapter 8 A quantitative analysis of the coronary artery in patients with unstable angina: can we characterize a malignant stenosis? 88

Chapter 9 A quantitative angiographic study of patients with unstable angina pectoris and a high grade stenosis of the proximal left anterior descending coronary artery 97

Chapter 10 A critical evaluation of quantitative coronary angiography 104

Samenvatting 123

Summary 125

Index 127

Curriculum Vitae 129 
The publication of this book was supported by a grant from the Dutch Heart Foundation and the RESCAR Foundation, Maastricht, The Netherlands. 


\section{Preface}

"A priest, a rabbi and a minister sat in a boat and sailed out. After a while the priest said to the others: "Gentleman, I have to relieve myself....". He stood up and walked away.

Shortly after he returned the rabbi claimed: "Gentleman, I have to relieve myself...". He also stepped overboard and walked away. After he returned the minister, who had a difficult time already, told his fellows: "Gentlemen, I also have to relieve myself. He stepped overboard but instead of walking away, sunk and drowned. The rabbi asked the priest: "Didn't you show him where the stones were?".

This classic story illustrates one of the laws in medicine. It shows how much you are in the need of help of senior scientists in order to succeed in your work. During the preparation of this book I had the privilege to work with some of the finest scientists there are: my friend Pedro Brugada and my teacher Hein Wellens. I owe them much because they told me where to find most of the stones... The ones missing were pointed out by Hans Reiber, Blagoja Janevski, Tjeerd van der Werf, Victor Legrand and Robert Vogel.

In 1940, the cardiologist had only at his disposal the stethoscope, the chest röntgenogram, the electrocardiogram, and his clinical astuteness.

Only fifty years later, the cardiologist still requires great clinical skills, but also has at his disposal echocardiography, radionuclide perfusion tests, digital radiography, computed tomography and nuclear magnetic resonance imaging. These imaging modalities resulted from the development of the digital computer, and the explosive advances in microelectronics. Cardiac imaging has rapidly evolved into a specialized area of interest shared by cardiologists, radiologists, engineers and physicists. Cardiac imaging is a field that is expanding quickly and it is clear that these 
computerized tools will become part of the foundations of cardiology.

However, only better understanding of their design, applications and limitations will make it possible to use them succesfully in patient care.

It is obvious that our technological revolution has contributed positively to our society. With an increase in computer technology and a better understanding of the biological variables in angiographic procedures, medicine has entered a new age'.

Maastricht, Spring 1989

\section{Acknowledgements:}

Preparation of a book involves the efforts of many more people than the author(s). This is particularly true in this case. I would like to thank all friends and colleagues who made it possible.

A special word of thanks goes to my wife, Loes, who has been able to lovingly manage and tolerate our three children and me, who has always supported all of my endeavours with encouragement, every step of the way, and who continuously helps me to keep the priorities of life quite clear in my mind. 


\section{Introduction}

Cineangiography is presently the accepted "gold standard" for evaluating the anatomy of the coronary arteries in man. This situation, however, is in a process of change. Digital image acquisition and processing techniques are graduately replacing film and direct film viewing in diagnosing coronary artery disease. In addition, quantification of physiologic parameters related to cardiac contraction and blood flow, which is difficult by using film-based technology, is more and more applied routinely using computer based image acquisition and processing systems. As these systems become faster and less expensive, and tools to analyze cardiac anatomy and physiology become more sophisticated and precise, cine-angiography will increasingly be replaced by digital angiography for $\mathrm{X}$-ray imaging of the heart. The change from film-techniques to digital methods of acquisition, storage, and processing of cardiac angiograms has primarily been motivated by progress in diagnostic and interventional procedures. Digital subtraction techniques and video image processing have resulted in a reduction of contrast dose and X-ray dose. Application of digital techniques did not only result in progress in diagnostic power but will also improve therapeutic techniques by rapid on line availability of image data as during percutaneous transluminal coronary angioplasty, the placing of intracoronary stents and coronary angiopyroplasty. As has been pointed out by us and other investigators, the use of $\mathrm{X}$-rays in cardiac studies is responsible for an important contribution to the total exposure of ionizing radiation of patients and medical personel $(1,2)$. The average $X$ ray dose received by patients during routine left ventriculography and left sided heart catheterisation is 120 times more than the dose received for a standard chest $\mathrm{X}$-ray. These findings have great implications 
for patients, staff and personel of cardiac catheterization rooms. The clinical application of video image processing and the introduction of digital subtractionangiography in angiographic studies of the heart, was introduced in the Academic Hospital of Maastricht, in 1984. In this book results obtained by these techniques will be discussed.

In chapter 1 the history of image processing of the heart and the concerns raised by the use of ionizing radiation to obtain these images is discussed.

Chapter 2 gives a brief outline of the video image techniques used and methods of investigation. Chapter 3 is a detailed description of a developed cinefilm marker unit which facilitates the acquisition of subtraction studies. Chapter 4 and 5 are devoted to the methods and results of efforts to reduce ionizing radiation during cardiac angiography of patients with cardiovascular disease. The clinical use of video image processing techniques is described in chapters $6,7,8$ and 9 . These chapters reflect the experience obtained in diagnosis and treatment of acute pulmonary embolism, left ventriculography during the acute phase of myocardial infarction, and the possibilities to obtain quantitative analysis of coronary arteries and the implication of these findings in patients with unstable angina.

A critical review of coronary cineangiography is presented in chapter 10 .

The thesis ends with a summary in the english and dutch language.

References

1. Huyskens C.J.: Dosimetry Index: a useful concept in operational radiation protection. IRPA 7, III: 1290, 1988.

2. Kicken P., Janssen J., Michels H., Huyskens C.: Radiation exposure during cardiac catheterization procedures. IRPA 7, II, 737, 1988. 


\author{
Johan H.A. Janssen, MD \\ Department of Cardiology \\ Academic Hospital Maastricht \\ University of Limburg \\ The Netherlands
}

The cardiovascular system has been a major area of interest for both scientists and physicians. Vascular experiments date back as far as the fifth century before Christ (1). In the second century anno domini, Galen introduced a hollow reed into arteries of animals to study blood flow. William Harvey's investigations into many previously unknown facts of the circulation are reported in his monumental book: "De Motu Cordis et Sanguinis", published in 1628 (2). Subsequently, many other experiments and studies were done but it was not until the discovery of X-rays by Roentgen in 1895 (3) that it became possible to visualize vessels in the intact body.

When Wilhelm C. Röntgen made the discovery of "a new kind of rays (X-rays)" in november 1895 he could not foresee the tremendous importance of this technique. However, the value of the discovery of X-rays was immediately realized. Fig. I shows the arteries of an amputated hand, obtain by E. von Haschek and Dr. O.Th. Lindenthal in 1896 only a few months after the discovery of the X-rays (Second Institute of Physics and Chemistry, Vienna) $(33,34)$.

The production and recognition of X-rays required several things. Electricity and vacuum tubes were necessary, and the experimenter had to understand some fundamental facts about the results obtained. Electricity as a phenomenon is as old as man, but the quantitative understanding of the subject had to wait for Michael Faraday. Faraday's discoveries were extensive. In a series of lectures on the properties of "matter", one was entitled " On radiant Matter". He observed the phenomenon of gases emitting light when they were electrified. He believed that this phenomenon represented a fourth state of Matter. 


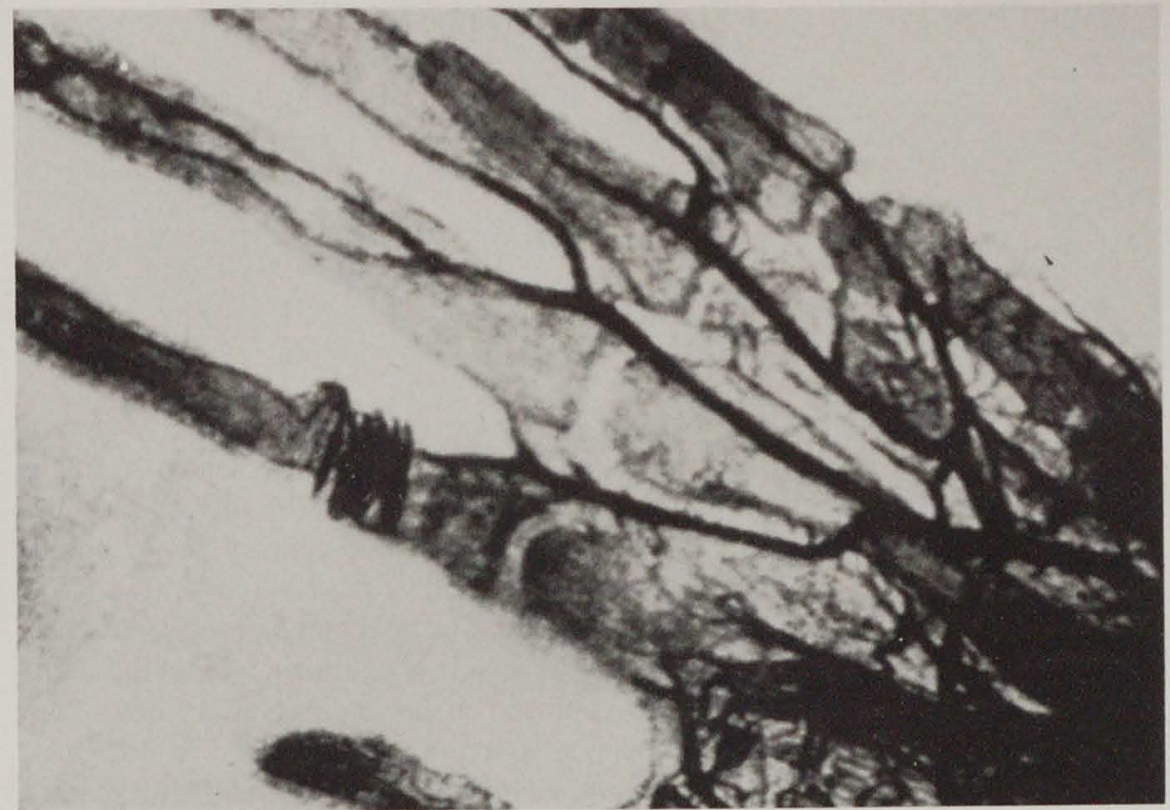

Figure 1

First use of X-rays in angiology by Hascher and Lindenthal. The image is obtained in 1896 by injection of Teichmann'scher Masser, a chalk containing solution into the arterial system of an amputated arm. The exposure time was $57 \mathrm{~min}$ utes.... (courtesy Prof. B. Janevski).
In 1879, William Crookes delivered an address on "Radiant matter" to the British Association for the Advancement of Science and began with a tribute to Faraday. Crookes showed that in high vacuum tubes with an induction coil to control current, matter would enter the ultragaseous state predicted by Faraday, and colors and other changes around cathode and anode would occur. He showed that rays were produced that cast shadows and caused certain compounds to glow. Noting the greenish yellow color of the glass subsequently seen in early X-ray tubes, he realized that rays, which he called "emissive rays", were being produced, but he did not recognize that these rays would penetrate opaque bodies (4).

At that time, several physicists were investigating cathode rays: Crookes in England, Goodspeed in Philadelphia, Philip Lennard and W.C. Röntgen in Germany. Heinrich Hertz had shown that cathode rays could pass through a sheet of aluminium within the tube. Lennard focussed the rays, and they passed out of the tube for a distance of 3 inches. He exposed photographic plates, secured in lightproof boxes, and obtained shadow images of opaque bodies. W.C. Röntgen studied the influence of electricity and cath- 
ode rays after the manner of Lennard. In november 1895 , he saw faint greenish fluorescent light on a small screen made of barium platinocyanide. This screen was far away from the Crookes tube, which was covered with black paper. This effect could not be explained by cathode rays. He recognized that he had found something new, and in december 1895 the results appeared as a "preliminary communication".

A well-known Dutch cardiologist, who made early use of radiology, was Wenckebach, who installed the new equipment in Groningen in 1931. About the same time röntgenograms were made in Einthoven's laboratory at specific points of the cardiac and respiratory cycle with simultaneous registration of the ECG and respiratory movements. The first thousand of papers on X-rays were published within a year of their discovery. They were accompanied by a dozen monographs.

In 1939 Robb and Steinberg (6) stated: "Heretofore there has been no method of visualizing the left chambers of the heart and the superior vena cava and no practical procedure for outlining the right chambers of the heart, the pulmonary circulation and the thoracic aorta in Man".

The development of angiocardiography began soon after Röntgen's announcement; injections were made into corpses and animals. By 1918, experiments were being done with water-soluble iodides in pyelography and air contrast in neurologic röntgenography. In 1921, iodized oil (lipiodol) was accidently injected into the subarachnoid space, and the patient appeared to suffer no ill effects. Intravenous injection of iodized oil in animals and patients had begun in the 1920's (5, 7). In 1923 the first report of an intravenous pyelogram was published (7) in which a short addendum stressed the clarity of the veins suggesting the use of the technique to visualize the vascular system. The first successful aortogram of the lumbar aorta was performed by Dos Santos, Lamas and Pereira-Caldas of Portugal. They began their work in 1925 and reported their results in 1929 (34).

Femoral arteriograms followed, and by the early 1930 's, many peripheral arteriograms were performed in a number of countries. 
Figure 2

Chest X-ray of Dr Werner Forssman showing a catheter introduced from the left arm to the right side of the heart.

Figure 3

Illustration of the Robb and Steinberg method. Contrast material is injected into an arm vein and when the patient experienced a dry taste in her mouth (circulation time !), angiography was performed.

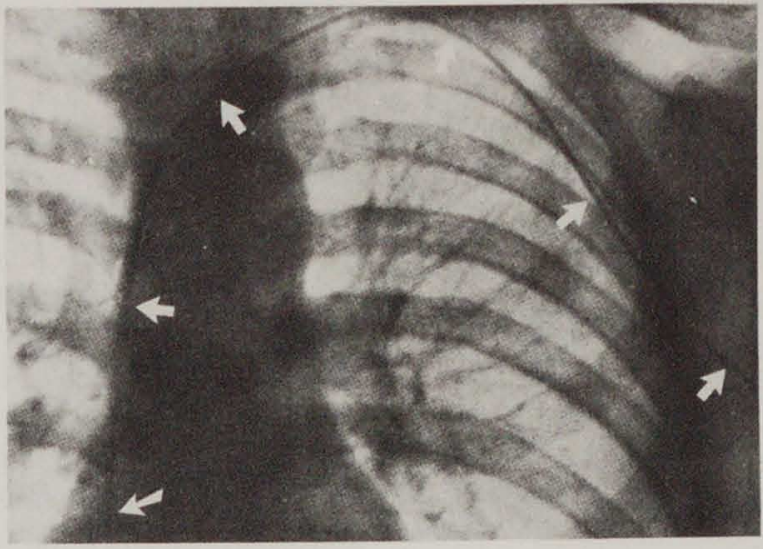

Interest was high in Argentina, Brazil and Portugal. A. Castellanos in Havanna, Cuba began to use angiocardiography in infants and children. In describing his work in 1937, he noted: "This method can also be applied to the adult for the same purpose with the necessary adaptions" (8). After the first experiments of Werner Forssman (figure 2) $(9,10)$ several investigators tried to visualize the chambers of the heart and great vessels $(11,12,13,14,15)$ even by direct puncture of the left ventricle (16).

Although later, the cardiovascular imaging technique was improved by using the direct catheter method, introduced by Forssmann, Andrè Cournand stated in

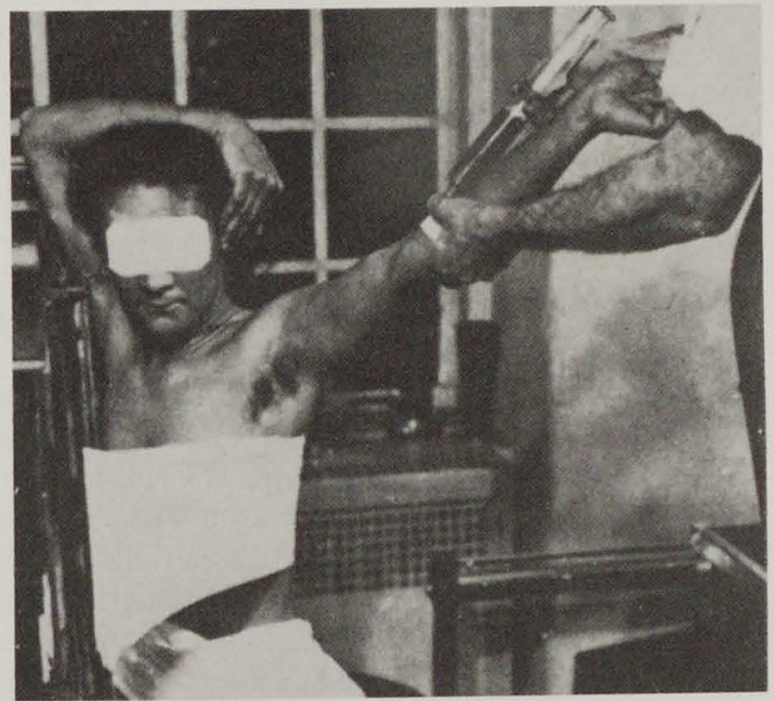


his classic article on the catheterization of the right ventricle in man (17): "Forssman first used catheterization of the right heart on himself, after exposure of a vein of the arm by a surgeon. Numerous other investigations since have used right heart catheterization for visualization of the right chamber of the heart and pulmonary vascular tree by means of contrast substance. The introduction of the Robb and Steinberg method, however, renders this method unnecessary for the latter purpose..." (figure 3).

As far as studies of the coronary arteries was concerned mankind had to wait for Sones (18) to develop in 1960 the selective catheterization of the coronary arteries. As so often happens by accident, while intending to make an angiogram of the aortic root, he injected contrast in the coronary artery. This ultimately led to the surgical treatment of coronary artery disease by the bypass technique (1967, Dr Favolavo and Dr Effer, Cleveland Clinic, USA).

In the beginning nobody was aware of the possible adverse effects of $\mathrm{X}$-ray radiation and radioactivity on the human body, but as early as 1896 the question was raised of possible complications of ionizing radiation exposure (19). Only two months after the announcement of the discovery of X-rays, Henri Becquerel, a French physicist, communicated his discovery of similar penetrating rays emitted from the salts of uranium. His discovery was, unlike that of the $\mathrm{X}$-rays, virtually unnoted by the public and scientists. Only a small number of scientists were interested in Becquerel's finding, and it was not until the discovery of radium by the Curies two years later that interest in radioactivity became widespread.

The initial lack of interest in radioactivity and X-ray radiation was then rapidly compensated by enormous activity. Investigators and physicians installed X-ray apparatus and performed their work without any concern regarding potential dangers. Such a lack of concern was quite understandable, because there was nothing suggesting the possibility that $\mathrm{X}$-rays could be hazardous. Indeed, one could expect the opposite. Who would suspect that a ray, similar to light but unseen, unfelt, or otherwise undetectable by the 
senses could be damaging to the person? More likely, it seemed to some, X-rays could be beneficial, both for prophylaxis and therapy. The widespread and unrestrained use of X-rays led to frank injury. Initially, these injuries were not attributed to $X$-ray exposure, in part because of the long period before symptoms developed and also because there seemed to be no reason to suspect $\mathrm{X}$-rays as the cause. While early experimenters neglected the skin effects they noted, others began to link X-ray exposure and skin burns (20).

The first warning of possible adverse effects of X-rays came from Thomas Edison, William J. Morton, and Nikola Tesla, who independently reported eye irritation during experiments with X-rays and fluorescent substances (21).

They originally thought that these effects could not be attributed to X-rays but rather to eye strain or, possibly, ultraviolet radiation from the fluorescence. However, other reports, describing skin effects similar to those seen with a severe sunburn, began to appear. These reports became so frequent that in 1896 , less than a year after Roentgen's announcement, E. Thomson, an american physicist, deliberately exposed the little finger of his left hand to an X-ray tube for several days, half an hour per day. The resultant effects - pain, swelling, stiffness, erythema and blistering - were convincing of the damaging effects of $\mathrm{X}$-rays for Thomson and others, but not to all. Many prominent physicians still denied a harmfull effect of X-rays. However, by 1900, 4 years after its discovery, it was clear to most of the medical and scientific community that X-ray exposure, when too frequent or intensive, could produce skinburns. Reduction in time and frequency of exposure were the most obvious ways to limit the dose to patients. Investigators sometimes used enclosed tubes or increased the distance to their equipment to protect themselves. Filtration of the X-ray beam was advocated prior to 1900 to limit the beam size (collimation). Around 1900 other techniques, including the use of intensifying screens to reduce exposure time and the use of higher $\mathrm{X}$-ray generating voltages were also introduced to minimize patient exposure to $\mathrm{X}$-rays. A Philips $\mathrm{X}$-ray system is shown in fig. 4 as it was used for fluoroscopy 

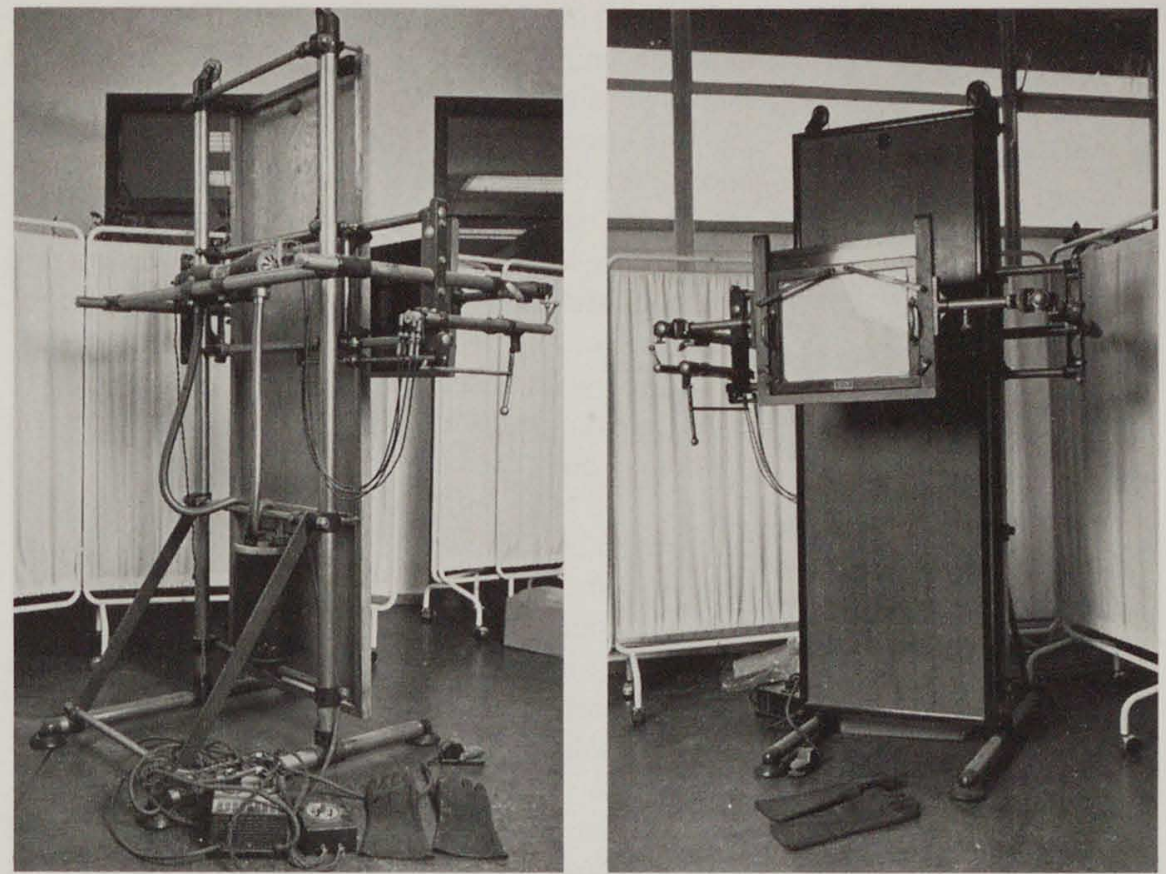

Figure 4

A: Philips X-ray apparatus. Note the X-ray tube, timer and gloves.

$B$ : The frontal sight showing the luminence screen from which also hard copies could be obtained. (courtesy Dr Rosier). by a general physician in Valkenburg, the Netherlands, until 1970. Note the direct luminence screen, the timer for taking hard copies and the led rubber gloves for protection. The need to provide patient protection was accelerated by malpractice suits favouring patients who had been injured by diagnostic $\mathrm{X}$-ray procedures.

Each year some 160 million Americans undergo approximately 250 million diagnostic X-ray examinations. In the Netherlands only in cardiac catheterization laboratories alone, around 35000 procedures (in 1988) are performed. It is not surprising that the possible hazards associated with such exposure creates much interest and controversy, in both scientific and public forums (figure 5).

In addition, the development of nuclear power and the resulting occupational and environmental exposure increased concern about the magnitude of the possible hazards. For over 30 years, national and international committees have been trying to estimate how many additional cancers and genetic defects, if any, result from exposure to low levels of ionizing 


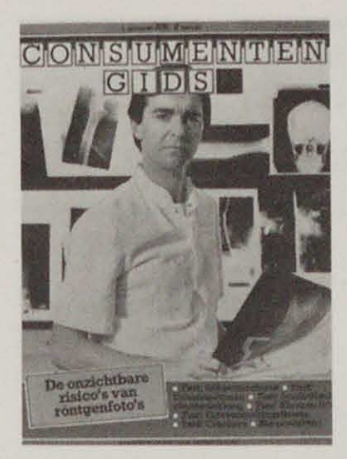

Figure 5

Title page of the Dutch journal for consumers in May 1985. The leading article stressed the potentional risk of medical radiation and suggested the introduction of a consumers "radiation passport". radiation at levels of naturel background (in the order of a few milli-Sieverts*). The biological effects of ionizing radiation on humans can be devided in early and late effects. When exposed to high levels of radiation acute dysfunction of organs (i.e. bone marrow) can lead to death within hours to months. From exposure to low levels of radiation tumor induction and leukemia are the most important effects on the exposed person. Genetic effects, however, may go undected for several decades. These effects are the so called late biological effects. The biological effects on the human body can be contemplated at several levels (figure 6 ). Most mutations, however will result in destruction of normal cell function which in turn may lead in some cases to malignant deterioration but mostly to death of that particular cell. Latent time between the exposure and apparrent adverse effect is approximately $10-13$ years for leukemia and 20-40 years for solid tumors. Extensive epidemiologic investigations indicate, however, that at present possible adverse effects after exposure to low doses of radiation, are too small to be detected. While it is necessary to improve our methods to estimate lowlevel effects, a relation between dose and radiationinduced cancer has been observed in practically all studies in humans $(22,23)$. No level of exposure appears to be entirely without some risk. A threshold dose below which there are no radiation effects has not yet been established in either humans or laboratory animals.

* Ionizing radiation can cause reactions in cells and tissue. During the ionizations, energy from the radiation is transferred and absorbed by the cells or tissue. The amount of absorption is mostly partial and not homogeneous. This is mainly dependant on the type of radiation and cell/tissue. Important for the amount of biological damage of the cell/tissue is the intensity of the energy absorption per mass. The absorbed radiation dose can cause different biological effects in tissue due to the differences in type of radiation that produces the absorbed dose. This difference in biological activity is defined by a quality factor $(\mathrm{Q})$. In health physics the product of the absorbed dose and $\mathrm{Q}$ is defined as the dosis equivalent. The SI unit of dosis equivalent is Sievert (Sv). More practical is the use of millisievert. Natural radiation at sea level in Western Europe is \pm 2 millisievert/year. One routine cardiac catheterization may expose the investigator to 50 microsievert/investigation $(=0.000050 \mathrm{~Sv})$ (29) ! 
Figure 6

The effects of ionizing radiation (from reference 37)
MOLECULAR

DNA DAMAGE

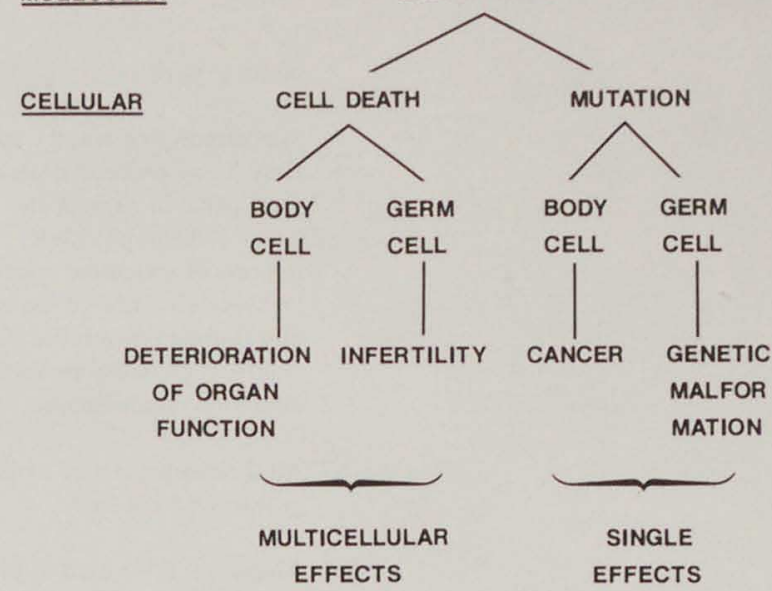

A detailed discussion about the possible adverse effects of ionizing radiation and the associated risks for patients and staff is beyond the scope of this book. The reader is referred to the publications of UNSCEAR and ICRP $(35,36)$.

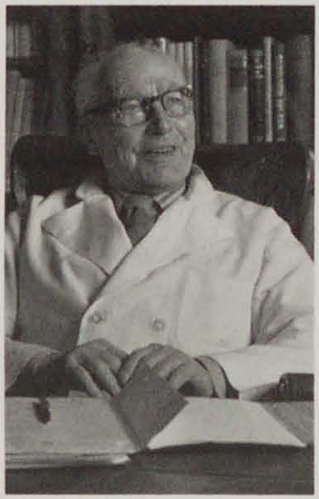

A historic review of radiation protection efforts is given in table 1 . In the early days of radiology and radiation protection Prof. v.d. Plaats (figure 7), former chairman of the Radiology Department of the Annadal Hospital in Maastricht The Netherlands (nowadays the Academic Hospital of the University of Limburg) and one of the founders of Medical Radiology in the Netherlands, suggested several ideas for radiation protection. He included a rather lengthy section specifically addressed to this problem in his classical book on medical X-ray techniques and diagnostic radiology (24).

Figure 7

Prof. G.J. v.d. Plaats, former chief of the Radiology Department of the Annadal Hospital, Maastricht, the Netherlands.

Table 1 Historic review of the first half century of radiation protection (adapted from reference 21)
Year Event

1895 Discovery of X-rays (November 8)

1896 X-ray report made public (January 3)

Discovery of radioactivity (February)

First reports of possible X-ray injury damage to eyes (March 3)

Concern expressed over possible X-ray
Investigator

\section{W.C. Röntgen}

W.C. Röntgen

H. Becquerel

T.A. Edison

W.J. Morton 
injury (March 14)

Skin effects first noted (April 18)

First X-ray protective device: a heavy glass plate to protect the eyes during dental radiography (July)

Reports of accidental injury (burns)

Deliberately induced experimental injury (burns) (November 18)

Gold leaf electroscope used to perform ionization measurements

F. Battclli

L.G. Stevens

W.H. Rollins

H.D. Hawks

E. Thomson

L. Benoist

1897 Air thermometer used to measure encrgy transfer by X-rays

E. Dorn

1898 Aluminum filter used as protective device (January)

E. Thomson

Lead rubber gloves (April)

W.A. Price

Leaded X-ray tube housing; collimators (July)

W.H.Rollins

Dark adaptation prior to fluoroscopy suggested (May)

F.H. Willians

Word "radioactivity" coined (July)

$P$. and M.Curic

Radium discovered (December)

$P$. and M.Curic

Gamma rays discovered

P. Villard

1899 Radiographer licensure recommended to protect public (April)

J. Dennis

Malpractice suit granted for X-ray burns (May)

Ozone hazard of X-ray generators noted Listing of protective devices (gloves, aprons etc.) in X-ray catalog
R. Friedlander Co.

1900 Increased target to skin distance to reduce skin dose

M.K. Kassabian

1901 X-ray lethality to person alleged (January 3 )

Skin burn caused by radium carried on person

H. Becquerel

$X$-ray lethality to mammals

W.H. Rollins demonstrated experimentally

1902 X-ray lethality to mammalian fetus demonstrated

W.H.Rollins

1903 Fractionation of exposure in fluoroscopy. Protection committec within

W.H. Rollins ARRS propesed.

First direct reading radiation instrument: the spinthariscope

\section{W. Crookes}


1904 First X-ray death attributed to cumulative overexposurc (October)

1905 First proposal of radiation unit based on ionization

1906 Introduction of the law of

1907 Mutation by X-ray reported in animals. X-ray cxposure monitored by photographic plate carried in pocket Use of gas-filled tubes for detection Wagner of radiation

1911 International radium standard and unit M. Curic

1912 Half value layer concept

T. Christen

1913 Introduction of hot cathode X-ray tubes permitting higher voltages

1915 British Röntgen Socicty adopts radiation protection recommendations

1920 First X-ray protection Committec of the American Roentgen Ray Society

1921 British X-ray and Radium Protection Committec issues first memorandum

1922 American Roentgen Ray Socicty adopts radiation protection rules Introduction of film badges for personnel monitoring

G. Pfahler

1925 First "Tolerance dose" proposed

A. Mutscheller

1927 Genetic effects of X-rays shown

H.J. Müller First commercial U.S. ionization chamber

J. Victoreen

1928 Röntgen unit formally adopted International X-ray and Radium Protection Committee formed (forerunner of ICRP)

1929 U.S. Advisory Committec on X-ray and Radium Protection formed (forerunner of NCRP)

Firsi portable survey meter 
1932 Concept of greater permissible dose for partial body irradiation (hands) introduced

G. Failla

Discovery of neutron

E. Chadwick

1934 Intern. commitee of X ray Radiation Protection recommends permissible dose of $0.2 \mathrm{R} / \mathrm{day}$

1935 Statement of the Bragg-Gray principle of cavity ionization

1936 USACXRP recommends reduction in permissible dose to $0.1 \mathrm{R} /$ day

1941 USACXRP recommends adoptation of maximum body burden of $0.1 \mathrm{uCi}$ for radium

$19434 \mathrm{R} /$ wk shown to cause injury

H.M. Parker

1944 Maximum permissible concentration for inhaled radioactivity introduced Rem introduced

H.M. Parker H.M. Parker

The discovery and development of computer technology and particularly the chip (fig. 8) played an important role in the development of medical imaging. The introduction of X-ray computed tomography

Figure 8

The relation between "digit" and "digital" is obvious. The chip is situated in the integrated circuit (IC). As part of the video image processor (VIP-300) this IC function is known as EPROM (erasable, programmable, read only memory).

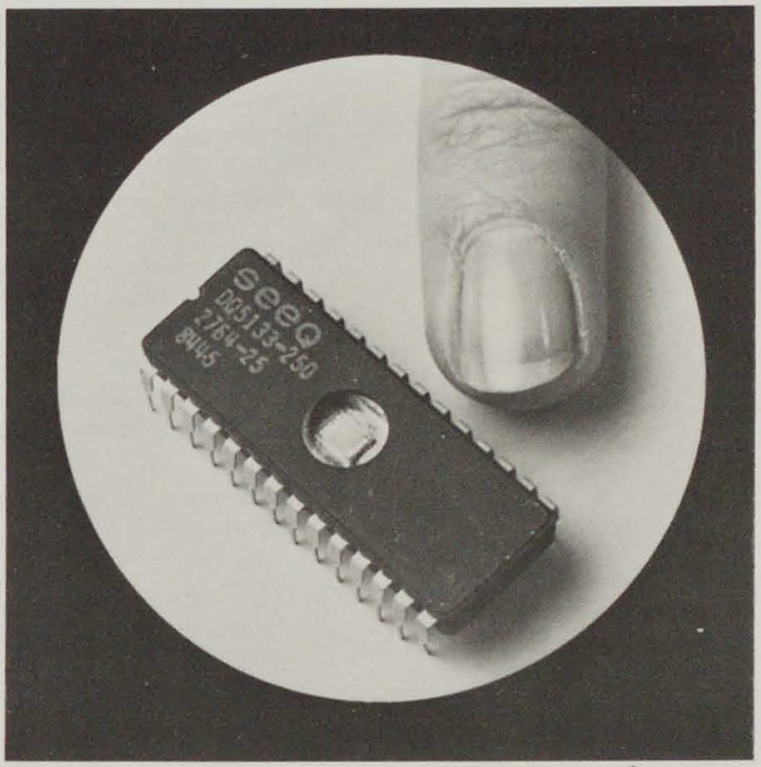



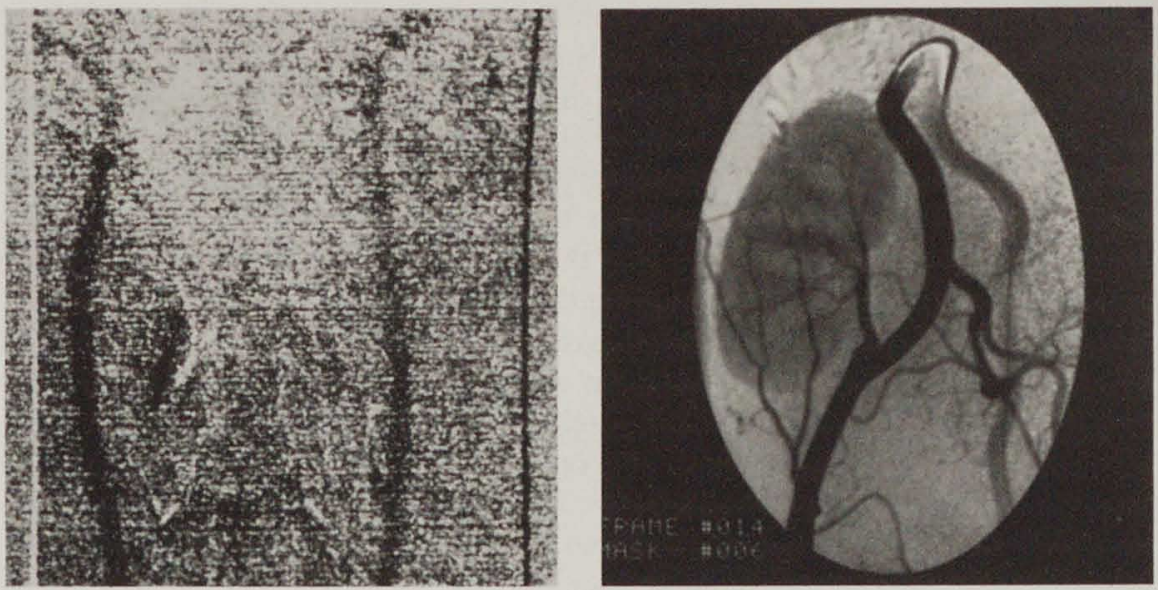

Figure 9

Subtraction image of canine carotid arteries, obtained in the mid 1970's.

\section{Figure 10}

Subtraction image of a transplant kidney, obtained in 1988 . Note the difference between figure 9 and 10 in resolution and small vessel detail. in 1971 came as a surprise to most of the radiologic community, including equipment manufacturers. Digital fluoroscopy research was motivated by several factors. A marriage between fluoroscopy techniques and computer processing became inevitable.

It was against this background and by trial and error that many of the concepts were discovered that are important today in the successful use of digital fluoroscopy equipment. Several research groups independently contributed to development of Digital Fluoroscopy. One of these was at the University of Arizona, led by Prof. S. Nudelman. They were mainly motivated by the wish to design a radiology department based on digital imaging. Their goal was to replace much of film radiography with images acquired using a video system. It was soon discovered that to operate such systems at radiographic exposure levels would require the use of high performance components including a high performance video camera. Moreover the need for fast and precise processing was best addressed with digital electronic technology.

One of the first temporal substraction images of canine carotid arteries is shown in figure 9. This image was generated in the mid 1970's. Although the image is noisy, the carotid arteries can be recognized.

This early picture differs markedly from the image shown in figure 10 from a recent kidney transplant study by Prof. Dr. B. Janevski from the University of Maastricht. This image demonstrates a clear improve- 
ment in contrast and small vessel detail. Apart from Nudelman's group, an important role in the development of digital fluorographic methods was played by Prof. P. Heintzen and Dr. R. Brennecke of the Kiel Kinderklinik in West-Germany. They were interested in the analysis of angiographic image sequences of the heart and used digital video processing to expedite the processing.

Finally, a group of investigators at the University of Winsconsin directed by Prof. C. Mistretta (fig. 11) also developed digital fluorographic imaging techniques. As opposed to the motivation of the Arizona and Kiel groups, the focus of their research was specifically related to various forms of image subtraction.

One of their next steps was to apply the subtraction concept to a more relevant clinical use. One potentional use derived from data manipulation is the production of functional images or images that reflect a physiologic parameter in addition to anatomic information. While absolute blood flow is hard to determine by any noninvasive or invasive method, flow velocity and relative blood-flow in large vessels is obtainable with small volumes of intraarterial contrast injections using the basic principle of indicator dilution techniques and evaluating time versus density relations of contrast bolus. Digital image processing has the capability to record and analyze regional Xray densities from several angiographic images with a high degree of contrast and spatial resolution, thus

Figure 11

$A$ : The first unit of the Wisconsin group used to perform subtraction studies.

$B$ : A video image processor as it is used in Maastricht.
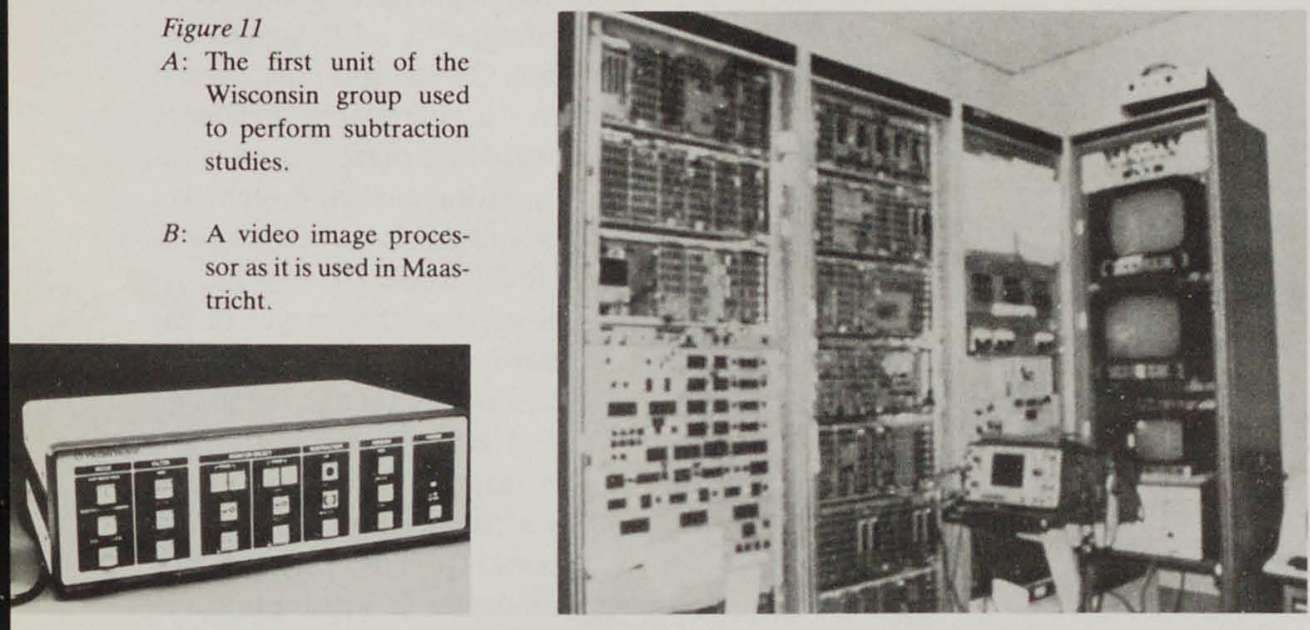
providing röntgendilution studies from the heart, blood vessels, and other organs.

Image processing in the clinical setting was stimulated by the great number of potential applications, diagnostic and therapeutic (25).

The primary aim of digital angiography was directed to improve the diagnostic capacity of radiography. However, use of digital angiography during arteriographic examinations has resulted in the possibility of using functional analysis. Functional imaging is the display of organ function using images. The creation of functional images may be as simple as the imaging of a compound known to behave in a way that characterizes the function of an organ (i.e. when using radionuclide tracers in conventional nuclear medicine) or as complex as the result of a mathematical function of a set images. The rationale for functional imaging is to allow the depiction of an important characteristic of the organ.

While initial studies attempted to demonstrate the technical feasibility of digital angiography in various diagnostic situations $(25,26,27,28,30,31,32)$, the clinical impact of diagnostic functional imaging of the heart and great vessels outweight the initial expectancies.

1. Haeser H: Lehrbuch der Geschichte der Medizin. Jena Duft Publishing 1875.

2. Harvey W.H.: De Motu Cordis et Sangiunis, 1628.

3. W.C. Röntgen: On a new kind of Rays (preliminary communication) Naturc 53:274-276,1896 (Originally published in Germany: Sitzungberichte der Wurzburger Physik-medic, Gesellschaft. 17:132-1419, 1895).

4. Cranc, A.N.: The Research trail of the X-ray. Radiology 23:131-148, 1934.

5. Doly $\mathrm{T}$ : Development of Angiography and cardiovascular Catheterization. Littleron, Massachusets, Futura Publishing group, 1976 p 200-350.

6. Robb J.P. and Stcinberg I: Visualization of the chambers of the heart, the pulmoney circulation, and the great blood vessels in man; a practical method. Am J Röntgenol 41:1-17, 1939.

7. Osborne E.D, Sutherland C.G., Scholl A.J. et al: Röntgenography of urinary tract during administration of sodium iodid. JAMA 80: 368-373, 1923.

8. Castellanos A, Pereivas R, Garcia A: La angiocardiografie radioopaque. Arch Soc. Estud Habana 31:523-596, 1937; cited by Doly (ref 5 ).

9. Forssman W: Die Sondierung des rechten Herzens. Klin. Wochnschr., 1929,8, 2085-2087. 
10. Forssman W: Ueber Kontrastdastellung der Höhlendes lebenden rechten Herzens und der Lungenschlagader. München. med. Wchnschr, 1931, 78, 489-492.

11. Egaz Moniz, Lopo de Carvalho, and Almeida Lima: Angiopncumonographic. Presse med. 1931, 39, 996-999.

12. Lopo de Carvalho and Egas Moniz: Visibility of the pulmonary vesscls (angiopncumography). Acta radiol., 1933,14, 433-452.

13. Ravina A: L'exporation radiologique des caisseaux pulmonaires per l'injection de substances de contraste. Progrés méd., nov. 3, 1934, pp 1701-1705.

14. Ameuille P., Ronneaux G, Hinault V, De Grez and Lemoine JM: Remarques sur quelques cas d' artériographic pulmonaire chez l'homme vivant. Ball et mém. Soc. Méd. d. hôp. de Paris, 1936, 60, 729-739.

15. Conte $\mathrm{E}$ and Costa A: Angiopncumograph. Radiology, $1933,21,461-65$.

16. Nuvoli I: Arteriographia dell'aorta toracica mediante pantura dell'aorta ascendente o del ventriculo's. Poli clinico, 1936, 43, 227-237.

17. Cournand A and Ranges H.A.: Catheterization of the right ventricle in man. Proc. Soc. Biol. Med. 46:462-466, 1941.

18. Sones FM and Shirey EK: Cine coronary angiography. Modern Concepts. Cardiovasc. Dis. 31, 735, 1962.

19. Trout E.D: The history of Radiation protection in the United Stated, Hospital Progress, 41, 1960.

20. Willis C.A.: Radiation protection; its beginnings and development. J. Radiation protection, 1, 37, 1976.

21. Kathren E.L and Tarr, NE: The origins of the Health Physics Society: Health Phys. 27, 419, 1974.

22. Boicc J.P jr, Land C.E., Shore R.E., Worman J.E, Tohnnaga $\mathrm{M}$ : Risk of breast cancer following low-dose radiation exposurc, Radiology, 1979; 131: 589-597.

23. Rall J.E, Becbe G.W., Hocl D.G. et al: Report of the National Institutes of Health ad Hoc Working group to Develop Radioepidemiological Tables. Washington D.C.: Government Printing Office, 1985 (DHHS publication no. (NIM) 85-2748).

24. van der Plaats G.J.: Medical X-ray techniques in diagnostic Radiology. A textbook for Radiographers and Radiological Technicians. First edition 1959, Centrex Publishing Company Eindhoven, The Netherlands. Chapters 3 and 4.

25. Böhm $\mathrm{M}$, Höhne $\mathrm{KH}$ : The processing and analysis of radiographic image sequences. In: Höhne KH (ed) Digital Image processing in medicine. Springer, Berlin Heidelberg New York p. 42-92, 1980.

26. Heintzen PH, Brennecke R, Bürsch JH: Digital cardiovascular radiology. In: Höhne $\mathrm{KH}$ (ed) Lecture notes in medical informatics. Proc Digit Image Proc in Med. Springer, Berlin Heidelberg New York p 1-14, 1981.

27. Höhne KH, Böhm M, Erbe W, Micolaz GC, Pfeiffer G, Sonne B, Bückeler E: Computer angiography: A new tool for X-ray functional diagnostics. Med. Prog. Technol, 6:23, 1978.

28. Vogel RA: The radiographic assessment of coronary blood flow parameters, Circulation, Vol.72, nr.3 p 460-465 1985.

29. Kicken P, Janssen J, Michels H, Huyskens C.: Radiation 
exposurc during cardiac catheterisation procedures. International Radiation Protection Association (IRPA 7), Vol II p 737.740, 1988.

30. Bürsch JH et al: Digital angiocardiography for assessment of congenital heart disease. In: Pediatric Cardiac Imaging, WF Friedman and CB Hoggins (eds) p64-75. WB Saunders Company, Philadelphia 1984.

31. Moodin DS et al: Assessing cardiac anatomy with digital subtraction angiography. J Am Coll Cardiol 5: 48-54, 1985.

32. LeGrand V, Mancini GBJ, Bates ER, Hodgson JMB, Gross $\mathrm{MD}$ and Vogel RA: A comparative study of coronary flow reserve, coronary anatomy and the results of radionuclide excreise tests in patients with coronary artery discase. J Am Coll Cardiol, 8:1022-1032, 1986.

33. Von E. Haschek und Dr. D.Th. Lindenthal: Ein Beitrag zur praktischen Verwerthung der Photographic nach Röntgen. Wiener Klinische Wochenschrift, nr, 4, 63-64, 1896.

34. Janevski B: The history of the angiography of the Upper Extremity, in "Angiography of the Upper Extremity" The Hague, Boston, London, Martinus Nijhoff Publ. 1982, pp. 3-5.

35. Ionizing Radiation: Sources and Biological Effects. United Nation Scientific Committec on the Effects of Atomic Radiation (UNSCEAR), 1982.

36. Recommendations of the International Commission on Radiological Protection, ICRP Publication 26, 1977.

37. Straling en de betekenis voor de gezondheid. Ir. Chr. J. Huyskens. Diktaat (SBD6448 c.v.) Technische Universiteit Eindhoven, 1987. 


\title{
Digital subtraction angiography: technology, equipment and techniques.
}

\author{
Johan H.A. Janssen, MD \\ Department of Cardiology \\ Academic Hospital Maastricht \\ University of Limburg \\ The Netherlands
}

\section{Introduction}

\section{Acknowledgement:}

Dr. Ir. Ed Gronenschild, Department of Medical Informatics and Statistics, University of Limburg is acknowledged for his enthusiastic support in the development of the digital software and critical remarks on the reproducibility of CFR measurement.

Technology

Before discussing digital imaging techniques and especially digital subtraction angiography it has to be emphasized that it is not the intention to give an extensive review of the physics of imaging. The main purpose of this chapter is to highlight some of the factors involved in imaging. Furthermore a more detailed description how the procedures in the forthcoming chapters were performed is given.

In cardiology, angiography is performed of the right and the left heart, the coronary arteries, the thoracic aorta and the pulmonary vasculature. The main difference between imaging in cardiology and general radiology is the movement of the object, caused by heart beat and respiration. This is the background against which some special features of digital imaging are highlighted.

First the similarities and differences between conventional film (cinefilm) imaging and digital imaging in general will be discussed. Secondly the features of digital imaging that are potentially interesting for cardiology will be discussed and the chapter will end with a detailed description of the techniques used in Maastricht for both conventional film and digital techniques.

Digital image processing is a computer technique for modifying and analysing real-world (i.e. non-computer-generated) visual information (images). The image is digitized by breaking it up into an array of discrete data points called pixels, each precisely defined by digital codes that establish the location and brightness of each pixel or data point. By converting the image into a series of digitized data points, the 


\section{Figure la}

During conventional cardiac angiography the signal of the imaging chain is transferred to cine film. After photograpic developments this film can be digitized for subsequent analysis by the Cardiovascular Angiography Analysis System (CAAS).

\section{Figure $1 b$}

Shows the on line digital acquisition of the imaging chain. Digital information is directly accessible via the host computer. In fact panel $A$ and $B$ are constructed in the same imaging chain in the cardiology suitc of the Academic Hospital of the Rijksuniversiteit Limburg, the Netherlands. computer can (1) logarithmically enhance the image: add or subtract images, alter image brightness, emphasize or de-emphasize details, locate edges or, (2) store the image, or (3) display the original or altered image.

This technique can be applied to any image or any information in the visual domain. Any activity which is visual in nature, or any information which can be extracted from an image now can be examined, tested, manipulated and enhanced by computer.

The range of applications for digital processing has grown rapidly in medical imaging, robotics, surveillance, graphics and many other areas. The advent of powerful yet inexpensive image processing hardware, has played an important role in the increase in number of imaging applications.

The first step in digital image processing is digitizing the image, which makes the image available to the computer as digital pixel data. This operation involves a number of pieces of hardware. In figure I an outline is given of the digital system used in our institution in Maastricht. Figure 1A shows the image acquisition system of which the resultant image is on $35 \mathrm{~mm}$ cine film. For off-line digital processing the film is displayed and via a charge-coupled device (CCD) camera the image is fed into a computer (CAAS). In figure $1 \mathrm{~B}$ the on-line acquisition of digital images is shown. An analog to digital converter (ADC) is built in together with the television camera of the image acquisition chain. The television camera converts the light (brightness) pattern of the image into analog electrical signals. These signals contain information about the brightness of each tiny region of the display, along with timing pulses which indicate the end of each display line (which is called the horizontal sync) and the end of each display frame (vertical sync). The
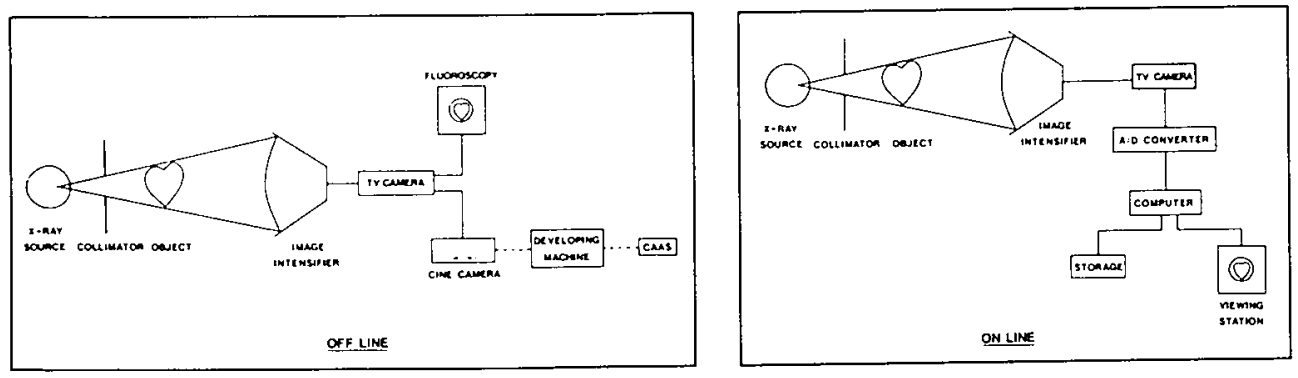
camera provides an output compatible with television broadcast standards (CCIR or EIA standards). The analog signal provided by the camera is then routed through a video acquisition device called a frame grabber, which converts the camera's analog signal into a digitized array that gives (1) horizontal position or pixel, (2) vertical position or row and (3) brightness of each pixel.

There is a fixed number of rows (usually 256 or 512 , depending on the spatial resolution of the frame grabber); each row is divided into a fixed number of picture elements (pixels; again 256 or 512). Thus the spatial image is divided into a two dimensional array: row (lines) $x$ columns (or pixels).

The total number of pixels which make up one digitized frame determines the spatial resolution of the signal; the amount of detail which one can detect. This can be thought of as the spatial granularity of the image, the number of light and dark dots which make up the image.

In cardiology, where the coronary arteries, vessels of $1.0 \mathrm{~mm}$ to $5 \mathrm{~mm}$ diameter, have to be visualized accurately, spatial resolution is of particular importance. The spatial resolution of a digital system is mostly thought of as being dependant only on matrix size of the digital video memories. If the image intensifier used has a width of 6 inch $=15.2 \mathrm{~cm}$, and pixel matrix used is $256^{2}$, then interpixel distance is $0.59 \mathrm{~mm}$. However, if instead of a matrix $256^{2}$ a matrix of $512^{2}$ was applied, then the pixel to pixel distance would have been $0.29 \mathrm{~mm}$. If in a patient with coronary artery disease, coronary vessel diameter is 2.5 $\mathrm{mm}$ and in this artery an $80 \%$ stenosis is present, the diameter to be detected is $0,5 \mathrm{~mm}$. Obviously recognition would be better with an interpixel distance of only $0.29 \mathrm{~mm}$ !

In addition to the pixel matrix size, several other system parameters such as 1) focal spot size of the $\mathrm{X}$-ray tube, (2) geometric enlargement factor (3) image intensifier resolution (4) resolution of the optics (5) resolution of the TV camera tube, (6) video bandwidth, and (7) resolution of the TV display monitor, each have their influence on the overall spatial resolution capability (7).

A well-proven technique for combining all these various degrading factors is the multiplication of the re- 
spective modulation transfer functions (MTF's) of each of the factors involved.

In 1973 Rose and coworkers (2) found a relation between expected contrast levels (c), vessel diameter (d), and desired precision (p) to estimate the exposure (N) needed to form an acceptable image.

$$
\mathrm{N}=\frac{1}{\mathrm{p}^{2} \mathrm{c}^{2} \mathrm{~d}^{2}}
$$

So, apart from MTF's of the system, also the applied $\mathrm{X}$-ray dose has a decisive role in the spatial resolution performance of a complete system.

A second kind of resolution is brightness resolution. This relates to how accurately a particular pixel code represents the brightness of the corresponding location in the original image. In a monochrome signal, it is the number of shades of gray which can be represented. This can be thought of as the brightness granularity of the digitized image. Brightness resolution is determined by the resolution of the analog to digital converter which performs the image acquisition. A 6 bit ADC is said to have a 6 bit gray scale, and divides the total analog image signal, or its intensity spectrum from total black to total white, into 64 values, sometimes called 64 shades of gray; an 8 bit ADC has an 8 bit gray scale and 256 shades of gray.

Sometimes the spatial and brightness resolutions of a frame grabber are specified together as " $512 \times 512 \times$ 8". This translates to 512 lines by 5128 -bit pixels of spatial resolution. The images of figure 2 illustrate how the number of samples into which the image is divided and the number of shades of gray used to display the image, affect the visual perception.

As stated before, in visualizing the structures of the heart (heart chambers and coronary vessels), the imaging chain has to meet special specifications. One of the critical factors is spatial resolution, another one is dictated by the moving of the target. Since respiration and heart beat result in a complex, fast movement of the structures under investigation, image acquisition has to be sufficiently fast in order to accurately study physiologic behaviour and morphologic features of the heart.

In an off-line configuration as pointed out in figure $1 \mathrm{~A}$ 
2 bits

$32^{2}$

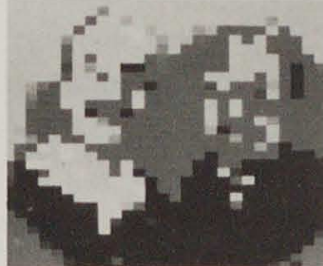

$64^{2}$

है

$128^{2}$
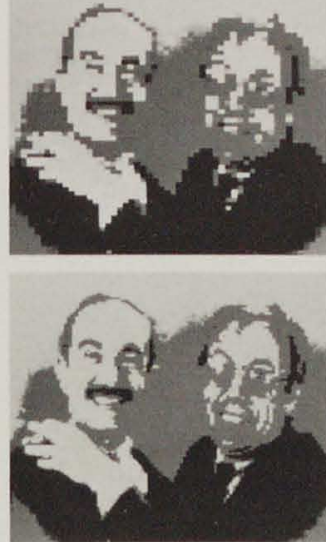

$256^{2}$

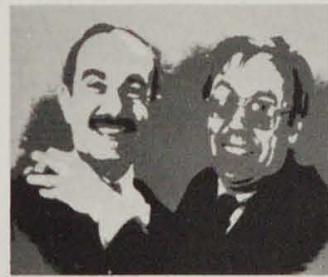

Figure 2

The ADC parameters and memory size determine both the contrast and spatial resolution of the digital image. The easily recognizable subjects (Simon Braat and Pedro Brugada) illustrate how visual perception is influenced by sample size and gray scale.
4 bits
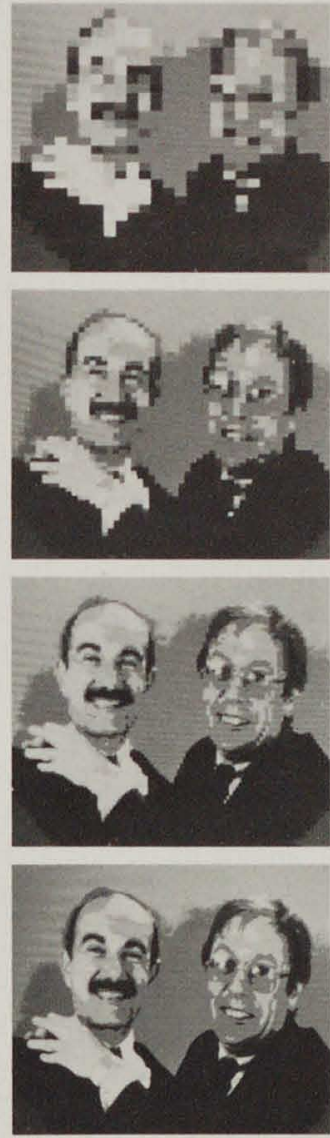

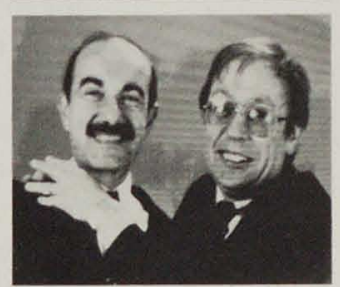

8 bits
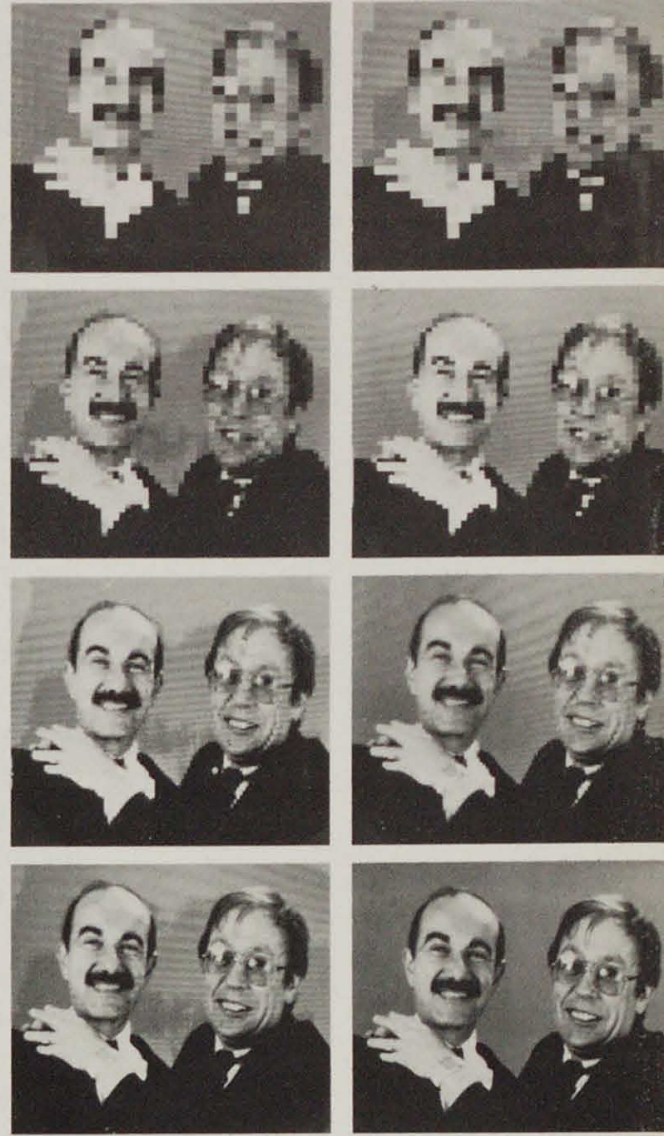

these specification can be met without great difficulty. Image acquisition on cine film at $50 \mathrm{frames} / \mathrm{sec}$ for left ventriculography (to study adequately the dynamic behaviour of left ventricular function), or 25 frames/ $\mathrm{sec}$ for coronary angiography (to study morphologic changes) is no problem.

In the described situation the CAAS system (Cardiovascular Angiography Analysis System, Pie Data Medical B.V) is able to digitize the image at high resolution ( $1330 \times 1700 \times 8$ bits). However, in the on-line situation, rate of image acquisition, resolution and storage of the digitized signal are hampered by technical limitations that present a bottleneck for the performance of the whole system. These bottlenecks 
Digital subtraction angiography: are interdependent due to basic physical laws although each of them, viewed separately, is of course also determined by the choice of technical factors in a given imaging system. In the digital part of the system, physical limitations are of no concern, but cost benefit considerations limit the performance achievable.

In the on-line situation as described in figure $1 \mathrm{~B}$ the digital system used is a Technicare DR 960. Due to a high speed digital disk configuration, acquisition of digital images is possible up to $30 \mathrm{frames} / \mathrm{sec}$. The resolution is $512 \times 512 \times 8$ bit. Maximal storage capacity is 1.2 Gbyte which allows storage for 8800 compressed $512 \times 512 \times 8$ bit images.

Apart from limitations in acquisition rate and storage capacity, resolution and matrix size are still restricted. High resolution images naturally call for a large matrix. On the other hand the choice of matrix size has important economic concequences as: 1) a large matrix size requires video frame storages of high capacity, and 2) the pixel rate increases with matrix size. Both factors will increase the price of a digital system considerably.

Overspecification of the matrix size has thus to be avoided and the judicious choice is the one which just suits the need. Also, the superficial idea that a 1024 matrix must be twice as good as a 512 matrix for image quality is refuted by recognition of the MTF's of presently available systems. The image quality will only improve by $12 \%-17 \%$ (1)!

Digital angiography does not specify either a particular apparatus or a specific radiographic procedure. It stands for a technique in which the traditional silver halide film/screen radiation receptor has been replaced by a photoelectronic receptor which signals are digitized and fed into a computer.

In general terms, a digital system comprises an X-ray source that directs a beam of $\mathrm{X}$-rays towards a region of interest; an $\mathrm{X}$-ray detector; an image intensifier that increases the brightness of the radiographic image; a video camera that converts the visual image into a video signal; an ADC and, finally, a computer capable of storing and manipulating the digital data.

Because of superimposition of a variety of anatomic structures (bone, soft tissue, fat, blood, air, etc) in a 


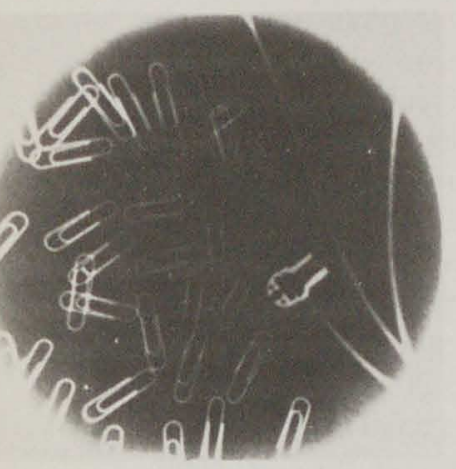

Figure 3

This model shows the usefulness of subtraction techniques. In $\mathrm{A}$ multiple paperclips are visible. In $\mathrm{B}$ it is difficult to determine whether paperclips were added. However, as shown in $\mathrm{C}$ by subtracting $\mathrm{B}$ from A the two added paperclips are easily identified.

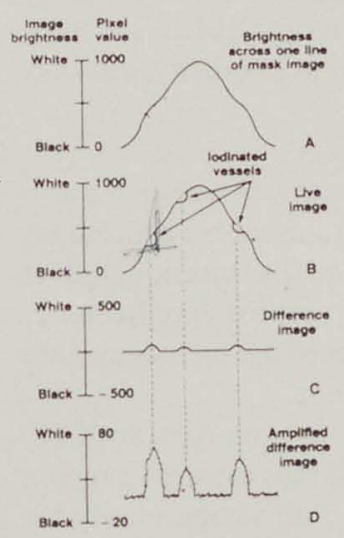

Figure 4

Schematic representation of subtraction imaging. The events occurring along one line are followed. After injection of iodine into the vessel subtraction reveals only the vessel lumen.
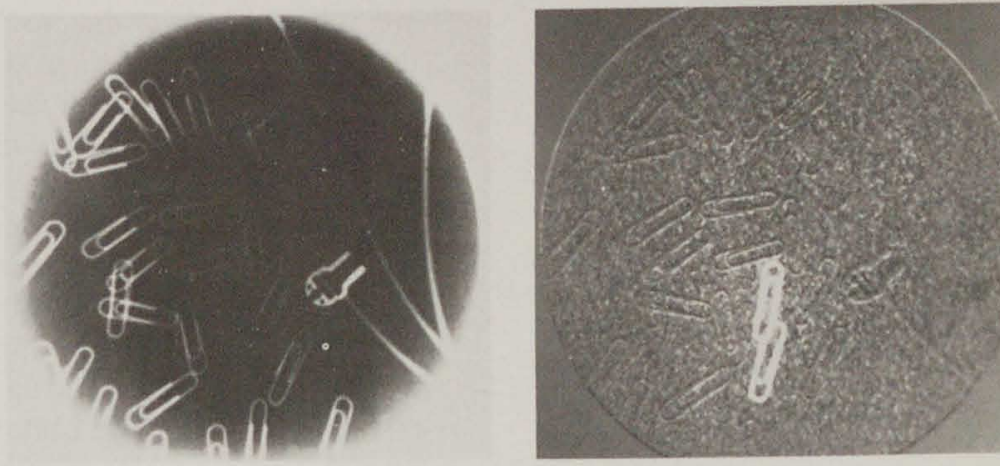

radiographic image, the detection and/or delineation of a particular structure within an image is potentially a difficult perceptual problem. The ideal image to analyze would be one in which all regions not containing a desired structure, had a background level of "zero", while the regions of interest would have a signal substantially different from "zero". The goal of subtraction is to provide a result as close to this ideal as possible. Although it is obvious that every component of the system has to meet special specifications for the "ideal" Digital Subtraction Angiography (DSA) system, it is beyond the scope of this chapter to discuss them in detail.

In general, subtraction is done by acquiring two (or more !) images in which only the signal of the studied region of interest differs and the intensity of all other regions remains the same.

Upon subtraction, all non-desired regions are canceled, thereby isolating the desired structure. Figure 3 demonstrates this using a home made model. This situation occurs during angiography, in which case iodinated blood flowing through arteries creates a change in radiographic image contrast from one picture to the next as the contrast bolus passes through (fig. 4).

The concept of subtracting one image from another to high-light the difference between them, is not new. Ziedses des Plantes (fig. 5) developed in 1932 film subtraction (fig. 6) (3), but it was not until the development of digital subtraction angiography (DSA) that subtraction has become sufficiently accurate to isolate less than $1 \%$ image contrast within images (4). In addition, the flexibility of DSA equipment has made a 


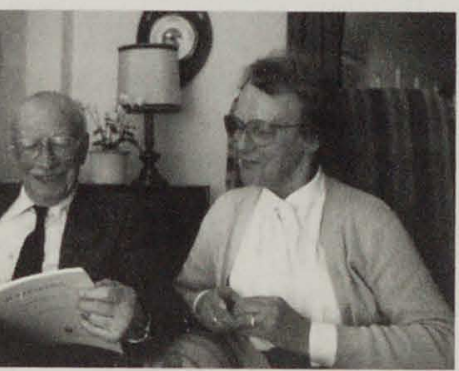

Figure 5

Prof. B.G, Ziedses des Plantes and his wife in their lovely home in Bloemendaal, The Netherlands, December 1988. variety of subtraction techniques available. Several different types of subtraction techniques are used for cardiac studies. Subtraction methods can be divided into two broad categories: temporal subtraction and energy (energy difference) subtraction (5). Energy subtraction is used in case soft tissue artefacts (i.e. introduced by swallowing or bowel movements) have to be cancelled out. The technique seems not very useful in cardiology and is not further discussed here.

Temporal techniques include: mask mode subtraction, time interval difference (TID) subtraction, and gated interval difference (GID). Temporal techniques are critically sensitive to motion (breathing, coughing etc.). Since the time separation between frames is greatest for mask mode subtraction, motion degradation occurs most frequently with this technique but can be alleviated by re-masking, pixel shifting and rotating programs now available with image processing computers. In figure 7 several "subtraction modes" are schematically explained. In mask mode subtraction the digitized data from peak opacified frames is subtracted from single or averaged frames of the same area before the arrival of the contrast medium. Overlying non-vascular structures that do not contain contrast material at the instant when the cardiac structure is maximally opacified are 'erased' from the image, thereby improving the visibility of vascular structures.

Another form of subtraction used in cardiology is time interval difference subtraction (TID). In TID the sets of frames subtracted from each other all contain contrast media but are separated slightly in time. Consequently, the resultant subtracted image (TID) image provides an indication of instantaneous changes in contrast levels throughout the cardiac cycle.

This mode is one of several possible methods used to enhance the diagnostic capabilities of digital ventriculography. TID images are sequential "difference" images produced by digitally subtracted image frames that are separated by two or more adjacent frames. Thus, the TID images can reflect the changes that occur in ventricular size during the cardiac cycle. This series of functional imaging greatly fascilitates the identification of the mitral and aortic valve planes and 

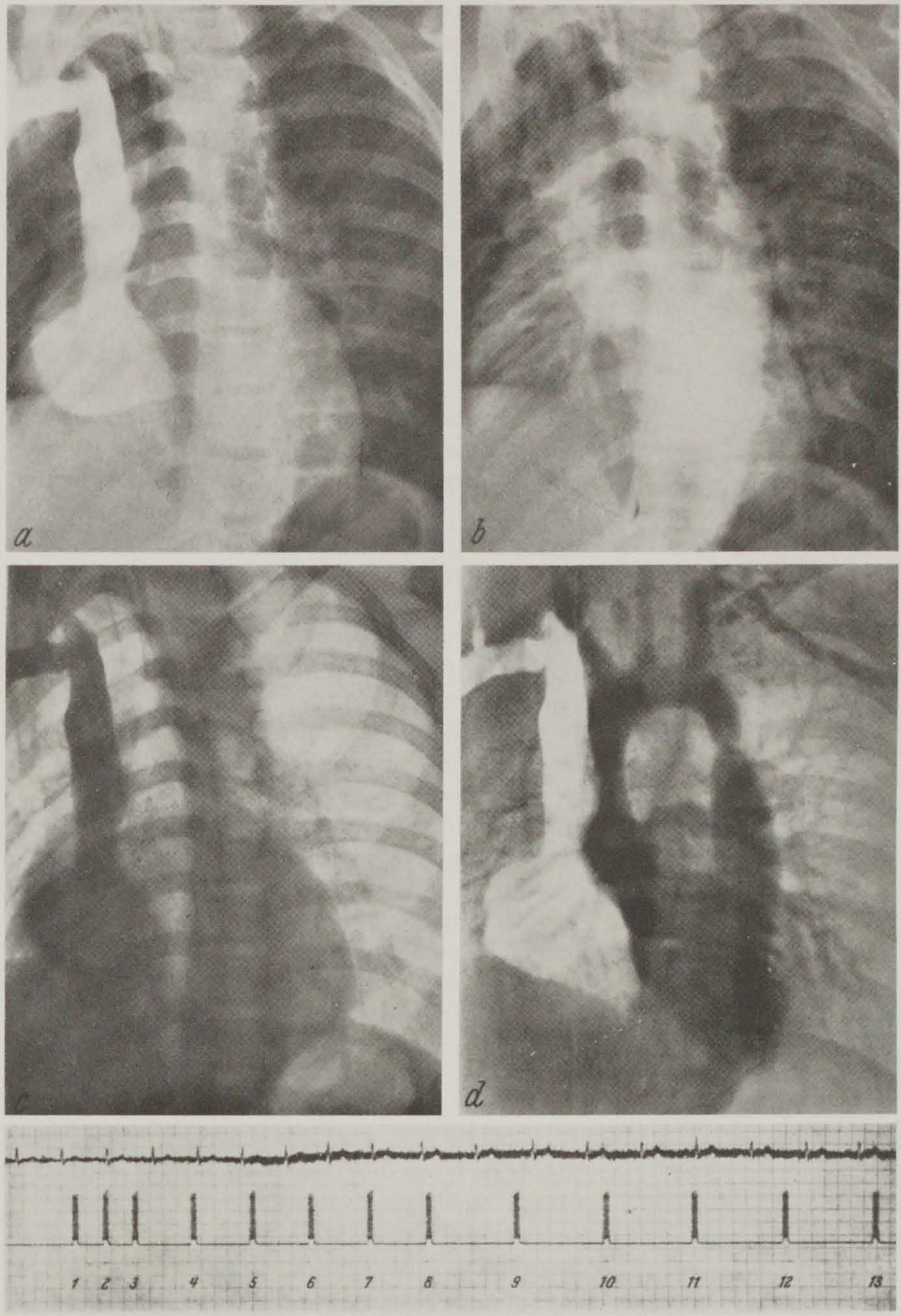

Figure 6

A 1959 subtraction study in a 15 years old boy with coarctation of the aorta (Prof. Ziedses des Plantes). On the electrocardiogram the acquisition pulse of the X-ray enabled "ECG gated" subtraction. A: Angiogram of the starting phase. B: Levogram with opafication of the aorta. C: Diapositive of A. D: Result of subtraction. 
Figure 7

Schematic representation of different subtraction techniques. In panel $A$ the difference between temporal subtraction and energy subtraction is shown (see text for explanation). Panel $B$ shows the time interval difference mode (TID) and the gated interval difference mode (GID). During GID the images are obtained at the same time of the cardiac cycle, preferably end diastole.
Post processing
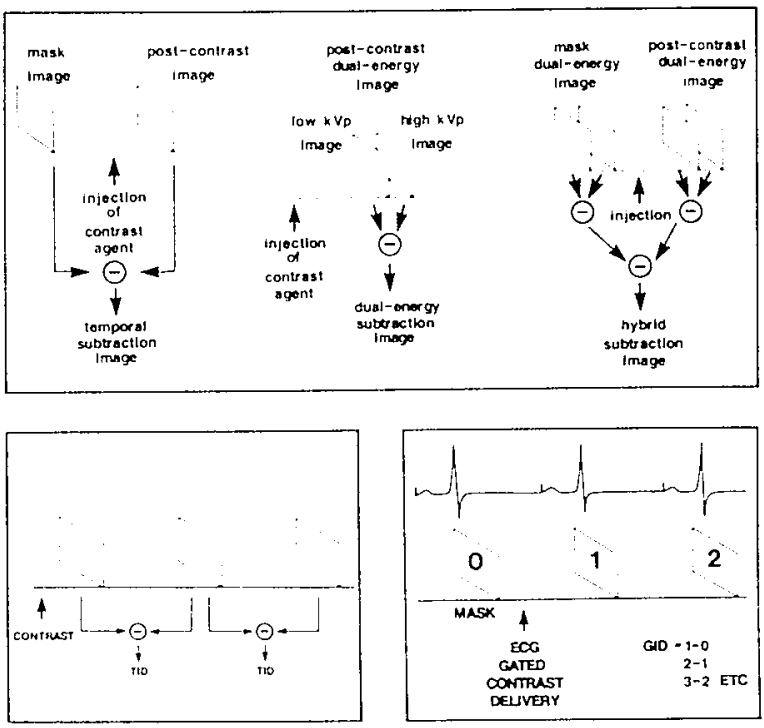

enhances the wall motion changes during the ejection and filling phases.

The TID method applied to the heart produces differences in resulting images that are due mainly to cardiac motion. This effect is undesirable when analyzing the appearance and disappearance of a bolus of contrast material injected into a coronary artery. Therefore, the synchronization of the beating heart with data acquisition and analysis is mandatory. Applying this knowledge to digital angiography, a new subtraction scheme was developed that produces another functional image using gated interval difference (GID) imaging. GID is related to TID except that the time interval is equal to the cardiac period. Application of GID has the effect of neglecting the motion of the heart, so that only those differences due to the appearance and or disappearance of contrast material from the previous cardiac cycle are recorded.

Current on line digital imaging systems do not provide diagnostic qualities equal to that from conventional cine film for studies of coronary lesions. Technical limitations in digital imaging result from limited resolution and noise (6). Clinical applications have taken advantage of the improved contrast sensitivity of image subtraction for the screening of functionally significant vascular abnormalities. Next to acquisition 
and remodelling possibilities the computer has fascilitated the development of many indirect functional or parametric images. These images are the result of processes being performed on original measured data in an attempt to bring out a functional property that may not have been obvious in the unprocessed data. In digital left ventricular angiography, one of the computer algorithms used is time interval difference

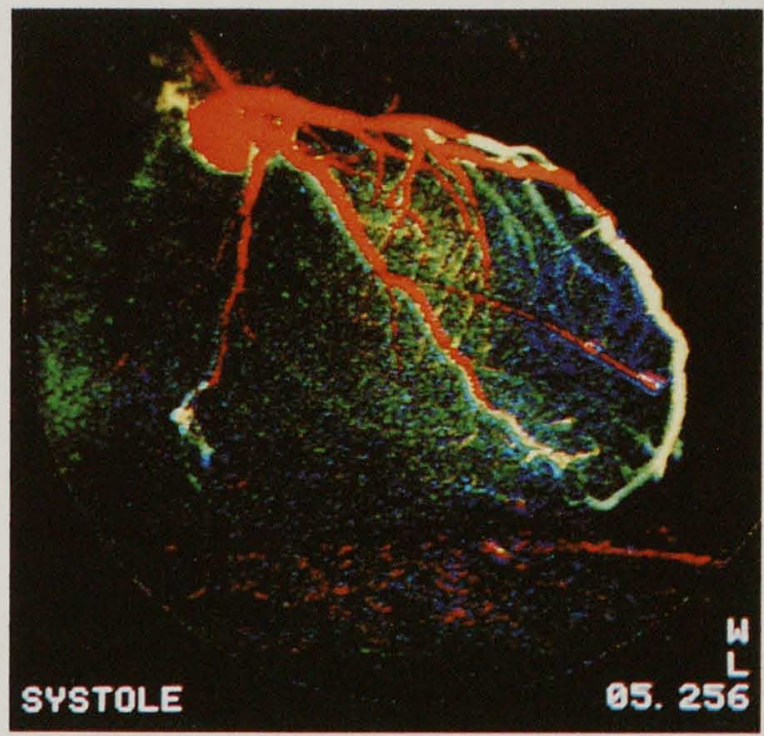

Figure 8

The left coronary system is shown. In panel A acquisition is in systole, in panel B during diastole. The colors represent the coding of contrast changes during subsequent cardiac cycle. (11)

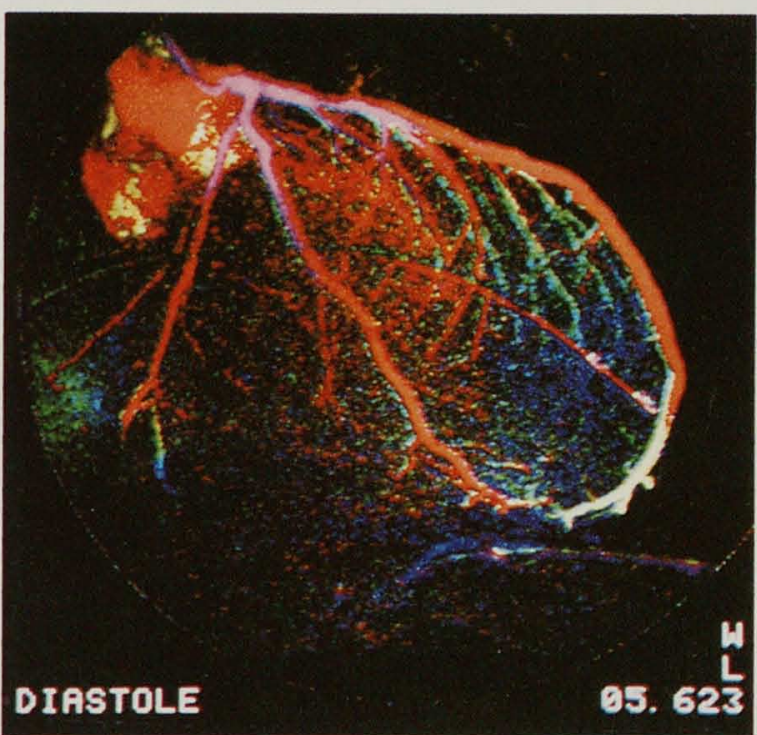



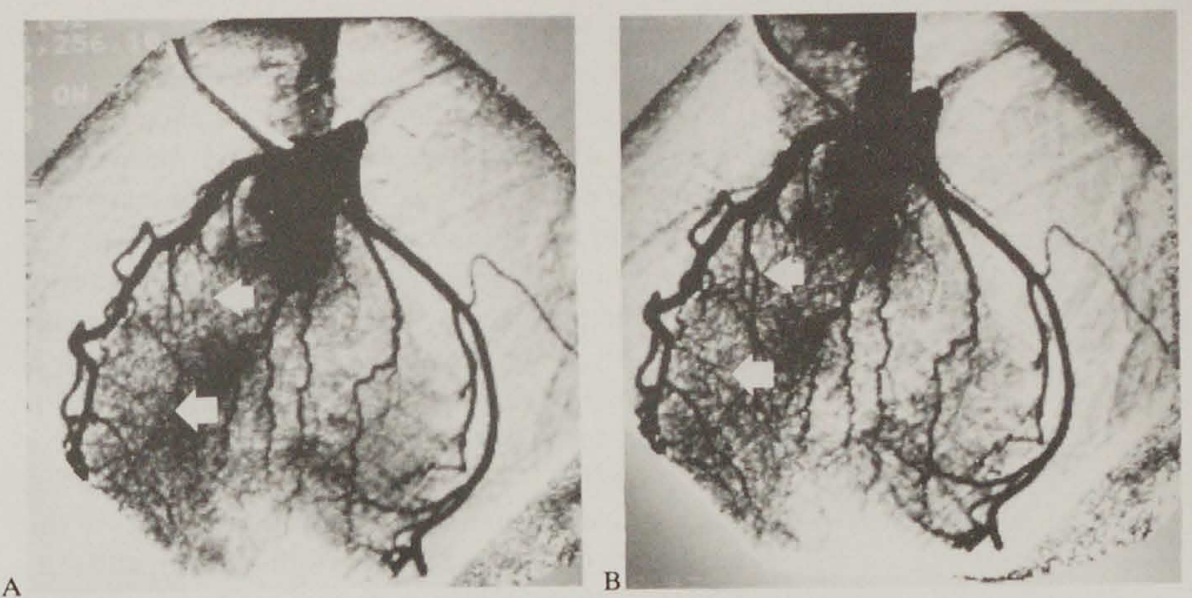

Figure 9

DSA of the left coronary artery in a patient with hypertrophic obstructive cardiomyopathy. Panel $\mathrm{A}$ is during systole, panel B during diastole. Note the occurrence of the saw-fish phenomenon, with squeezing of the septal branches of the LAD (7).

(TID) subtraction mode. In coronary angiography mask mode subtraction and gated interval imaging are used (GID). In GID the time derived data are used to determine the arrival time of the contrast material at each pixel, the time to maximum or time to mean opacification and the pixel density at that time for each pixel.
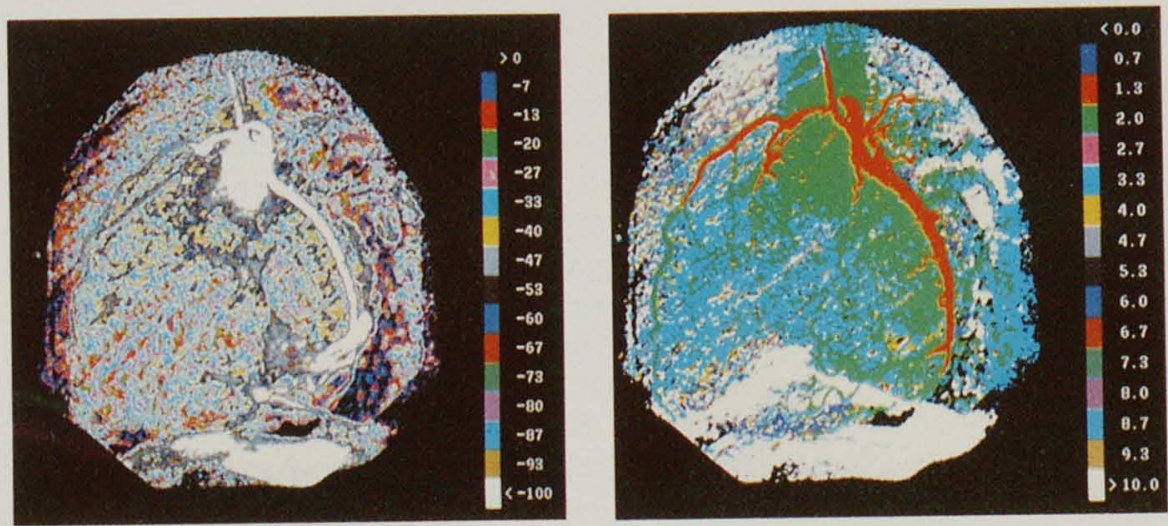

Figure 10

Panel A shows the injection of contrast material in the left coronary system in the left lateral projection. It shows the sequence of events during the perfusion of the myocardial tissue until contrast appears in the mouth of the coronary sinus. The left anterior descending coronary artery (LAD) has a proximally located area stenosis of $85 \%$. For each pixel the maximum density reached is color coded. Panel B shows the same sequence as in panel A but now the computer calculated the arrival time. These data can also be color coded for rapid visual interpretation. 
The output is a functional image, i.e. an image in which color is modulated according to the time needed to achieve a certain density level for each pixel. This image, represents the entire post injection image sequence in a single image by visualising the myocardial blush following intracoronary contrast material administration, thereby demonstrating the region of myocardium perfused by the coronary artery in question (fig. 8). Accurate absolute flow quantitation is not yet possible; instead, qualitative assessment is being used to recognize normal and abnormal flow distribution (fig. 9). The true power of the method lies in the relative comparison of functional images in the same patient before and after vasodilatation, and during interventions. Color coding is used in functional imaging because variations in pixel intensities are thought to represent quantitatively the function being studied. However, the relationship between an observed gray level of a pixel and the absolute intensity of a pixel is not linear. This makes it difficult for the observer to determine absolute levels visually, or even to recognize the equality of gray levels from two remote zones, with different surroundings. Also, the human visual system is not capable of detecting much more than 32 gray levels. These problems have been the motivation behind the use of pseudocolor to represent matrix intensities in functional images. In the figures 10 and 11 an example is given of parametric (functional) imaging. After selective injection of contrast into the left coronary system, on line digital images were acquired at a rate of one gated image per cardiac cycle. All images were taken at end diastole. Using the above described techniques 2 sets of functional images were constructed by the computer both before and after vasodilatation (induced by the injection of $5 \mathrm{mg}$ Papavarine intracoronary) (8). Figure 10 A shows the maximal density pictures while panel $B$ represents the time density images. (Arrival time, time to maximum opacification and mean time to maximal opacification in the region of interest).

Figure 11 shows the constructed time density curves for several regions of interest. With the use of these parameters relative coronary blood flow and coronary blood flow reserve (CFR) can be derived according to the formula: $(9,10,11)$ 


\section{Table IA}

Threshold

pixel

Appearance

$8 \% \quad 10 \% \quad 12 \%$

time

$\begin{array}{lll}180 & 175 \quad 170\end{array}$

Influence of threshold value on calculation of the appearance time.

Table IB

$\begin{array}{ll} & C F R \\ \mathrm{~T}_{\text {apn }} & 1.75 \\ \mathrm{~T}_{\text {max }} & 1.30 \\ \mathrm{~T}_{\text {mean }} & 1.11\end{array}$

Influence of substitution of Tmax and Tmcan for Tapp in the determination of CFR. CFR value may vary $\pm 30 \%$, depending on the time parameter chosen.

\section{Equipment and} Techniques
$\mathrm{CFR}=\left(\frac{\text { Maximal density }}{\text { time }}\right)_{\text {hyperaemic }}:\left(\frac{\text { Maximal density }}{\text { time }}\right)_{\text {basal }}$

Time is expressed in cardiac cycles but can be converted to seconds when heart rate and image acquisition rate are known.

The example in table 1 shows the relative importance of differences in pixel treshold definition or the use of appearance time $\left(T_{a p p}\right)$, time to maximal density $\left(T_{\text {max }}\right)$ or mean time to maximal density $\left(T_{\text {mean }}\right)$ for the calculations of CFR. At this point of time several approaches for measurements of the physiologic significance of left ventricular behaviour and coronary bloodflow are presently undergoing development and validation $(12,13,14)$.

At present validation studies are occurring both in animals and patients in an attempt to better diagnose, evaluate and ultimately improve the management of patients with heart disease (15).

In the Maastricht cardiac catheterisation room a Siemens cardioscope U-arm linked to a Pandoros optimatic Generator is used for acquisition (figure 12). The acquired image is transferred on to $35 \mathrm{~mm}$ film. This cine image can be off line digitized using a VIP-500 video image processor linked to a LSI 11/73 computer (figure 13). Opposite to this, the acquired image can be transferred on line to a video camera linked to a Technicare DR 960 DSA computer. Using the real-time digital radiographic technique, frames in $512 \times 512$ resolution are directly recorded on a high speed disk which allows acquisition at a speed of 30 frames/sec.

In some studies, described in chapters 6 and 7 , instead of the DR 960 a video image processor (VIP 300) was used for on-line subtractions of the video signal produced by the imaging chain. The matrix size was $512^{2}$. The images were stored on videotape.

In the off-line situation, cineframes were analysed by the Cardiovascular Angiography Analysis System (CAAS). This system, which has been described in detail in chapters 8,9 and 10 , consists of a Tagarno $35 \mathrm{CX}$ cineprojector from which the cinefilm is converted using a CCD camera. This signal is fed into a VIP 500 video image processor, an LSI $11 / 73$ host computer (RSX-11M + Operating system) with ter- 
Figure $11 \mathrm{~A}$

Panel A shows the distinction of contrast material through the cardiac cycle (no 3-no 12). Frame no 2 was chosen as mask image. For several regions of interest the time density curves are constructed panel B.
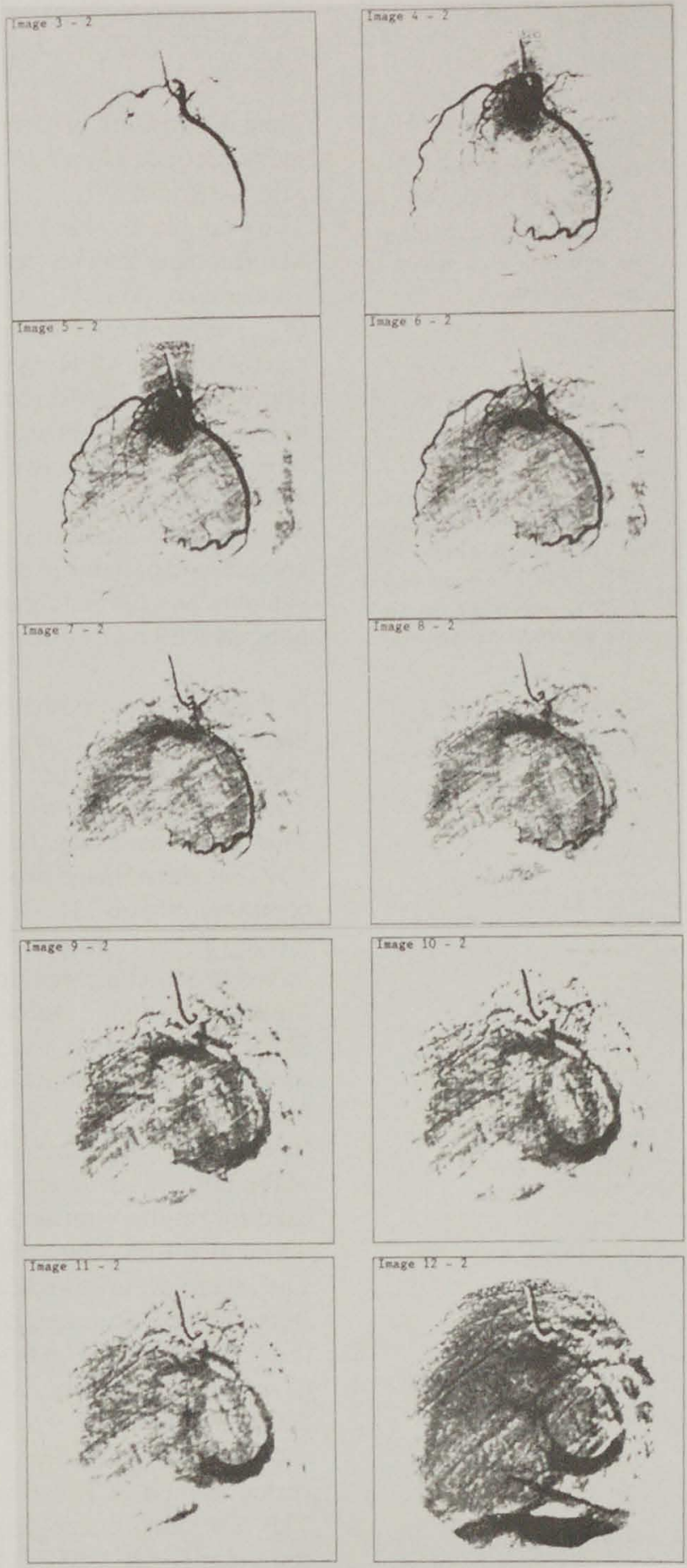

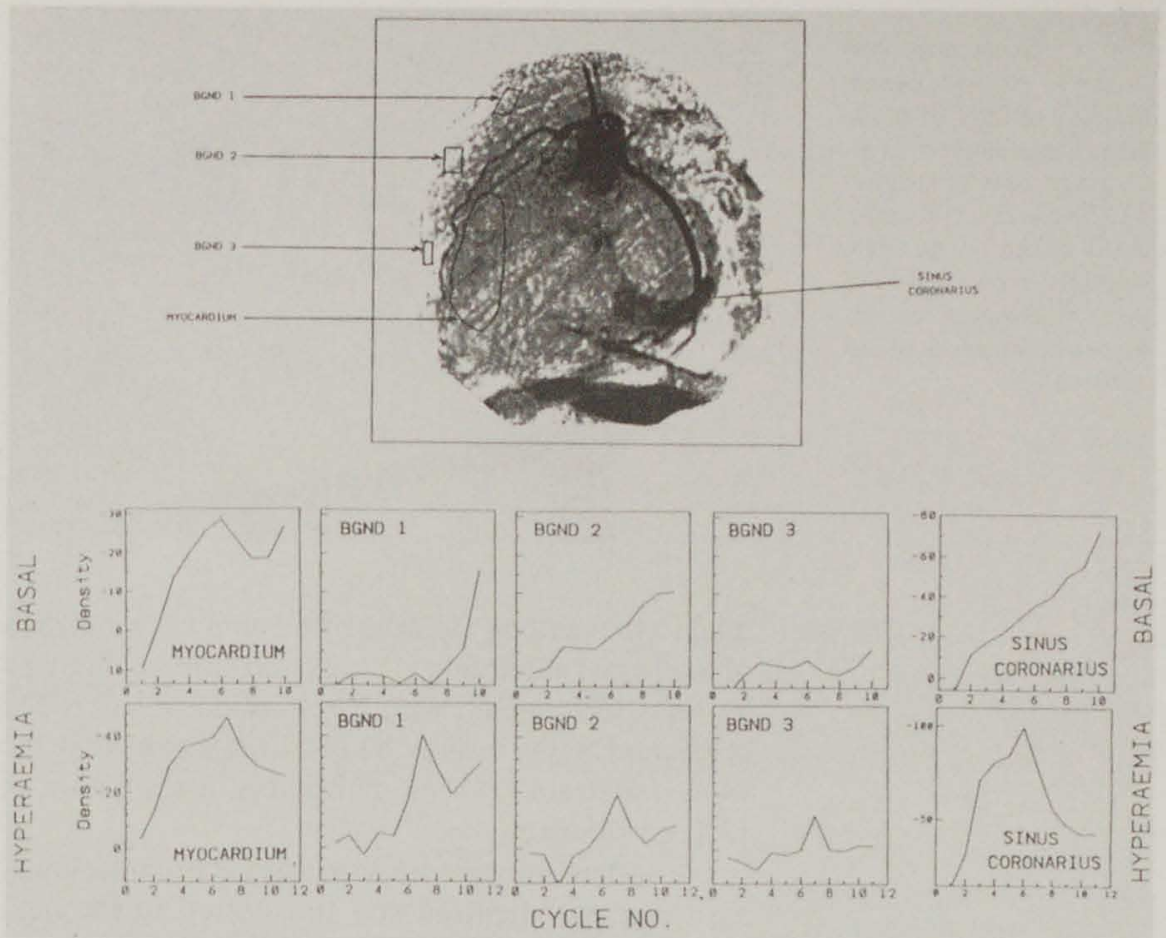

Figure $11 B$

\section{Figure 12}

The cardiovascular angiographic suite. The image intensifier of the $\mathrm{U}$-arm is connected to both a cinefilm camera and a videocamera connected to the digital system.

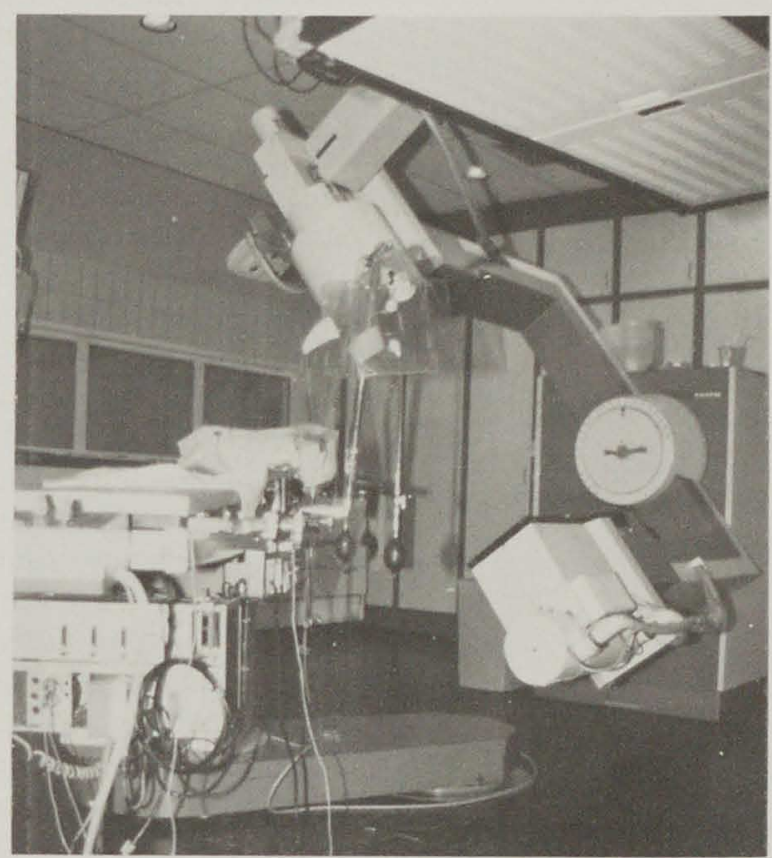


Figure 13

The Cardiovascular Angiography Analysis System (CAAS) consists of a Tagarno which has been modified to transfer the image to a CCD camera. This camera is linked to the main computer. From the desk of the main computer the image can be manipulated and analysed.

Techniques

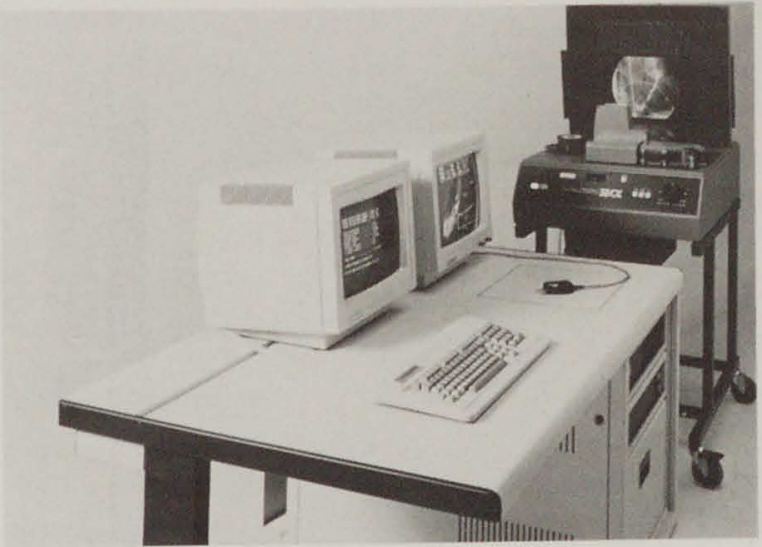

minal and a writing tablet. Any $6,9 \mathrm{~mm} \times 6,9 \mathrm{~mm}$ area of a selected cineframe $(18 \times 24 \mathrm{~mm})$ can be digitized by the CCD camera with a resolution of $512 \times 512$ pixels and 8 bits of grey levels. This means that the whole cineframe can be digitized at a resolution of $1330 \times 1770$ pixels.

In the on-line situation the video signal from the imaging chain was digitized and transferred to the high speed disc (capacity 1.2 Gbyte). For review and postprocessing a terminal of the host computer with monitor was installed in the catheterization room. Resolution of the images are $512^{2} \times 8$ bits gray scale.

Application of digital radiographic image enhancement is dependant upon precise inter-frame correspondence. This basic requirement of digital imaging is complicated in its cardiac application by the cyclical cardiac motion. Therefore ECG-gated frame aquisition is required to produce acceptable visualization of cardiac structures, unless digital acquisition at very high rates (more than $12.5 \mathrm{f} / \mathrm{s}$ ) is possible. Either patient motion (especially respiration) or use of nonECG correspondent frames can significantly degrade final image quality. Additionally, contrast medium administration itself, can alter inter-frame correspondence both directly by changing ventricular geometry due to its negative inotropic effect and indirectly through alterations in cycle length. The latter can be substantially reduced by atrial pacing.

Early enthusiasts of intravenous digital subtraction angiography believed that this development heralded 
the end of selective angiography. Angiographic skills would be rendered obsolete, they said, since vascular imaging would be performed by venous injection without the need for direct catheterization $(16,17)$. Others however have indicated that intravenous DSA is of relatively little value in cardiology as an imaging modality because of its technical and clinical limitations $(18,19)$.

Intravenous digital angiography can provide excellent diagnostic information but often requires a relatively healthy, cooperative patient for optimal image quality. Each image requires the injection of approximately $30-40 \mathrm{ml}$ of contrast into a periferal vein, the superior caval vein, or right atrium. Total contrast delivered in a study may approach $200 \mathrm{ml}$. Good cardiac output is essential to obtain good image quality. There is otherwise a slow delivery of contrast agent to the arterial circulation with excessive dilution. This phenomenon was already known to the first investigators using the intravenous route (see chapter 1 , reference 6). Excellent images can be obtained in ideal patients but many patients cannot safely undergo intravenous digital angiography. In patients with diabetes or renal disease, large contrast volumes can induce or worsen renal failure. Patients with cardiac disease, including prior myocardial infarction or a history of congestive failure, can experience acute worsening of congestive failure or angina, due to the cardiovascular stress of a large contrast volume injection. Motion artifacts preclude satisfactory studies in many elderly and uncooperative patients.

Intraarterial digital angiography, on the other hand, has overcome many of the disadvantages of intravenous DSA and has been shown to have unique advantages over standard angiography.

Intraarterial digital subtraction angiography provides vascular imaging with minimal contrast dosis, thereby greatly decreasing patient discomfort and allowing multiple contrast injections for evaluation of the entire vascular system from the aortic arch to the coronary arteries. Since only small volumes of diluted contrast are necessary, small catheters ( 5 french) can be used, possibly allowing diagnostic studies to be performed on an outpatient basis. Intraarterial studies are much better tolerated and allow more complete imaging with less patient discomfort than in- 


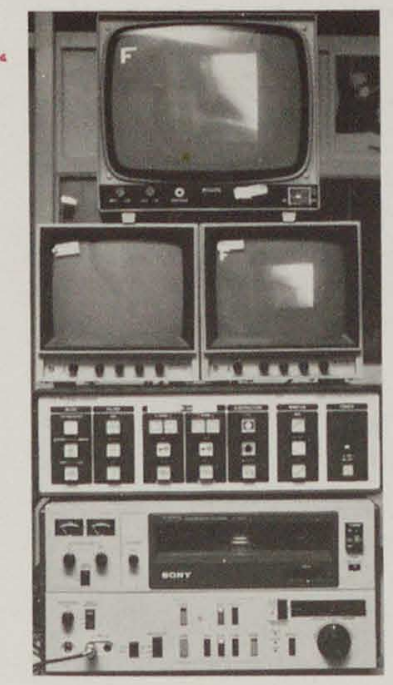

Figure $14 a$

The VIP-300 as it can be used as a "portable" device. The analog video signal is fed into the VIP 300 and displayed on a monitor. The manipulated image can be viewed on line and recorded on video.

\section{Figure $14 b$}

The interventional cardiologist as he uses digital imaging.

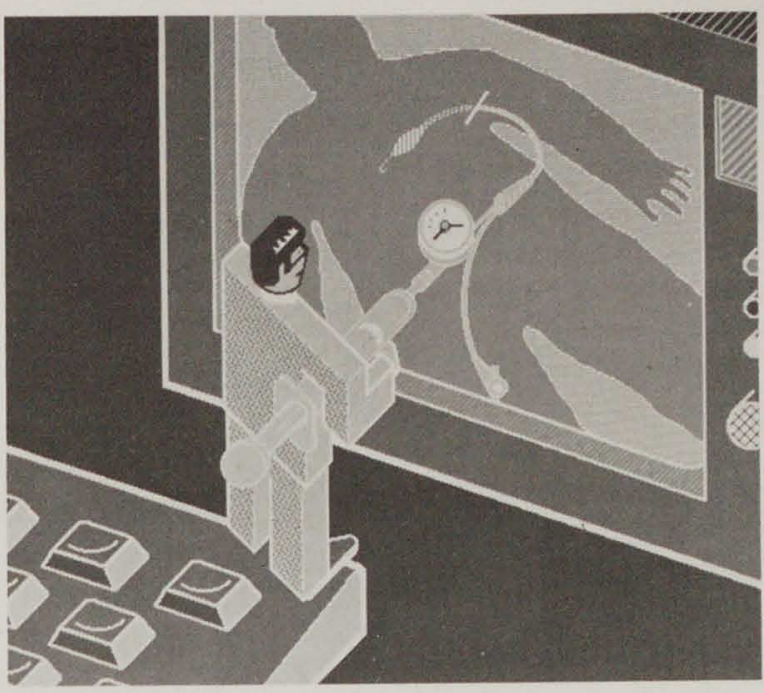

travenous studies. The quality of the study is less dependant on patient cooperation. In this way intraarterial DSA can be in advantage to the interventional cardiologist during PTCA or angiopyroplasty (figure 14). Overall image quality is significantly better than with intravenous imaging.

As was pointed out, however, in a recent report (20) total body intravenous digital subtraction angiography may prove to be useful in imaging wide spread vascular abnormalities in a relatively physiologic state (figure 15).

Since in the forthcoming chapters the techniques used are not always mentioned a summary of intraarterial techniques is given. All catheterizations were carried out using the same strict standards as during routine catheterisation investigations. Procedures were carried out aseptic, all patients were fully heparinized by injecting $75 \mathrm{mg}$ (1500 IE) Thrombolyquine before catheterization (21). Intravenous and or intraarterial pressures were at all times continuously monitored. The electrocardiogram was recorded and during digital image acquisition used for ECG triggered contrast delivery and image acquisition. During the procedure it was ensured that the patient was comfortable and could cooperate with the procedure. During all acquisition procedures the patient was asked to hold his/her breath in deep inspiration. Careful explanation and 


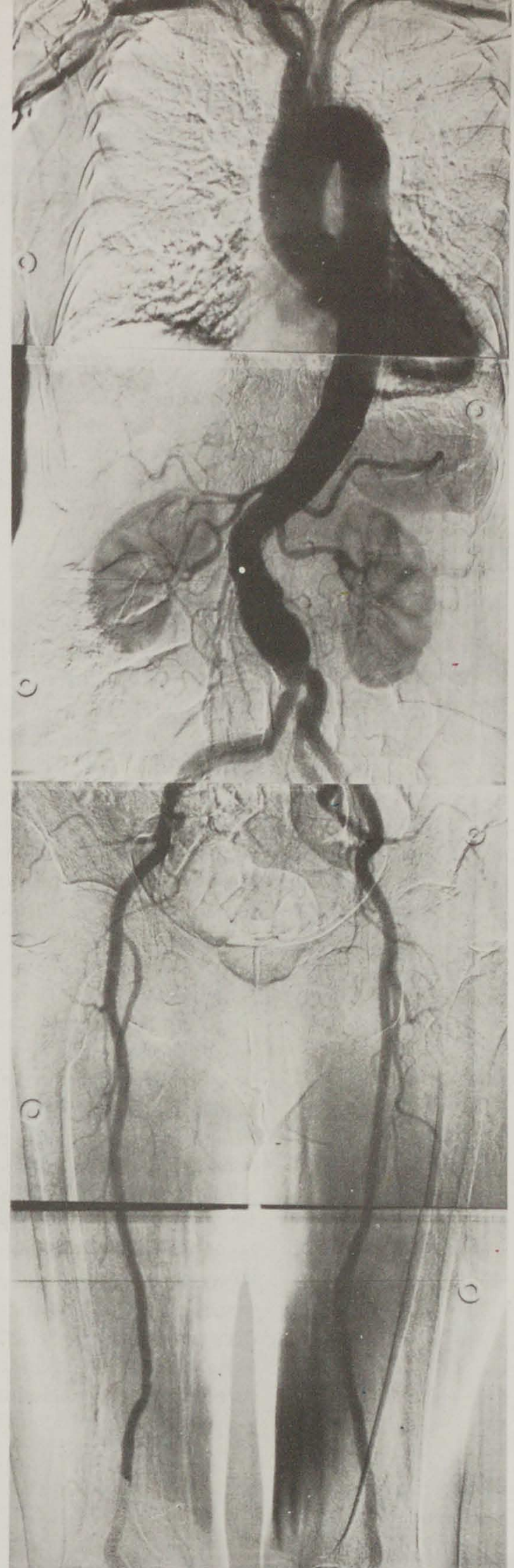


instruction to the patient was essential to succeed in obtaining an optimal diagnostic digital investigation. The contrast material used was Natrium-Meglumine ioxaglate (Hexabrix ${ }^{\mathrm{R}} 320 \mathrm{mg} \mathrm{V} / \mathrm{ml}$, Guerbet, Byck, the Netherlands) delivered by a Medrad mechanical pump.

During cineangiography images are acquired at a speed of $50 \mathrm{frames} / \mathrm{sec}$ for ventriculography and 25 frames/sec during coronary angiography. Because there exists a flicker in the image on the monitor during 25 frames/sec, we use a gapfiller which provides every other image with the image data of the previous image. In this situation a $50 \mathrm{frames} / \mathrm{sec}$ video image on the monitor is present while only 25 frames/ sec are present on the cine film. The gapfilling technique will be discussed in more detail in chapter 5 .

Left ventriculography is performed after hemodynamic measurements in the 30 degree right anterior oblique projection and usually also in the 60 degree left anterior oblique projection.

Right ventriculography is performed in the anteroposterior projection and the 90 degree lateral projection.

The size of the image intensifier used for ventriculography is 9 inch, for coronary angiography the 5 inch intensifier is applied. A modified Judkins technique was used for catheterization using French 7 or 8 pigtail catheters for left ventriculography. For right ventriculography a Berman catheter was employed to ensure a steady position in the apex of the right ventricle.

As is being described in chapter 7 left ventriculography can be performed with diluted contrast. In this case digital enhancement of the contrast is achieved by an on line video image processor, the VIP 300 .

The usual contrast dose used for ventriculography varies with the body size of the patient, but is usually between 30 and $40 \mathrm{ml}$ injected with a flow rate of 15 $\mathrm{ml} / \mathrm{sec}$. During low dose ventriculography $50 \%$ to $70 \%$ of the contrast material (e.g. 9cc- $15 \mathrm{cc}$ contrast material) was diluted with plain saline to a volume of 30 to $40 \mathrm{ml}$. The diluted volume was necessary to ensure a general opacification of the ventricle.

Cine coronary angiography is selectively performed using a modified Judkins technique. For left and right coronary artery angiography a French 7 selective 
catheter is usually employed. Opacification of the left coronary artery takes place after it is ensured that no wedging of the catheter is present. Before introducing the catheter into the ostium of the left system $2 \mathrm{cc}$ of contrast material is injected in order to check correct intraluminal catheter position. If the catheter is correctly positioned in the ostium of the left coronary artery system, several images are performed in different projections. The projections used are right anterior oblique, right anterior oblique with 30 degree cranial angulation, left anterior oblique 45 degree with caudal and cranial angulation, left anterior oblique 60 degrees and a right lateral position. At all times the patient is positioned in such a way that optimal imaging of the region of interest is possible with at the same time a sufficiently large part of the tip of the catheter in the same field of view. This to make optimal off-line analysis by CAAS possible (see chapters 9 and 10). During cine angiography $9 \mathrm{ml}$ of contrast material is mechanically injected (Medrad pump) with a flow rate of $4 \mathrm{ml} / \mathrm{sec}$. Pressure delivered by the pump is limited to $450 \mathrm{PSI}$. During injection it is assured that back flow is observed. The pump injection is not routinely ECG triggered and the command to inject is manually given by the investigator. During right coronary artery catheterization basically the same procedure is followed. The projections used are the left anterior oblique 60 degree and 30 degree right anterior oblique. In selected cases a lateral view is additionally performed i.e. when retrograde filling of the left anterior descending artery is present. Since the right coronary artery is smaller than the left coronary artery, the amount of contrast injected is $6 \mathrm{ml}$ with a flow rate of $3 \mathrm{ml} / \mathrm{sec}$. Also in this case the power injector is limited to deliver a pressure of 450 PSI.

In on line digital angiography, performed with the Technicare DR 960 the introduction of catheters remains similar to the methods just described. With the recent introduction of smaller size catheters (French 5) with good torque and flow characteristics we tend to switch from French 7 to French 5 catheters*. A reduction in pressure time of the femoral artery in the groin of the patient and less interference with flow in the coronary ostium seems an advantage of this recent development. As for the projections, only those are selected where there is as little overlap as possible of 
non perfused myocardium. Since the functional postprocessing techniques as previously described, relate flow to density, overlap of non perfused heart muscle may influence the outcome. Therefore for studies of the left anterior descending coronary artery a left lateral view is chosen, for the circumflex artery a 60 degree left anterior oblique and for the right coronary artery the 30 degree right anterior oblique projection.

Since in subtraction motion artefacts may degrade the image considerably, heart frequency is kept constant by right atrial pacing just above the intrinsic sinus frequency. In case of atrial fibrillation high speed acquisition is used ( 30 frames/sec) to be able to compare after the injection the best suitable images. During right atrial pacing one diastolic frame is taken at $78 \%$ of the predicted R-R interval. Although the motion of the heart is even more stable later in dias-

Figure $16 a$

DSA of the left coronary artery. Subsequent frames, at an acquisition of one frame per cardiac cycle, show the passage of contrast through epicardial vessels and cardiac muscie. In the last frame the venous return into the coronary sinus and right atrium is apparent.
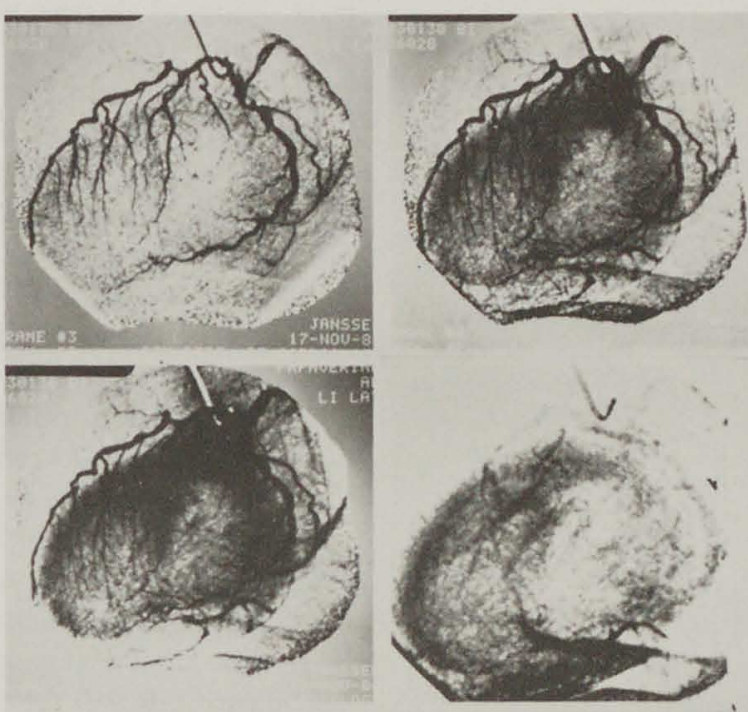
tole (ie $90 \%$ of the R-R interval), it was technically difficult to trigger the DSA unit at higher intervals than $78 \%$. When triggered at higher intervals in patients with heart rates over 90 beats/minute, the DR 960 would skip images during the acquisition run. During digital coronary angiography, image acquisition and the delivery of contrast were ECG triggered and controlled by the host computer.

No measures were taken to trigger the right atrial pacemaker and the imaging chain on the electrical power system of the catheterization room so that theoretically up to $40 \mathrm{msec}$ difference in timing of "identical" images could occur (12). During coronary angiography no dilution of contrast as with left ventriculography was performed for resolution reasons.

Contrast density influences the X-ray dose in such a way that dilution of contrast would cause unaccept-
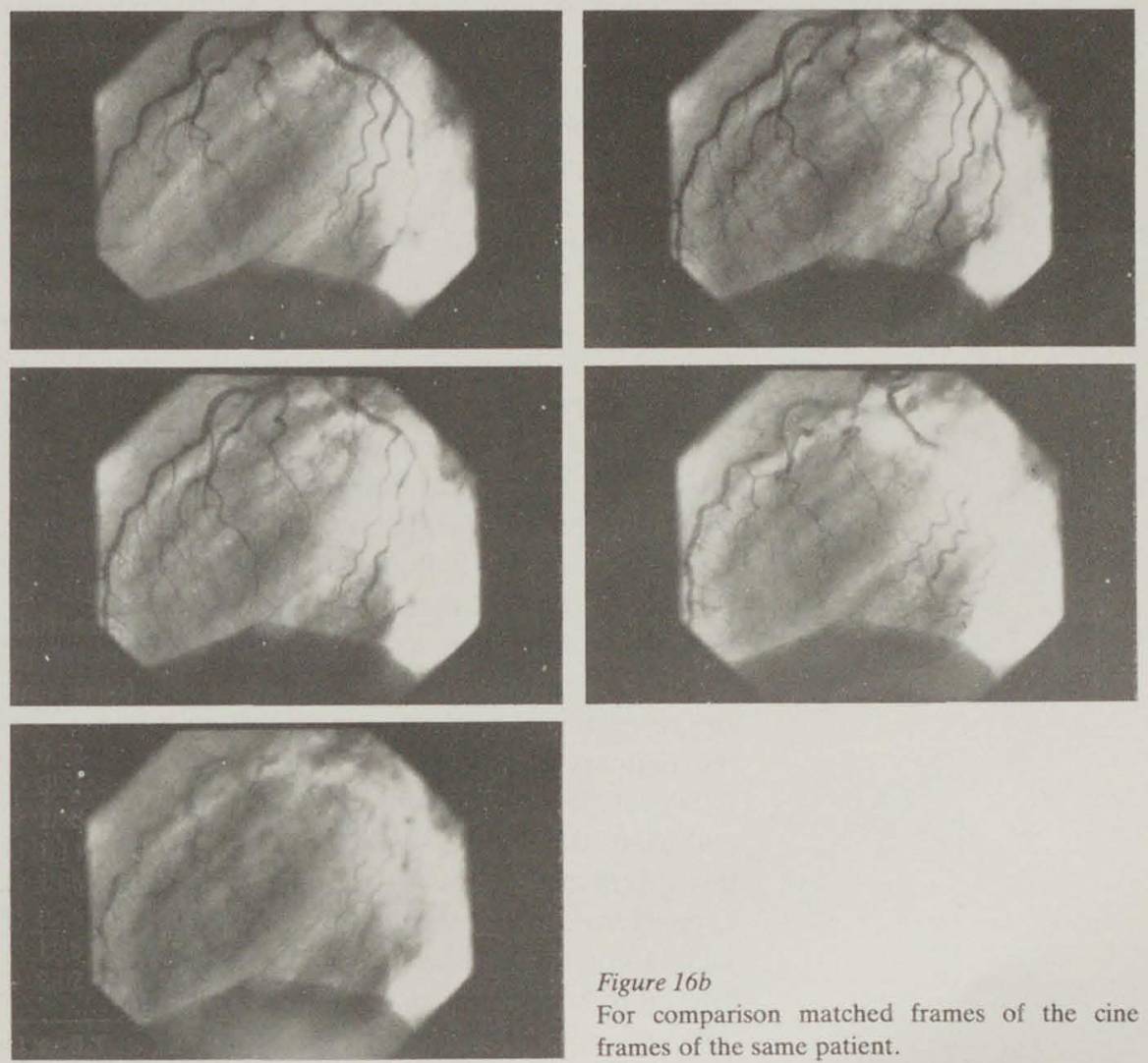

Figure $16 b$

For comparison matched frames of the cine frames of the same patient. 
able $\mathrm{X}$-ray doses and an unacceptable signal to noise ratio for coronary angiography $(1,22)$. For the right coronary artery $6 \mathrm{ml}$ contrast was injected with a flow rate of $3 \mathrm{ml} / \mathrm{sec}$, for the left coronary artery $9 \mathrm{ml}$ contrast was mostly appropriate with a injection rate of $4 \mathrm{ml} / \mathrm{sec}$ (figure 16).

The effect of the amount of contrast on densitometric calculations was studied in ten patients. With injection intervals of 3 minutes, $9 \mathrm{ml}, 4 \mathrm{ml}$ and $2 \mathrm{ml}$ were injected before and after the administration of $5 \mathrm{mg}$ Papaverine intracoronary (ic) with a flow rate of $4 \mathrm{ml}$ per second. All other imaging parameters were kept constant. The results are given in table 2 . From this study it appears that considerable variations may be present. Further studies are needed to investigate the clinical value of these differences.

Pulmonary angiography was exclusively performed using the digital subtraction technique. Depending on the clinical situation a catheter was introduced using the veins of the groin or arm. Preferably a pigtail catheter was put into the right ventricle or main pulmonary artery. Depending on the pressures found a decision was made for selective or non-selective angiography. In non-selective angiography a bolus of $20-30 \mathrm{ml}$ of contrast is delivered at a speed of 10 $\mathrm{ml} / \mathrm{sec}$. The field of view includes the main stem of the pulmonary artery and the main branches of the right and left pulmonary arteries. It may be necessary to repeat injections several times with repositioning of the catheter and adjusting the position of the image intensifier to avoid misinterpretation caused by preferent flow patterns or positioning of the patient.

With the selective (balloon-occlusive) technique only $5-10 \mathrm{ml}$ of contrast material is hand injected distally from the balloon; this, to decrease the risk of hemodynamic instability following contrast injection.

In conventional angiography of the pulmonary tree the delivery of $40 \mathrm{ml}$ of contrast is no exception. However, in patients with acute massive pulmonary embolism this may be hazardous (chapter 6). Since this group of patients is short of breath and often hemodynamically unstable, subtraction techniques carry a great risk of being non diagnostic. We therefore employ continuous on-line mask mode subtraction with the VIP 300 (chapter 6) or on-line digital 
Table $2 B$

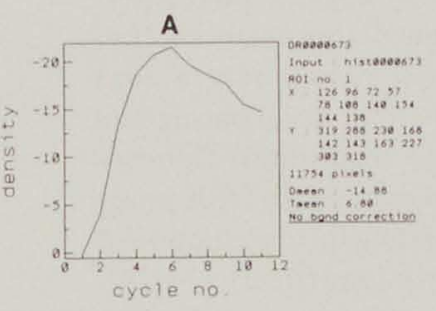

B
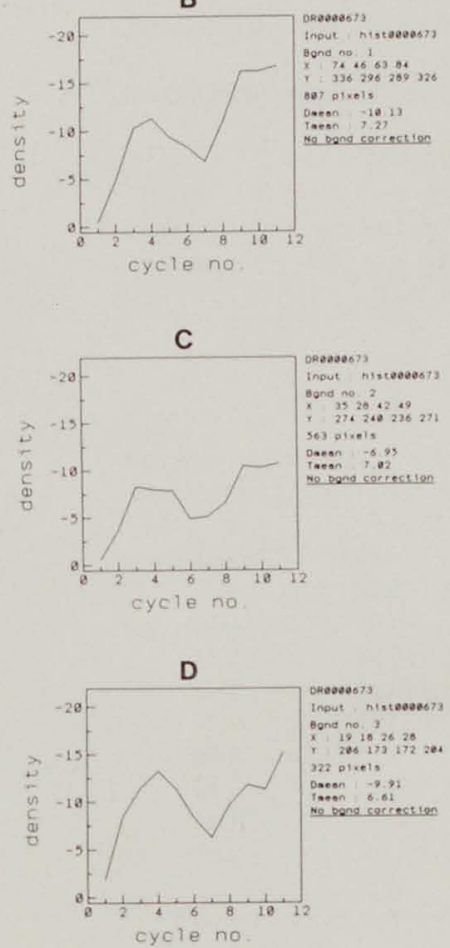

Table 2A

\begin{tabular}{|c|c|c|c|c|}
\hline \multicolumn{2}{|c|}{ CFR: (Tmax) } & \multirow[t]{2}{*}{ (Tapp) } & \multirow[t]{2}{*}{ (Tmean) } & \multirow[t]{2}{*}{ (Tmax-Tapp } \\
\hline Injec & & & & \\
\hline Volu & & & & \\
\hline 9 & 1.27 & 1.34 & 1.50 & 1.24 \\
\hline 5 & 0.91 & 0.81 & 0.82 & 0.97 \\
\hline 2 & 0.56 & 0.52 & 0.51 & 0.57 \\
\hline 9 & 0.99 & 1.01 & 1.00 & 0.98 \\
\hline 5 & 0.52 & 0.65 & 0.57 & 0.44 \\
\hline 2 & 3.33 & 2.16 & 3.60 & 4.36 \\
\hline 9 & 1.05 & 0.64 & 0.94 & 1.33 \\
\hline 5 & 0.74 & 1.04 & 0.77 & 0.56 \\
\hline 2 & 0.38 & 0.50 & 0.40 & 0.30 \\
\hline 9 & 1.28 & 0.99 & 1.40 & 1.50 \\
\hline 5 & 0.51 & 0.63 & 0.54 & 0.38 \\
\hline 2 & 0.13 & 0.13 & 0.13 & 0.12 \\
\hline 9 & 1.79 & 1.72 & 1.46 & 1.83 \\
\hline 5 & 0.80 & 0.92 & 0.81 & 0.73 \\
\hline 2 & 0.82 & 1.00 & 0.75 & 0.65 \\
\hline 9 & 0.99 & 1.03 & 1.02 & 0.97 \\
\hline 5 & 1.05 & 1.04 & 1.02 & 1.05 \\
\hline 2 & 1.03 & 0.91 & 0.98 & 1.12 \\
\hline 9 & 0.97 & 0.83 & 1.03 & 1.05 \\
\hline 5 & 0.81 & 0.85 & 0.86 & 0.79 \\
\hline 2 & 1.62 & 1.57 & 1.25 & 1.64 \\
\hline 9 & 0.95 & 0.92 & 0.93 & 0.96 \\
\hline 5 & 1.09 & 1.05 & 0.94 & 1.11 \\
\hline 2 & 0.84 & 0.83 & 0.70 & 0.85 \\
\hline 9 & 1.40 & 1.83 & 1.40 & 1.11 \\
\hline 5 & 0.85 & 0.81 & 0.80 & 0.86 \\
\hline 2 & 1.64 & 1.25 & 1.48 & 2.00 \\
\hline
\end{tabular}

During identical procedures $9 \mathrm{ml}, 5 \mathrm{ml}$ and $2 \mathrm{ml}$ of Hexabrix ${ }^{\mathrm{R}}$ were injected into the left coronary artery of ten patients at a flow rate of 4 $\mathrm{ml} / \mathrm{sec}$. The procedure was repeated in the same patient after the intracoronary administration of $5 \mathrm{mg}$ Papavarine to create maximal hyperaemia. Appearance time (Tapp), time to maximal density (Tmax) and mean time to maximal density (Tmean) were computed. Coronary blood flow reserve was calculated using the following equation:

$$
\mathrm{CFR}=\left(\frac{\text { Maximal density }}{\text { time }}\right)_{\text {hyper }}:\left(\frac{\text { Maximal density }}{\text { time }}\right)_{\text {basal }}
$$

Threshold for contrast density per pixel was $10 \%$.

One of the conclusions that can be made is that the use of $2 \mathrm{ml}$ of contrast material is insufficient for adequate analysis. As is pointed out in table 2B the background noise (panel B,C,D) has almost the same magnitude as the density of the coronary artery (panel A). 
angiography (DR 960) at 30 frames/sec with good results. Atrial pacing is not attempted in patients with pulmonary embolism and image acquisition is not ECG triggered since frequently atrial and ventricular rhythm disturbances are present in these patients (23). Also the impact of cardiac motion is less important than the respiration artefacts. In all cases a good positioning of the copper filter is essential in obtaining diagnostic images since the mediastinum and heart absorb X-ray differently than the lung fields. For pulmonary angiography, images are obtained in the anterior posterior projection and the $10-20^{\circ}$ left anterior oblique projection.

In patients in which pulmonary angiography is performed to document anatomical abnormalities (i.e. atrial septal defects, abnormal venous return etc.) optimal imaging is ensured by right atrial pacing and hold inspiration during image acquisition. Densitometric (functional) analysis of pulmonary DSA images has been successful in evaluating the distribution of contrast flow to either side of the lung (figure 17) (24).

Table 3

Reproducibility and its influence on CFR of a given densitometricmeasurement was tested in 9 patients.

In each patient two repeated injections of $9 \mathrm{ml}$ of contrast material was performed.

$$
\begin{aligned}
& \text { For each injection } O \text { (flow) was determined by } O=\frac{V}{T} \\
& V=\int_{\text {roi }} \text { Dmax-background and } \mathrm{T}=\underset{\text { roi }}{\int} \operatorname{Tmax} ; \underset{\text { roi }}{\int} \mathrm{Tapp} ; \underset{\text { roi }}{\int} \mathrm{Tmean} ; \\
& \int_{\text {roi }}^{\text {Tmax-Tapp }}
\end{aligned}
$$

Of two repeated injections $Q 1: Q 2$ was calculated for each time parameter. The mean and standard deviation show a good reproducibility with a maximal variation of CFR of 0.5 .

\begin{tabular}{ccccc} 
& (Tmax) & (Tapp) & (Tmean) & (Tmax-Tapp) \\
O1/O2 & 1.11 & 0.74 & 1.12 & 1.49 \\
& 0.87 & 0.74 & 0.91 & 0.92 \\
& 0.65 & 0.77 & 0.58 & 0.61 \\
& 0.93 & 0.67 & 0.90 & 1.18 \\
& 1.02 & 0.83 & 0.97 & 1.14 \\
& 1.29 & 1.59 & 1.14 & 1.06 \\
& 0.58 & 0.65 & 0.56 & 0.46 \\
& 1.53 & $\mathbf{1 . 7 0}$ & 1.30 & 1.46 \\
& 1.18 & 0.61 & 1.19 & 2.02 \\
\hline mean \pm SD & $1.0 \pm 0.3$ & $0.9 \pm 0.4$ & $1.0 \pm 0.2$ & $1.1 \pm 0.5$
\end{tabular}




\section{Figure 17}

A pulmonary digital angiogram is shown of a patient with a $2: 1$ shunt on the atrial level. Arrival time is color coded.

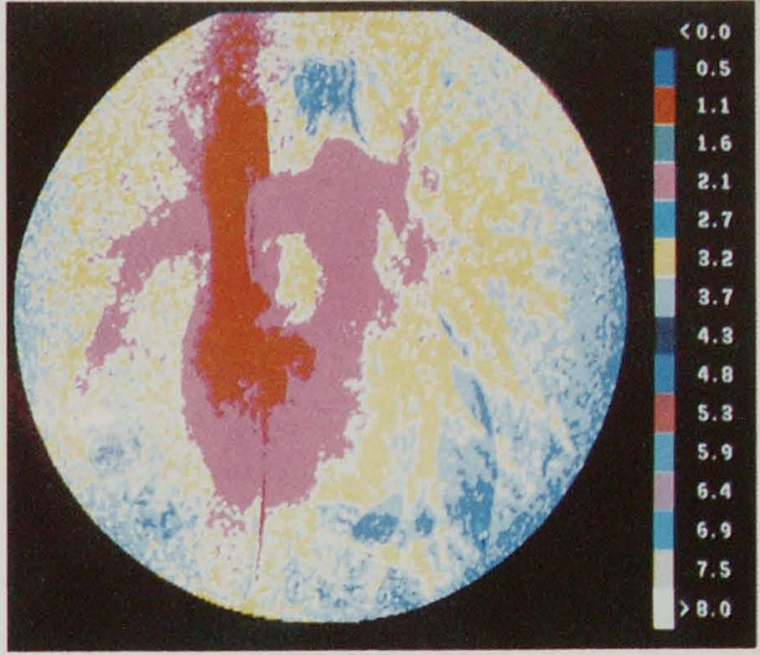

For densitometric purposes DSA images from any cardiac phase are suitable, provided that pulmonary contrast material has not yet started to run of the pulmonary veins. The method has been applied in children with peripheral pulmonary stenosis, tetralogy of Fallot and TGA. Likewise, the success of surgical repair was documented either by central cardiac or intravenous contrast injections (25).

1. Verhoeven LAJ, : Digital Subtraction Angiography (DSA) page 159. Thesis, University of Delft, Netherlands, 1985.

2. Rose A: Vision: Human and electronic. New York, Plenum Press, 1973.

3. Ziedses des Plantes, B.G.: Planigraphie en subtractie. Röntgenografische differentiatiemethoden. Thesis, University of Utrecht, Netherlands, 1934.

4. Mistretta et al: Multiple image subtraction techniques for enhancing low contrast periodic objects. Inves. Radiol. 1973; $8: 43-44$.

5. Kruger RA, Mistretta CA, Crummy AB: Digital K-edge subtraction radiography. Radiology 1977, 126:243-246.

6. Brody WR: Digital Radiography. Proc SPIE 314, 1981.

7. Pedro Brugada, Frits Bär, Chris de Zwaan, Denis Roy, Martin Green, Hein JJ Wellens. "Saw-fish" systolic narrowing of the left anterior descending coronary artery. An angiographic sign of hypertrophic cardiomyopathy. Circulation 1982; 66: 800-803.

8. Zijlstra F, Reiber JHC, Serruys PW: Does papavarine dilate the epicardial coronary arteries ? Implications for the assess- 
ment of coronary flow reserve. Cath. Cardiovasc. Diagn. 14:1, 1988

9. Marcus M, Wright C, Doty D. Easthan C, Laughlin D, Krumm P. Fastenow C. Brody M: Mcasurements of coronary velocity and reactive hyperemia in the coronary circulation of humans.

10. Bookstcin JJ, Higgings CB: Comparative cfficacy of coronary vasodilatory methods. Invest Radiol 12: 121, 1977.

11. Hoffman J.: Maximal coronary flow and the concept of coronary vascular reserve. Circulation 70: 153, 1984.

12. Werf T. van der, Heethaar RM, Stegehuis H, Meyler FL: The concept of apparent cardiac arrest as a prerequisite for coronary digital subtraction angiography. JACC; 2 : 1984; 239-244.

13. Vogel R, LeFree $M$, Bates $E$ et al: Application of digital techniques to selective coronary arteriography, use of myocardial contrast appearance time to measure coronary flow reserve. Am Heart J 1984; 107: 153-164.

14. White C, Wright C, Doly D, Hiratza L, Eastham C, Harrison $\mathrm{D}$ and Marcus $\mathrm{M}$. Does visual interpretation of the coronary arteriogram predict the physiologic importance of coronary stenosis ? N. Engl. J. Med. 1984; 310: 819-824.

15. Klocke FJ: Measurements of coronary flow reserve: defining pathophysiology versus making decisions about patient care. Circulation 76: 1183, 1987.

16. Ovitt T.W., Capp MP, Fisher HD et al: The development of a digital video subtraction system for intravenous angiography. Proc. SPIE 167, 61. 1978.

17. Kruger R, Mistretta C, Houk Tet al: Computerized fluoroscopy in real time for non-invasive visualization of the cardiovascular system. Radiology 130, 49-57, 1979.

18. Molloi S., Peppier W., Folts J, Toggart E, et al: High-pass filtered dual-energy coronary angiography. Circulation: in press.

19. Buda A, Mancini J: Future directions and integrative approaches in digital cardiac imaging. In: Digital cardiac imaging, Martinus Nijhoff Publ. 1985.

20. Nitatori T, Hachiya J, Koremagen T, Furuya Y: Whole bodyintravenous digital subtraction angiography. Radiology 1985 ; 156: 829-830.

21. Wallace S, Medeliin H, de Jongh D and Gianturco C: Systemic heparinization for angiography AJR 1972; 116: 204-209.

22. Kundell H, Revesz G: Lesion conspicuity. structured noise and film reader crror. Am J Röntgenol, 1976; 126: 1233-1238.

23. Brugada $\mathbf{P}$, Gorgels $\mathbf{A}$, Wellens HJJ: The electrocardiogram in pulmonary cmbolism. In: What's new in electrocardiography ?. Wellens $\mathrm{HJJ}$ and Kulbertus HE (eds.), Martinus Nijhoff Publisher, p. 367, 1981.

24. Bürsch JH: Densitometric studies in digital subtraction angiography: assessment of pulmonary and myocardial perfusion. Herz, 1985; 10: 208-214.

25. Bürsch JH: Digital angiocardiography for assessment of congenital heart disease. In: Pediatric Cardiac Imaging, WF Friedman and CB Higgins (eds.), WB Saunders Company, Philadelphia. USA, 1984; p. 64-75. 


\title{
The use of an automatic cine film marker for optimal quantitative assessment of coronary artery dimensions.
}

\author{
Johan H.A. Janssen MD, Sjef Ackermans Bsc \\ Hein J.J. Wellens, MD \\ with the technical assistance of \\ Mrs. A. Akkermans and H. Quint, \\ Department of Cardiology, \\ Academic Hospital Maastricht, \\ University of Limburg, \\ The Netherlands
}

Introduction

Herrick's original hypothesis that acute myocardial infarction is the result of coronary thrombosis has recently been confirmed by several studies $(1,2)$. Moreover, patients with unstable angina pectoris or the related syndrome of nonmural myocardial infarction may also have occlusive or nonocclusive coronary thrombosis $(3,4,5,6)$. Recent technical advances, including quantitative and qualitative coronary arteriography, postmortem coronary arteriography with serial reconstruction of the microanatomy of obstructive lesions, intraoperative coronary angioscopy, and biochemical studies at the time of chest pain, have all brought to light the importance of thrombosis superimposed on ruptured plaque in unstable angina pectoris, as well as in acute myocardial infarction and sudden death. Angiographic evidence that the severity of coronary arteriosclerosis is similar in both unstable and stable angina pectoris has been widely accepted (7). However, from angiographic studies before and after the administration of thrombolytic agents it is suggested that in most patients, unstable angina pectoris appears to result from rupture of a fixed atherosclerotic plaque, with superimposed thrombosis. Intermittend coronary obstruction due to platelet thrombi may contribute to additional transient decreases in the diameter of the coronary artery and to the provocation of ischaemia. 
In treating these "acute coronary syndromes" medical therapy with thrombolytic agents or platelet inhibitor active drugs, alone or in concert with interventional procedures such as acute percutaneous transluminal coronary angioplasty (PTCA) (8), stenting (9), etc, are being studied.

Parrallel to the recent evolution in our understanding of the acute coronary syndrome and the subsequent developments in treatment, new insights in the prevention of coronary artery disease have led to an intense research in this field $(10,11)$.

The results of lipid lowering diets and the progression of coronary atherosclerosis (12) has arisen a great interest in both the medical community and amoung laymen.

Coronary angiography is still the only technique available for the visualization of the coronary tree in humans and for the assessment of coronary artery morphology and estimation of the degree of stenosis. With the development of digital coronary angiography not only morphology but also functional behaviour of the coronary artery tree can be studied (13). In determining the efficacy of treatment and in observing the process of arteriosclerosis it becomes essential to use reproducible, observer independant, quantitative measurements of coronary angiograms (14-17).

In this study we assessed the value of an automatic cine film marker in the quantitative analysis of coronary diameter stenosis, densitometrically determined area stenosis and the determined "plaque area". Since at end-diastole the heart is at a relative "standstill", a proper timer for this end-diastolic cineframe could greatly fascilitate the reproducibility of quantitative analysis, also when it is routinely employed by a non medically educated assisstant.

Methods

The cinefilms were analysed with the Cardiovascular Angiography Analysis System (CAAS), which has been extensively described elsewhere (16). The parameters compared were mean diameter (in $\mathrm{mm}$ ) percent diameter stenosis, densitometrically determined percent area stenosis and plaque area (in $\mathrm{mm}^{2}$ ).

For cinefilm analyses, those frames were selected for analysis that were marked by the R-wave of the elec- 
Figure 1

A single cine frame which is marked by the R-wave triggered LED. trocardiogram. Next to analysis of two consecutive R-wave marked cine frames, the three cine frames encompassing the R-wave frame were analysed. A description of the cinefilm marker is given below.

Our cinefilm unit is an Arritechno 35 cine camera, which is mounted on a cardioscoop U-arm. On removing the film camera, the preshaped LED is embedded in the back of the groundplate of the Arritechno. In this way the space between LED and the cinefilm is about $1 \mathrm{~mm}$. The LED is connected to the ECG trigger by use of spare wires in the Arritechno camera. Connection of the ECG signal from the surface ECG to the trigger unit allows R-wave detection and amplification of the signal. On the front panel of the trigger unit, two control LED's and potentiometers are available to adjust the sensitivity for detecting a certain R-wave and to adjust, using a oneshot, the pulse width. The pulse width is $2 \mathrm{msec}$ in order to produce a small, well-defined dot on the cinefilm without blurring the image (figure 1). The first control LED indicates the presence of a qualified pulse, and the second is a control of the function of the LED in the camera (18).

In this way, before running the cinefilm, the operator can not only adjust the signal but can also control the presence of the dot on the film. In 4 patients with proximal disease of the left descending coronary artery, a cardiac catheterisation was performed using a modified Judkins technique. The left coronary artery was visualised using a 7 French catheter. Nine $\mathrm{ml}$ of contrast material $\left(\right.$ Hexabrix ${ }^{R} 320 \mathrm{mg} \mathrm{I} / \mathrm{ml}$ ) was injected at a flow of $4 \mathrm{ml} / \mathrm{sec}$. Film frame acquisition was 25 frames a second. The coronary artery was visualised in several projections, however, only the projection in which the stenosis was judged visually as most

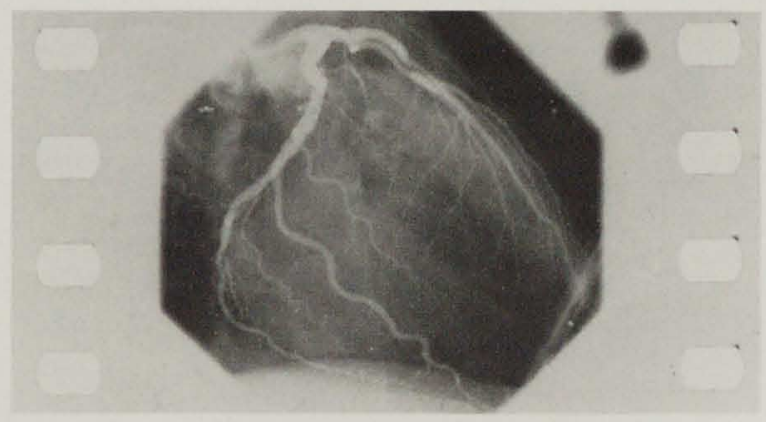


Figure?

Cinc acquisition (frames 1 27 ) is presented during one cardiac cycle. Frame 1 and 27 were marked by the Rwave of the clectrocardiogram. Frame 2, 3 and 4 were compared to 1 and 24,25 and 26 to 27 . The difference in diameter of coronary vessel in mm between frame 1 and frame 27 was also expressed as pereentage of mean diameter of the vessel during the cardiac cycle (frame 2-26).
Results

\section{$\begin{array}{lllllllllll}1 & 2 & 3 & 4 & \cdots & 14 & \cdots & 24 & 25 & 26 & 27\end{array}$}

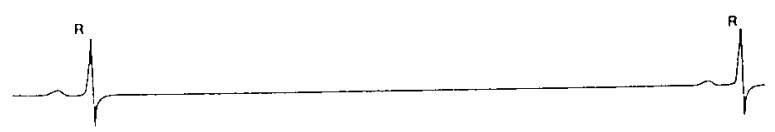

severe was analysed using CAAS. On each patient in between two R-wave marked cine frames, six frames were analysed. Three frames following the $R$-wave and three frames preceding the next $R$-wave marked cine frame (figure 2). All measurements were calculated as mean difference $\pm \mathrm{SD}$ as compared to the adjacent R-wave marked cine frame. By this way systolic and diastolic difference \pm one cardiac cycle could be obtained.

Since analysis of coronary cine frames depends on subjective decision of the investigator, no correction can be made for which cycle is analysed. Therefore we also studied the variation between diameter analysis of two subsequent $\mathrm{R}$-wave marked cine frames. These variations were expressed as the difference between those R-wave marked cine frames, expressed as percentage of the mean diameter of the coronary artery during the whole cardiac cycle. For this purpose frame to frame analysis was performed.

Each analysed coronary artery (only proximal left anterior descending coronary arteries were analysed) was divided in 5 subsegments. The average length of the analysed vessels was $28 \mathrm{~mm}$. During coronary angiography all patients were on oral nitroglycerine, B-blockers and calcium antagonists. During the investigation multiple injections of intracoronary nitrates were given before the analysed frames were taken. Of each separate frame analysed, CAAS determined the parameters discussed above.

In 4 patients a total of 972 frames were analysed. Figure 3 shows an example of the diameter analysis of a segment of the coronary artery. In between two cinefilm markers (no. 1 and 27) 25 cine frames were analysed and the coronary diameter assessed in $\mathrm{mm}$. For this example the mean diameter was $2.61 \pm 0.12$ (SD). At the first marker of the R-wave (frame 1) the diameter was $2.64 \mathrm{~mm}$, at the subsequent marker (frame 27 ) the coronary diameter was $2.60 \mathrm{~mm}$. The 
Figure 3

Graph representing the mean diameter in $\mathrm{mm}$ of a proximal segment of the LAD. The cardiac cycle consisted of 27 frames. Frames No. 1 and 27 were marked by the trigger unit.

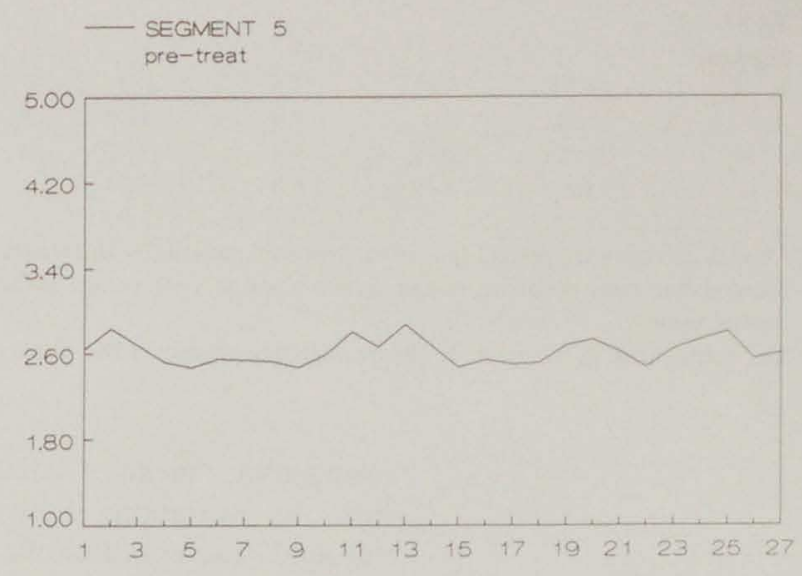

maximal diameter of the segment reached was 2.87 $\mathrm{mm}$, the minimum diameter $2.47 \mathrm{~mm}$. In Table 1 the combined results of the 4 patients are summarized regarding the variation in between these frames of a $\mathrm{R}$-wave marked cine frame. The ranges of the mean differences in diameters and standard deviations compared to frame to frame analysis are presented in Table 2. The results are expressed as the percentage deviation occurring during one cardiac cycle when analysis at the cine film marker is compared to the mean diameter of the vessel. During the cardiac cycle mean length of the analysed coronary segments

TABLE 1

Preceding marked frame

$\begin{array}{lllllll} & -3 & -2 & -1 & +1 & +2 & +3 \\ \begin{array}{l}\text { \% diameter } \\ \text { stenosis }\end{array} & 2.43 \pm 2.62 & 0.43 \pm 2.42 & 0.06 \pm 2.30 & -0.65 \pm 5.20 & -1.12 \pm 0.59 & -1.87 \pm 1.29 \\ \begin{array}{l}\text { (densitome- } \\ \text { tric) \% area } \\ \text { stenosis }\end{array} & 2.68 \pm 3.31 & 0.43 \pm 4.19 & 1.81 \pm 6.31 & 0.5 \pm 3.17 & 1.75 \pm 4.02 & -1.0 \pm 2.25 \\ \begin{array}{l}\text { mean vessel } \\ \text { diameter }(\mathrm{mm})\end{array} & 0.03 \pm 0.07 & 0.02 \pm 0.12 & -0.12 \pm 0.17 & 0.09 \pm 0.05 & 0.03 \pm 0.03 & -0.06 \pm 0.07 \\ & & & & & & \\ \begin{array}{l}\text { plaque area } \\ \left(\mathrm{mm}^{2}\right)\end{array} & 0.95 \pm 1.95 & -0.83 \pm 0.89 & 0.52 \pm 2.36 & -0.37 \pm 0.82 & -0.09 \pm 0.63 & 0.22 \pm 0.69\end{array}$

Following marked frame

(All differences were not significant)

Mean differences and standard deviation (means $\pm \mathrm{SD}$ ) of the measurements in the frames with the measurements obtained in the marked frame $(0)$. 
TABLE 2

$\begin{array}{lllllll}\text { Segment } & 1 & 2 & 3 & 4 & 5 & \text { Mean } \pm S D \\ 1 & 13.29 & 6.4 & 3.6 & 8.3 & 5.17 & 7.35 \pm 3.7 \\ 2 & 10.31 & 0.0 & 7.4 & 11.8 & 5.1 & 6.92 \pm 4.6 \\ 3 & 19.67 & 29.9 & 9.4 & 13.2 & 31.9 & 20.4 \pm 10.5 \\ 4 & 9.09 & 7.49 & 6.8 & 1.14 & 13.6 & 7.62 \pm 4.4\end{array}$

Of each coronary segment ( 1 to 5 ) of the 4 studied patients the difference in vessel diameter at the $R$-wave marked cineframe occurring in one cycle is given as a percentage of the mean vessel diameter over that cardiac cycle.

The value mean $\pm S D$ refers to the average deviation over the whole arterial segment in one patient.

changed by a mean of $4.5 \%$ (range $0.55 \%-7.3 \%$ ). For the variations between three cine frames "around" the end diastolic frame (R-wave marked) the results were not found to be significantly different from the values of the reference frame. For percent diameter stenosis the mean differences values varied from $2.43 \%$ to $0.06 \%$ with the standard deviation varying from 0.59 to $5.2 \%$. For densitometrically determined percent area stenosis the mean differences values varied accordingly from $2.68 \%$ to $0.43 \%$ with a standard deviation between 6.31 and $2.25 \%$. There is no consistent pattern found to allow a particular frame to produce consistently smaller values, nor a significant difference between diastolic and systolic frames could be demonstrated.

For mean diameter $(\mathrm{mm})$ and plaque area $\left(\mathrm{mm}^{2}\right)$ the mean differences are even smaller with also smaller variations in standard deviation. These data demonstrate that variations within three frames of the "end diastolic" frame are within a narrow range, however, are associated with quite large standard deviations. This may be indicating the problems one can encounter in a single patient or single analysis. From the results as presented in Table 2 this observation is also stressed. Here the difference between two consequetive $\mathrm{R}$-wave marked cine frames is expressed as percentage of the mean diameter of the coronary segment analysed during one cardiac cycle. In this case mean difference from one cardiac cycle to the next cardiac cycle ranges from $0.0 \%$ to $31.9 \%$ ! We did not study the possible incorrect identification of the $R$ wave due to a maximal delay of $40 \mathrm{msec}$ ( 25 frames/ $\mathrm{sec}$ ) in delivery of the dot on the film. When comparing the measurements of Table 1 and Table 2, it becomes apparent that deciding on another frame 1,2 
or 3 from the end diastolic frame may not result in statistically significant differences but that deciding on which cardiac cycle should be analysed does seem to be crucial (see also chapter 10) depending on the type of study performed.

In previous studies Reiber et al assessed the reproducibility of repeated analysis by CAAS of the same cine frame and of repeated cineangiography and came to the conclusion that standardization of the angiographic acquisition procedure is essential to minimize variability in measurements (19). In their studies they tried to select images from repeated angiographic investigations at exactly the same moment in the cardiac cycle, preferably enddiastole. They stated, however, that due to the human selection of the cine frame intra- and interinvestigator variability occurred, even among experienced cardiologists. In a second study they confirmed the variabilities in measurements of arterial dimensions caused by these intra- and interinvestigator variability (20). They concluded, however, that the selection of a cine frame for quantitative analysis in the end-diastolic phase of the cardiac cycle is not very critical. For analysis, however, they used only three frames before and after an "optimal" frame as judged by one cardiologist.

We assessed the value of an automatic cine film marker for routine use in quantitative analysis of coronary angiograms. Among sources of error in the quantitative diameter analysis of coronary arterial segments are quantum noise in the image, noise contribution of the video and optics chain, quantitation errors in the analog to digital conversion, the effects of resampling the data along scan lines through the square grid of the digital data, observer variations in the definition of center positions within the selected arterial segment, possible manual corrections to the arterial contours selection of begin and end-points of the obstructive lesion and biological effects such as vasomotor tone and the incorrect assumption that contrast replaced blood during the angiography. According to Reiber (16), the "technical factors" are responsible for variations in diameter of maximally $0.10 \mathrm{~mm}$. In vivo, the dimensions of a normal coronary arterial segment may vary as much as $6.0 \pm 2 \%$ over a cardiac cycle because of vasomotor tone and differences in aortic 
pressure (pulsatile effect) (12). From table 2 it can be concluded that variations in mean diameter of coronary vessels can range from $7 \%$ to $20 \%$. Apart from possible errors in measurement caused by movement of the heart, pulsatile flow and insufficient mixing of the contrast agent with the blood, this may be an expression of degree of atherosclerosis. The foreshortening of the analysed coronary vessel was between $0.55 \%$ and $7.3 \%$. Because of the high accuracy of CAAS in determining diameters in $\mathrm{mm}$, these results can be explained by vasomotor tone of the coronary arterial segments and the pulsatile effect of the blood stream in the aorta. The findings in the patients studied, however, may even underestimate the maximal deviation from the mean arterial diameter since all patients received intracoronary nitrates and were on concommitant antianginal medication known to cause (sub)maximal vasodilatation of the coronary arteries. From our results it is suggested that even with optimal determination of the end-diastolic cine frame variations in diameter measurement may be unavoidable.

Since the majority of the applications of quantitative coronary cineangiography require the comparison of the arterial dimensions in a control group with those in a treated group, our findings suggest that careful selection of the cine frames to be compared is necessary. Depending on the type of studies it may be mandatory to employ frame to frame analysis over a whole cardiac cycle to avoid bias. In this setting the use of an automatic ECG triggered cine film marker may prove useful.

1. Simoons ML. Serruys PW, Brand $M$ vd, Res J, Verheugt FWA, Krauss XH, Remme WJ, Bar F, Zwaan C de, Laarse A vd, Vermeer $F$, Lubsen $J$ : Early thrombolysis in acute myocardial infarction: limitation of infarct size and improved survival. JACC, 7:729-742,1986.

2. Mathey DG, Kuck KH, Tilsner V, et al: Non-surgical coronary artery recanalization in acute transmural myocardial infarction. Circulation;63: 489-97, 1981.

3. Rentrop P, Blanke H, Karch KR,ct al: Selective intracoronary thrombolysis in acutc myocardial infarction and unstable angina pectoris. Circulation:63: 307-27, 1982.

4. Ambrose JA, Winters SL, Stern A, et al: Angiographic morphology and the pathogenesis of unstable angina pectoris. J. Am Coll Cardiol,5:609-16, 1985.

5. Zwaan C de, Bär FWHM, Janssen JHA, Swart HB de, Vermeer F, Wellens HJJ: Effects of thrombolytic therapy in un- 
stable angina: Clinical and angiographic resuits. JACC 12: 301-309, 1988

6. Sherman CT, Litvack F, Grundfest W, Lee M, et al: Coronary angioscopy in patients with unstable angina pectoris. $\mathbf{N}$ Engl $\mathbf{J}$ Med;315:913-19, 1986.

7. Fuster V, Frye RL, Connolly DC, Daniclson MA, et al: Angiographic patterns early in the onset of the coronary syndromes. Br Heart J, 37:1250-5, 1975.

8. Serruys PW, Wijns W, Brand M, Ribeiro V, Fioretti P etc: Is transluminal coronary angioplasty mandatory after successful thrombolysis? Quantitative angiographic study. Br Heart J 257-265, 1983.

9. Sigwart S, Puel J, Mirkovitch V, Joffre F, Kappenberger L: Intravascular stents to prevent occlusion and restenosis after transluminal angioplasty. N Engl J Med; 316:701-06, 1987.

10. Lipid Research Clinics Program. The Lipid Research Clinics Coronary Prevention Trial Results II. The Relationship of Reduction in Incidence of Coronary Heart Disease to Cholesterol Lowering. JAMA; 251:365-74, 1984.

11. Hjermann I, Velve Byre K, Holme I, Leren P: Effect of dict and smoking intervention on the incidence of coronary heart discase. Lancet;ii:1303-10, 1981.

12. Arntzenius AC, Kromhout D, Barth JD et al: Lipoproteins, and progression of coronary atherosclerosis: The Leiden Intervention Trial. N Eng J Med; 312:805-11, 1985.

13. Legrand V, Mancini J,Bates E, Hodgson J, Gross M, Vogel $R$ : Comparative study of coronary flow reserve, coronary anatomy and results of radionuclide exercise tests in patients with coronary artery disease. J. Am Coll Cardiol; 8:1022-32, 1986.

14. Holder D, Johnson A, Stolberg H, Campbell M et al: Inability of caliper measurements to enhance observer agreement in the interpretation of coronary cineangiograms. Can J Cardiol 1:24-29, 1985.

15. Scoblionko D, Brown G, Mitten S, Caldwell J, Kennedy W, Bolson E, Dodge H: A new digital electronic caliper for measurement of coronary arterial stenosis: Comparison with visual estimates and computer-assisted measurements. Am J Cardiol 53: 689-693, 1984

16. Reiber J, Serruys P, Kooijman C, Wijns W, Slager C, Gerbrands J, Schuurbiers J, Boer A, Hugenholtz P: Assessment of short-, medium-, and longterm variations in arterial dimensions from computer assisted quantification of coronary cineangiograms. Circulation 71: 280-288, 1985.

17. Spears J, Sandor T: Quantitation of coronary artery stenosis severity: limitations of angiography and computerized information extraction. In Reiber J, Serruys P (eds): "State of the art in quantitative coronary arteriograpohy: Martinus Nijhoff Publishers, the Netherlands, 1986.

18. Janssen J, Ackermans S, Mulkens G, Winter R: A modified ECG-triggered cine film marker Unit for DSA studies of the heart and great vessels. Angiology 37; 9: 654-657, 1986.

19. Reiber J, Serruys P, Kooijman C, Slager C, Schuurbiers J, den Boer A: Approaches towards standardization in acquisition and quantitation of arterial dimensions from cineangiograms. In: Reiber J, Serruys P (eds): "State of the art in quantitative 
coronary arteriography". Martinus Nijhoff Publishers: 1986.

20. Reiber J, van Eldile-Helleman P, Visser-Akkermans N, Kooijman C, Serruys P: Variabilities in measurement of coronary arterial dimensions resulting from variations in cine frame selection. Catheterization and cardiovascular diagnosis; $14: 221-228,1988$.

21. Hori $M$, Inoue $M$, Shimazu $T$, Mishima $M$ et al: Clinical assessment of coronary arterial clastic properties by the image proccssing of coronary arteriograms. Comp Cardiol; 393-395, 1983. 


\section{CHAPTER 4}

Acknowledgement:

Wc like to thank Prof. Dr. Ir. A. Hasman, Department of Mcdical Informatics and Statistics, University of Limburg, for his critical review of the manuscript.

\section{Introduction}

\section{Figure 1}

(taken from ref. 3 with permission) shows the percentage of workers that are exposed to a certain level of ionizing radiation. Radiation exposure is expressed as dosimetry index which is defined as $\underline{H(t)} \times 100 \%$.

$$
\text { f. } \mathrm{H}_{\text {tim }}
$$

The dip in the curve of "cyclotron" workers may be explained by a better cducation in health physics, however, the main difference between cardiologist and staff as compared to other workers with ionizing radiation is the need for the cardiologist to stay next to the patient in order to perform the investigation! (diagnostic or therapeutic).

\section{Radiation reduction during cardiac fluoroscopy using a video image processor.}

Johan H.A. Janssen MD, Boudewijn Verstraelen $\mathrm{MSc}^{*}$, Sjef Ackermans BSc+, Frits Bär, $\mathrm{MD}$ and Pedro Brugada, MD.

Department of Cardiology and + Radiology, Academic Hospital Maastricht, ${ }^{*}$ Pie Data Medical B.V. Maastricht.

University of Limburg

The Netherlands

The increasing number of cardiac investigations, diagnostic as well as therapeutic, has created a great interest in the development of techniques that will reduce the risks of ionising radiation for patients and investigators.

Recent studies have shown that the impact of fluoroscopy on total radiation dose can be considerable during cardiac procedures

$(1,2)$. When compared to other professions $(3)$ which are exposed to ionizing radiation, cardiologists and their staff are at the upper radiation limits of what is legally allowed (fig. 1). Since the cardiologist is continuously needed at the bedside during radiation exposure, performing sometimes complex procedures (electrophysiologic procedures, percutaneous trans-

\section{PROPORTION OF WORKEAS EXCEEOING} GIVEN DOSE LEVEL PER OUARTER

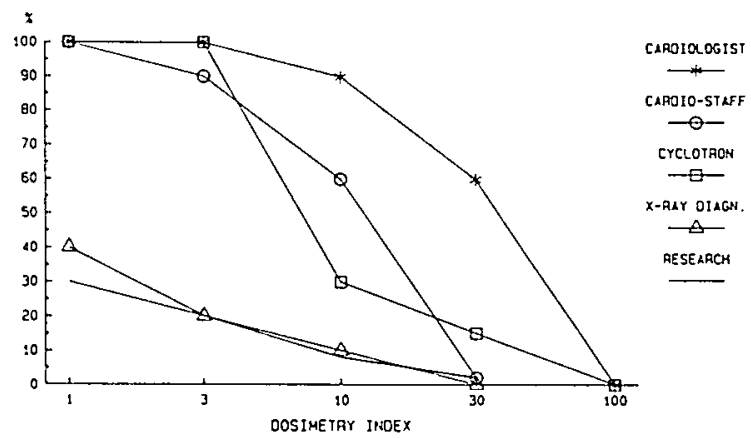


Methods

Figure 2

A radiographic image from the thorax, several catheter positions are shown which are regularly used during electrophysiologic studies. $\mathrm{RA}=$ quadripolar lead in the right atrium; $\mathrm{H}=$ bipolar lead in his bundle area; $\mathrm{CS}=$ quadripolar lead in the coronary sinus; LV and $\mathrm{RV}=$ quadripolar leads in the left and right ventricular cavity respectively. luminal coronary angioplasty), radiation reduction becomes essential.

We like to report our experience with a recursive digital filter during cardiac fluoroscopy.

In the Academic Hospital of Maastricht between 250 and 300 electrophysiological studies are performed yearly. During these procedures we routinely place catheters under fluoroscopic guidance in the right atrium, right ventricle, near the tricuspid valve to register a His bundle electrogram, or in the coronary sinus (figure 2).

Catheter positioning may take up to 70 minutes or longer when mapping procedures of the arrhythmias are performed.

During electrophysiological studies a Video Image Processor (VIP 300) was evaluated in order to reduce radiation for patient and staff.

The VIP 300 is a device with 2 digital memories of $512 * 512 * 8$ bits. The first memory in series with the monitor provides the possibility of filtering, last image hold and gapfilling. The second memory connected to a separate monitor is used for reference or to select masks for digital subtraction. The VIP 300 can perform vascular tracing, time interval difference, subtraction and road mapping. In this study the filtering techniques were used to reduce exposure during fluoroscopy.

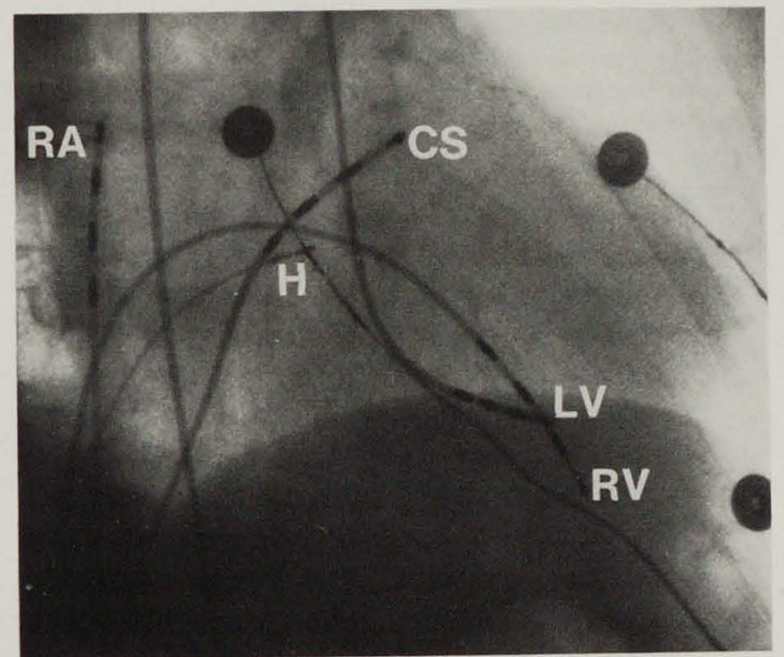


Figure 3

The right side of this composed image shows the filtered effect (VIP 300) of the "low radiation" image presented on the left side (Courtesy of Ad den Boer Bsc, Thoraxcenter Rotterdam, The Netherlands).

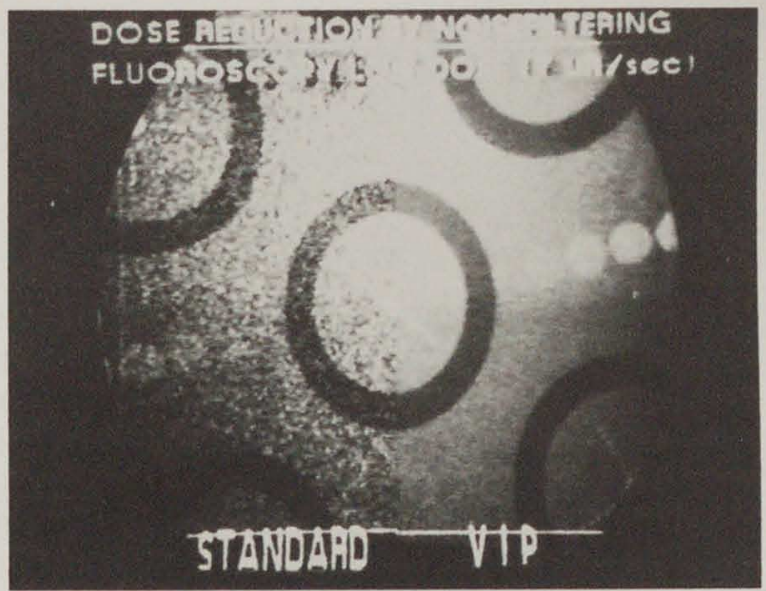

During the cardiac investigation the cardiologist needs fluoroscopy for guidance and correct catheter positioning. The quality of the video image needed is largely subjective and greatly dependent on the skills and experience of the investigator.

Electrophysiologic investigations were always carried out by the same experienced investigator. In four patients we looked at 5 minutes intervals of fluoroscopy during the cardiac study. Standard fluoroscopy was alternated with reduced fluoroscopy. The magnitude of exposure reduction was subjective to the opinion of the investigator performing the catheterization. Second, without the investigator being informed, the radiation dose was altered using the VIP 300 in 11 patients.

Radiation exposure was measured as $\mathrm{R}^{*} \mathrm{~cm}^{2}$ using a flat ionisation chamber( Diamentor, PTW Freiburg, West Germany), located on the X-ray tube housing. By reducing the intensity of the radiation source the video image will be degraded and quantum noise will become more apparent. The signal-to-noise in the video chain is proportional to the square root of the $\mathrm{X}$-ray exposure (4). The VIP 300 can then enhance the degraded "low radiation" image to a subjectively sufficient level by filtering the introduced noise (figure 3).

The noise filter algorithm used is a recursive digital filter: 


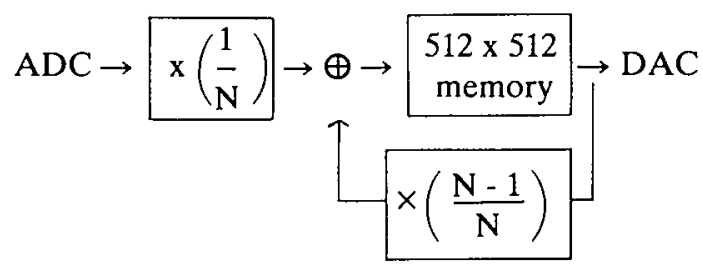

The pixel value is obtained from the analog to digital converter(ADC) and multiplied by $(1 / \mathrm{N})(\mathrm{N}=$ filter coefficient). For $\mathrm{N}=2$ half of the value of the incoming pixel is added to half of the memory contents corresponding to the same pixel. Under the assumption that the image did not change, the pixel value, except for noise, will be constant. The white noise intensity reduction can be calculated to be:

in noise $\sqrt{=\frac{1}{N^{2}}+\left(\frac{1}{N^{2}}\right)\left(\frac{N-1}{N}\right)^{2}+\frac{1}{N^{2}}\left(\frac{N-1}{N}\right)^{2}\left(\frac{N-1}{N}\right)^{2}+\ldots}$

When the noise energy is reduced the same image quality is obtained using a lower exposure. If for $\mathrm{N}=2$ an attenuation of noise energy is achieved of a factor of 0.58 than the improvement in signal to noise ratio is $1: 0.58=1.7$. The exposure reduction achievable is then $(1.7)^{2}=3$. For $N=4$ the $X$-ray exposure can be reduced with a factor 7 . For $\mathrm{N}=8$ the factor of exposure reduction possible is 15 .

When a pixel goes from complete black $(0)$ to white (1), the output of memory will be $0,1 / 2,3 / 4,7 / 8$, etc, separated in time by the sampling interval. For a normal interlaced video system this time is $40 \mathrm{msec}$ $(50 \mathrm{~Hz})$ or $36.66 \mathrm{msec}(60 \mathrm{~Hz})$.

As follows from (1) output $Y_{n}$ (sample $n$ ) depends on the input $X_{n-1}$ (sample $n-1$ ) and the output $Y_{n-1}$ (sample $\mathrm{n}-1)$ :

$Y_{n}=\frac{1}{N} X_{n-1}+\frac{N-1}{N} \cdot Y_{n-1}$

For $\mathrm{N}=2$ this becomes for example

$Y_{n}=1 / 2 X_{n-1}+1 / 2 \quad \cdot Y_{n-1}$ 
The input values of the pixel considered can be described by:

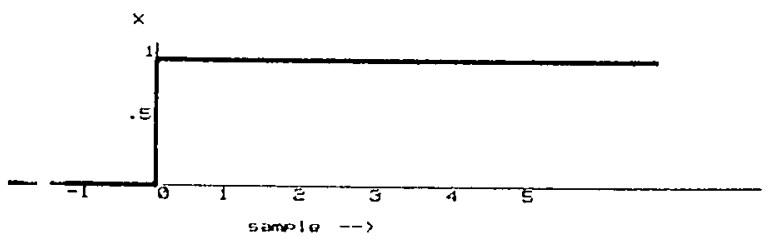

The output values of the considered pixel will change as a function of time as follows:

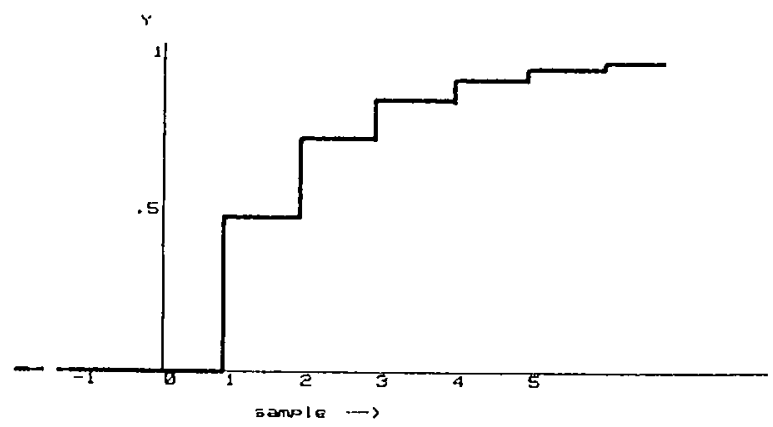

In general motion lag is introduced by filtering the image. Therefore the VIP 300 is equiped for cardiac applications with a mode that reads every field instead of frame (fast filter mode). This reduces the motion lag by making the pixel update frequency twice as high. Vertical resolution is 256 lines in this case, instead of the normal 512 lines.

For dynamic images the reduction of the image content can be described by:

$Y_{n}=\frac{1}{N} X_{n-1}+\frac{N-1}{N} \cdot Y_{n-1}$

where $X_{n}=e^{i w n T}, T$ represents the sampling interval, $w$ the angular frequency, related to the frequency $f$ as $\mathrm{w}=2 \mathrm{f}$ and $\mathrm{i}=\mathrm{V}-1$

For a linear system the output will be

$Y_{n}=A(w) \cdot e^{i w n T}$ 
Substitution in (3) gives:

$$
\begin{aligned}
A(w) & =\frac{1}{N-(N-1) e^{-i w T}} \\
& =\frac{1}{N-(N-1) \cos w T+(N-1) \sin w T} \\
|A(w)|^{2} & =\frac{1}{(N-(N-1) \cos w T)^{2}+((N-1) \sin w T)^{2}} \\
& =\frac{1}{N^{2}-2 N(N-1) \cos w T+(N-1)^{2}}
\end{aligned}
$$

For $\mathrm{w}=0$ substituted in $(5)$

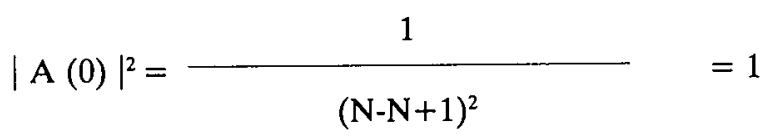

For the frequency $f=\frac{1}{2 T}$ it follows that $w=\frac{2 \Pi}{2 T}$ and

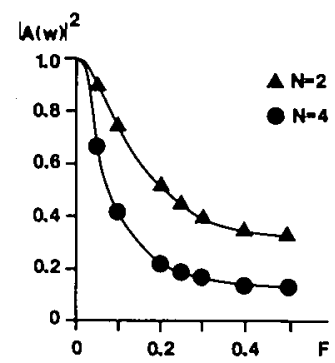

Figure 4

The amplification by the VIP-300 filter as function of the input frequency for $N=2$ and $N=4$. The vertical axis represents the amplification $\left(|\mathbf{A}(w)|^{2}\right)$. The horizontal axis denotes the frequency (measured in units $1 / T)$ of the input signal. $w T=\Pi$

Therefore: $\cos w T=\cos \Pi=-1$

$$
\text { For } \begin{aligned}
& N=2\left|A\left(\frac{\Pi}{T}\right)\right|^{2}=\frac{1}{2 N-1}=\frac{1}{3} \\
& N=4 \quad\left|A\left(\frac{\Pi}{T}\right)\right|^{2}=\frac{1}{2 N-1}=\frac{1}{7}
\end{aligned}
$$

Figure 4 shows the amplification as function of the input frequency for $\mathrm{N}=2$ and $\mathrm{N}=4$.

The ultimate determinant of contrast detection in a radiographic image is the quantum noise of the imaging process. Random noise results in a granular struc- 
ture superimposed on the structure of an image. The definition of the signal-to-noise ratio (SNR) that is used most in imaging is:

The ratio of the maximum video signal $\left(V_{M}\right)$ to the standard deviation (or root mean square (RMS) value) of the random noise $\left(V_{N}\right)$ :

$$
\mathrm{SNR}=\mathrm{V}_{\mathrm{M}} / \mathrm{V}_{\mathrm{N}}
$$

The SNR is often given on a logarithmic scale (unit: decibel, $\mathrm{dB}$ ):

$$
\mathrm{SNR}=20 \log \left(\mathrm{V}_{\mathrm{M}} / \mathrm{V}_{\mathrm{N}}\right)(\mathrm{dB})
$$

In modern $\mathrm{X}$-ray imaging systems the quantum noise is considerable higher than the video chain noise contribution.

Results

How much can X-ray exposure actually be reduced using the VIP-300?

Table 1 shows the results in four patients where standard radiation exposure was reduced, while the image was being enhanced using the filter mode of the VIP 300. Optimal exposure reduction was reached, of course, at the discretion of the investigator. Body weight and length of the patients were comparable. Fluoroscopy procedures were carried out in the same

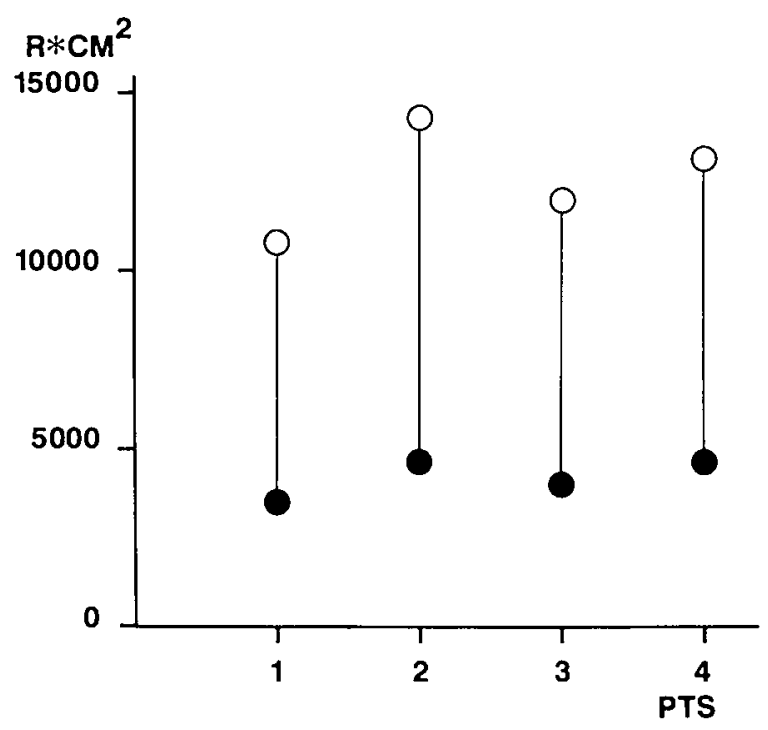

Table 1: Radiation exposure in 4 patients with (black dots) and without the use of the VIP-300 (open circles). 
Table 2: Radiation exposure in 11 patients with (black dots) and without the use of the VIP-300 (open circles).

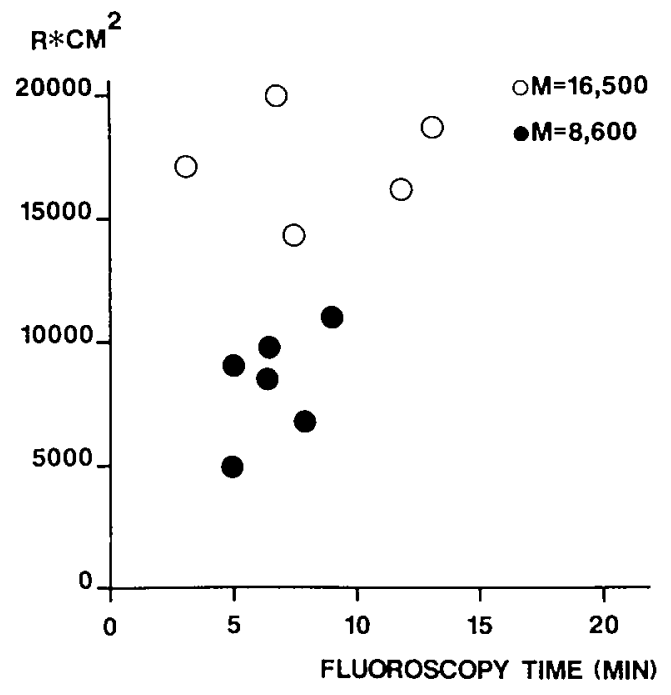

projection of the X-ray tube. Mean exposure ( \pm SD) was $14,500 \pm 5,600 \mathrm{R}^{*} \mathrm{~cm}^{2}$ in the standard mode and $6,600 \pm 2,200 \mathrm{R}^{*} \mathrm{~cm}^{2}$ in the filtered mode.

During the electrophysiologic investigations of eleven patients radiation exposure was changed without notifying the investigator. In $5 / 11$ patients the mean standard radiation exposure was $16,500 \pm 7,600 \mathrm{R}^{*} \mathrm{~cm}^{2}$. Exposure during noise filtering was $8,600 \pm 4,200$ $\mathrm{R}^{*} \mathrm{~cm}^{2}$ in 6/11 patients studied (Table 2). During the procedures with low exposure and a filtered image the investigator was perfectly satisfied with the quality of the image. Fluoroscopy time in patients in which "normal" exposure was used, did not differ from the procedures in which "low" exposure fluoroscopy could be employed. During this procedures $\mathrm{N}=2$ was chosen for filtering.

Discussion

With the development of new techniques in cardiology as for example thrombolytic treatment in patients with myocardial infarction, impending myocardial infarction, coronary angioplasty, coronary angioscopy, transcoronary chemical ablation of cardiac arrhythmias, etc, the number of complex cardiac catheterization procedures will increase. Not only for the patient who possibly has to undergo several catheterizations in the setting of an acute coronary syndrome, but also for the staff involved, radiation exposure is a possible hazzard. Although the radiation exposure during cineangiography is much high- 
er when compared to fluoroscopy, due to excessive fluoroscopy times, the contribution of fluoroscopy to total exposure may be considerable. Total exposure in patients during cardiac catheterization can be approximated with a formula in which fluoroscopy time is expressed in minutes and filmlength in meters (during acquisition at $25 /$ frames/sec) (1):

Total exposure $\left(\mathrm{R}^{*} \mathrm{~cm}^{2}\right)=255$. Fluoroscopy time $(\min )+60$. Filmlength $(\mathrm{m})$.

It is obvious that fluoroscopy times should be kept as low as reasonably achievable. During complicated procedures, however, this time, may still be considerable. The fast filter mode introduced here, makes it possible to use less radiation, while "image quality" can still be ensured.

Significant problems are encountered when objectively comparing alternative imaging methods, centering mainly on the lack of suitable experimental designs and the inadequacy of current methods used for calculating and stating results. Even with the best available experimental designs, it may be difficult to approach the ideal of rigorously comparing like to like, and any investigation may be compromised in this manner. In our approach we used the judgement of one experienced cardiologist to grade the quality of the filtered image. However, as is shown in Table 2, also in a blinded experiment a considerable reduction in radiation exposure was possible.

In conclusion the use of a video image processor during cardiac fluoroscopic procedures seems to be advantageous in reducing radiation exposure for patient and investigator.

1. Kicken P, Janssen J, Michels M, Huyskens C: Radiation exposure during cardiac catheterization procedures. International Radiation Protection Association (IRPA) 7, II, 737, Pergamon Press, Sydney, 1988.

2. Bultman J, Fokker P, Hofman M, v.d. Reijden C, van der Werf T: Stralingsbelasting van het medische personeel tijdens hartcathetcrisaties. NTVG; 131, 620-624, 1987.

3. Huyskens C: Dosimetry index: A useful concept in operational radiation protection. IRPA, III, 1290, Pergamon Press, Sydney, 1988.

4. Brody WK: Tutorial in digital systems. In: Digital Radiography, WK Brody (ed.), Raven Press N.Y., USA, p. 19,1984. 


\title{
Radiation reduction during cardiac cineangiographic procedures using a video image processor
}

\author{
Johan H.A. Janssen, MD, Sjef Ackermans, Bsc*, \\ Frits Bär, MD, Pedro Brugada, MD \\ and Hein J.J. Wellens, MD \\ Departments of Cardiology and Radiology* \\ Academic Hospital Maastricht, University of Lim- \\ burg, \\ The Netherlands
}

Introduction:

Methods
Radiation exposure to the operator during cardiac catheterization may limit the number of procedures a physician can perform safely (1-4). The advent of angiographic epuipment with high output generators and X-ray tubes and the ability to perform easily angulated projections of the coronary circulation potentially increases radiation exposure to the operator, whereas the use of radiation protection devices decreases that exposure (5). However, a major determinant of operator radiation exposure necessarily remains the length of time spent during fluoroscopy and cineangiography. We undertook the present study to evaluate the value of a video image processor in reducing $\mathrm{X}$-ray exposure during cardiac cine-angiography procedures.

Cardiac catheterization protocol: All 110 patients studies were performed in a cardiac catheterization laboratory equiped with a Siemens Cardioscoop Uarm interfaced with a Pandoros generator. Left ventriculograms were performed in a $30 \mathrm{RAO}$ and 60 LAO projection using a film speed of 50 frames/s. Coronary angiography was performed using a film speed of 50 frames/s in 58/110 patients (group 1) and using $25 \mathrm{frames} / \mathrm{s}$ in 50/110 patients (group 2).

Radiation exposure was measured as exposure-area product ( patient entrance dose) in $\mathrm{R}^{*} \mathrm{~cm}^{2}$ using a Diamentor F-1 (PTW Freiburg, West Germany). The 
Results

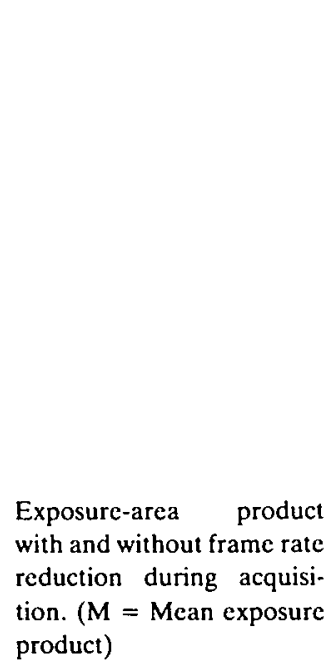

video image processor used was a VIP-300 (Pie Data Medical, Maastricht, The Netherlands) which used two digital memories of $512 * 512 * 8$ bits. During cineangiography a radiation reduction was obtained in group 2 by reducing the frames/s during cine coronary angiography from 50 frames/s to 25 frames/s. This reduction would cause a flicker on the video monitor during the procedure. Although only 25 frames $/ \mathrm{sec}$ were present on the cinefilm, the investigator was still viewing real time 50 fields/sec on the monitor since the gapfiller algorithm of the VIP 300 ensued an easy to interpret image by breaking up the frame into two fields and informing every other field with the same information as the previous field on the video monitor.

Figure 1 summarizes the distribution of the exposurearea product in group 1 and group 2. Mean exposurearea product during the whole angiography procedure in group 1 patients was $14000 \mathrm{R}^{*} \mathrm{~cm}^{2}$. In contrast, mean exposure-area product in group 2 patients, in which the VIP-300 was used, turned out to be significantly less: $9500 \mathrm{R}^{*} \mathrm{~cm}^{2}(\mathrm{p}<0.05)$. Factors that might account for higher radiation exposures during angiography, such as patient weight and body surface area, were not significantly different comparing group 1 and group 2 . Investigation time and fluoroscopy time needed for catheter positioning were similar among group 1 and group 2 patients. As expected video-

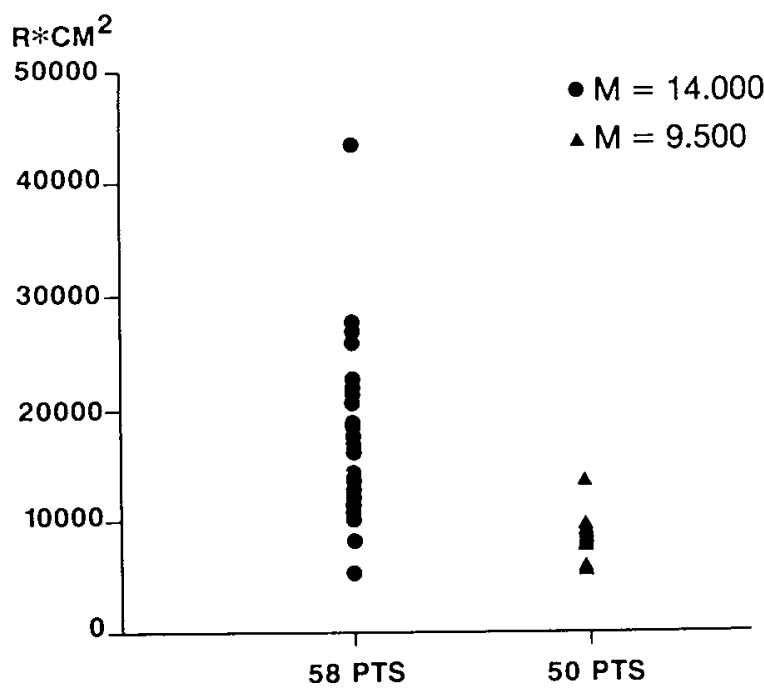


length was not different between groups but a mean of 70 meters cine film was used in group 1 whereas in group 2 a significant reduction to a mean of 50 meters was obtained $(p<0.05)$.

Discussion

With the development of cardiac intervention techniques such as percutaneous transluminal coronary angioplasty, acute thrombolytic studies and electrophysiological studies it is not surprising that operator and patient radiation exposure increases $(6,7)$. Most centers are using 50 frames/s or 60 frames/s to visualize the left ventricular wall motion and coronary anatomy. Reduction to 25 frames/s is not feasible for left ventriculography since the appreciation of movement and dynamic events during the cardiac cycle becomes more difficult and artefacts might be introduced. Coronary anatomy, however, can be accurately visualized using only 25 frames/s. In interventions such as percutaneous transiuminal coronary angioplasty it is not even necessary to record cinefilm at a rate of 25 frames/sec. Since the actual procedure is performed during fluoroscopy, high quality 'cine images' are recorded on a digital memory disc. In this way the images on the digital disc can provide a complete run or a single, high quality image for reference during the procedure. Documentation on cine film is then performed only at the end of the procedure. During the invasive procedure and recording of the cinefilm the investigator depends on the information on the videoscreen. The with the cine image concommitant recorded video image calls attention to an area that may be questionable regarding the presence or absence of obstruction. The investigator needs the video image to confirm that the region of interest is actually recorded and he has the possibility of panning the image so that all information necessary is recorded on cinefilm. With an acquisition rate of $25 \mathrm{frames} / \mathrm{s}$, however, a flicker is introduced on the video screen which makes it more difficult to judge from the video image the coronary anatomy with an acceptable degree of confidence. This is particularly important in a laboratory where trainees will be routinely involved in angiographic procedures. By using the gapfiller of the VIP-300 every second field is informed with the same information as the previous field. In this way it is possible for the investigator to judge coronary anato- 
my more consistent on the videoscreen at 50 fields $/ \mathrm{s}$ while actually only 25 frames/s are recorded on cinefilm. In this study no cinefilms recorded at a frame rate of 25 frames/sec were judged to be of insufficient quality for proper diagnosis and clinical decision making. In the laboratory where trainees are routinely involved in angiography, health physics should be an integral part of the educational program. Since the medical community is responsible for a significant contribution of radiation burden on the "community", and in this medical community cardiac angiography plays a major role $(8,9,10)$, it is necessary to reduce exposure for patients and staff as much as possible. This means that procedures should be performed according to a protocol. The use of radiation protection devices should be employed since they decreases exposure levels considerably (11). They may sometimes be difficult to use because they interfere with the motility of the X-ray equipment and with the contact of the physician with the patient. Therefore it becomes more prudent to reduce exposure to patient and staff by using the above described method using a video image processor during cardiac cine angiography and cardiac fluoroscopy (12). In this study the exposure reduction was achieved by reducing the cineframe acquisition during coronary angiography with $50 \%$. From the results, however, it is apparent that only a reduction of $\pm 32 \%$ in exposure was reached. This is only due to cine angiography since total investigation time and fluoroscopy time were identical between groups. The exposure-area product (XAP) can be approximated with a formula in which fluoroscopy time is expressed in minutes and filmlength in meters (regression coefficient $=0.9)(10)$ :

$$
\mathrm{XAP}=255^{*} \text { Fluoroscopy time }+60^{*} \text { Cinefilm length }
$$

Substitution of the measured mean cinefilm length of group 1 and group 2 (fluoroscopy time is identical in both groups) calculates a reduction of exposure of \pm $29 \%$. Probably the contribution of left ventricular cineangiography and the heterogenity of patients (figure 1) account for the observed difference. Apart from the reduction in $\mathrm{X}$-ray exposure, a considerable amount of reduction of film cost was achieved which makes this technique in terms of budget control even more appealing. 

frames/s in combination with the use of a gapfiller is a valuable additional way to reduce $\mathrm{X}$-ray exposure for both patient and staff during invasive cardiac investigations.

1. Rueter FG: Physician and patient exposure during cardiac catheterization. Circulation 1978; 58; 134-9.

2. Malsky SJ, Roswit B, Reid CB, Haft J: Radiation exposure to personnel during cardiac catheterization. Radiology 1971; 100: 671-4.

3. Wold GJ, Schclke RV, Agarwal SK: Evaluation of physician exposure during cardiac catheterization. Radiology 1971; 99 : $188-90$.

4. Balter $S$, Sones $F M J_{r}$, Brancato R: Radiation exposure to the operator performing cardiac angiography with $\mathrm{U}$-arm systems. Circulation 1978; 58; 925-32.

5. Gertz EW, Wisneski JA, Gould RG, Akin Jr.: Improved radiation protcction for physicians performing cardiac catheterization. Am J Cardiology 1982; 50: 1283-6.

6. Dash H, Leaman D: Operator radiation exposure during percutaneous transluminal coronary angioplasty. JACC Vol 4, no 4, 84: 725-8.

7. Janssen J, Verstraelen B, Tijdens F, Ackermans S, Sanchez $H$, Bär F, de Bocr A.: Radiation reduction during electro physiological investigation using a video image processor. 69th Scientific Assembly of the radiological society of North America, Chicago nov 1983.

8. Hagekyriakou J, Chaudri MA: Radiation exposure to patients during cardiac angiography and coronary angioplasty. IRPA 7;2:732-35, 1988.

9. Huyskens CJ.: Dosimetry index: a useful concept in operational radiation protection. IRPA 7;3:1290-93, 1988.

10. Radiation exposure during cardiac catheterization procedures. Kicken P, Janssen JHA, Michels H, Huyskens CJ. IRPA 7;2:73740, 1988.

11. Standards for protection against radiation. Washington DC: United States nuclear regulatory commission rules and regulations. Title 10, chapter 1, part 20. 1982: 1-3.

12. Radiation reduction during cardiac fluoroscopy using a video image processor. Janssen JHA, Verstraelen B, Ackermans S, Bar F, Brugada P. In:Clinical application of video image processing in cardiac angiology, chapter 4 . van Gorcum, Maastricht, The Netherlands, 1989. 


\author{
Johan H.A. Janssen, MD, Chris de Zwaan, MD, \\ and Hein J.J. Wellens, MD \\ Department of Cardiology, \\ Academic Hospital Maastricht, University of Lim- \\ burg, The Netherlands
}

Introduction

Cardiac catheterization provides the definite diagnosis in most cases of pulmonary vascular disease, particularly when combined with pulmonary angiography. Since the early studies of Cournand and Ranges (1), Dexter et al (2), and Zimmerman et al (3), the technique of cardiac catheterization has advanced rapidly, and large numbers of such procedures are performed daily throughout the world with minimal morbidity. The recent advent of balloon flotation catheters has added a new dimension to cardiac-pulmonary catheterization, especially in critically ill patients at the bedside (4). The accumulated experience of the last 10 years has clearly documented that pulmonary angiography is a valuable and safe procedure, even in critically ill patients (5) although dependent on the initial pulmonary artery pressure (6). This procedure, particularly when the selective technique is used $(7,8)$ remains the most sensitive and specific diagnostic procedure in detecting pulmonary embolism despite recent improvements in the specificity of pulmonary ventilation-perfusion scanning techniques $(9,10)$. As recent studies have shown that the immediate and long term prognosis of acute pulmonary embolism is closely related to pulmonary artery pressure (11) and the behaviour of the pressure after acute thrombolytic therapy with heparin or streptokinase, it becomes essential to be able to diagnose pulmonary embolism accurately and fast after the onset of complaints. We therefore evaluated the use of a video image processor, which allows the digitization and on-line subtraction of a continuous fluoroscopic image during acute pulmonary angiography. 
Because of suspicion of pulmonary embolism on clinical and electrocardiographic grounds (12), an acute pulmonary artery angiogram was performed in combination with right sided heart catheterization in 8 patients admitted to the coronary care unit or general intensive care unit.

Catheter introduction was accomplished in the catheterization laboratory via either an incision and venotomy in the right or left antecubital fossa or percutaneously (Seldinger technique) through the right femoral vein. A pigtail catheter was used in the percutaneous femoral approach while a pulmonary artery balloon catheter was used in all other cases. Pulmonary arteriography was combined with a full hemodynamic study of the right side of the heart $(6,13)$, since in experienced hands these data may be obtained rapidly with no increase in risk. The studies were performed on a Siemens cardioscope $U$-arm with a Pandoros generator using an image intensifier size of 6 or 9 inch. Pulmonary angiography was carried out by injecting a 15 or $30 \mathrm{cc}$ bolus of radiographic contrast material (Hexabrix ${ }^{\mathrm{R}} 320 \mathrm{mgl} / \mathrm{ml}$ ) with a flow rate of 15 $\mathrm{cc} / \mathrm{sec}$ in the main pulmonary artery and filming the left and right hemithoraces simultaneously in the anterior posterior projection; segmental and handinjected superselective injections were made in those cases $(4 / 8)$ where they increased the diagnostic capabilities (15) or were considered necessary because of high pressures (above $70 \mathrm{mmHg}$ ) in the pulmonary artery $(6,15)$. It uses a standard CCIR or EIA video signal on a $512 \times 512 \times 8$ bit pixel matrix. During angiography it is controlled by means of a remote control system, so that the operating physician could select his best mask just prior to the injection of the contrast material. This seemed to be an essential part of the procedure since patients suffering from pulmonary embolism suffer from shortness of breath, a major problem in subtraction techniques. By this operator controlled 'masking' the physician could decide to take a new mask during the run if severe breathing artefacts were present. After every injection subtracted images were recorded on a video system (Sirecord, Siemens Erlangen, DDR). Both the arterial and venous phase were carefully studied. In this case 'resubtraction' of the recorded subtracted images was possible to enhance special regions of interest or to 

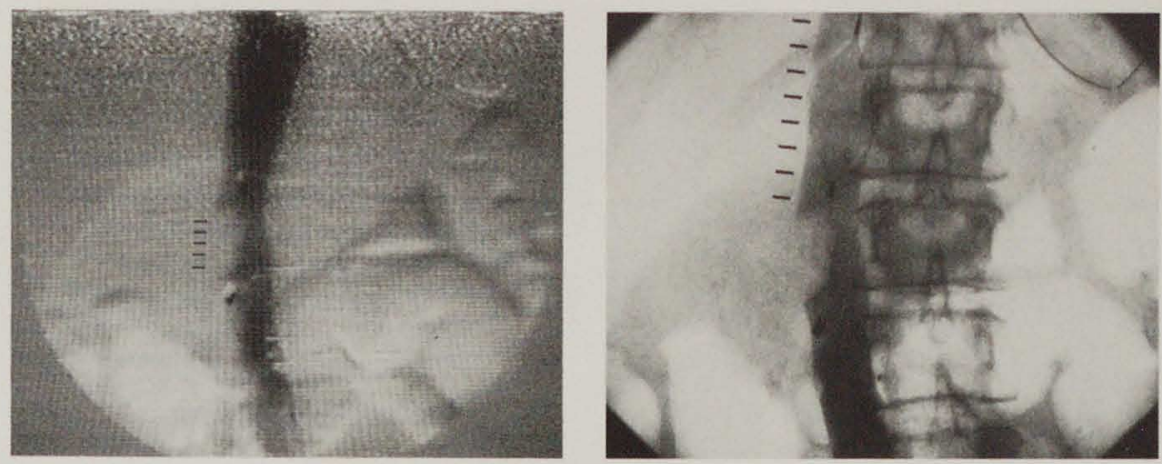

Figure 1

During the evaluation of recurrent pulmonary embolism a thrombus was found in the inferior caval vein, $\mathrm{A}$ : using on line digital subtraction fluoroscopy (VIP-300). The figure $B$. also shows the introduced caval filter (Günther filter ${ }^{\mathrm{R}}$, Cook, Netherlands) on a cine frame.

Results minimize the effects of subtraction artefacts. In $4 / 8$ patients which were hemodynamically unstable immediate superselective treatment with a thrombolytic agent (streptokinase in 3 pts, recombinant tissue plasminogen activator in $1 \mathrm{pt}$ ) was initiated, using a dose of approximately 500,000 units given in a 24 hour period, followed by heparin iv therapy for 7 to 10 days. In one patient a temporarily caval vein filter (24) was percutaneously introduced via the internal jugular vein, after the detection of a caval thrombus (figure 1).

Of the 8 patients studied, $6 / 8$ studies were of adequate diagnostic quality. In one patient the subtraction of the pulmonary angiogram was not sufficient to exclude pulmonary embolism due to respiration artifacts. In the other patient no angiogram could be

Table 1

$\begin{array}{lllrll} & \text { PPA } & \text { TT } & \text { RR(sys) } & \mathrm{SO}_{2} \mathrm{PA} & \mathrm{SO}_{2} \mathrm{FA} \\ & & & & & \\ 1^{*} & 80 / 30 & 50 / 20 & 100 & 50 & - \\ 2 & 50 / 20 & & 110 & 69 & 90 \\ 3 & 65 / 25 & & 80 & - & - \\ 4^{*} & 40 / 20 & 25 / 10 & 90 & 62 & 85 \\ 5 & 35 / 10 & & 110 & 70 & 89 \\ 6^{*} & 60 / 30 & 30 / 15 & 85 & 45 & 80 \\ 7 & 40 / 20 & & 90 & - & 87 \\ 8^{*} & 40 / 20 & 40 / 20 & 95 & 35 & 90\end{array}$

PPA $=$ Pulmonic Artery Pressure RR $=$ Arterial blood pressure measured after Riva Rocci SO2 = oxygen saturation in PA or FA (femoral artery). Pressures are expressed in $\mathrm{mmHg}$, oxygen saturation in percentages. TT represent the PA pressures after thrombolytic therapy. Patient $1,4,6$ and 8 were treated with a thrombolytic agent. 


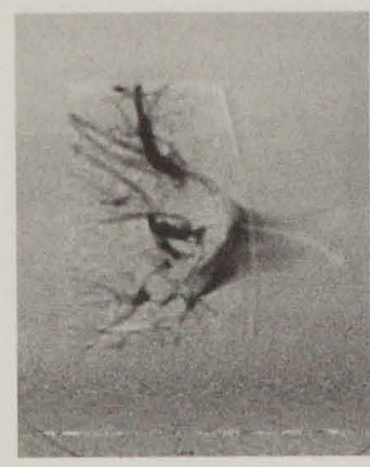

Figure 2

$A$ : Selective injection in the right pulmonic artery. Major occlusion by thrombus is seen, possibly associated with spasm.

$B$ : The result 12 hours after the start of selective streptokinase infusion. It is clear that the thrombus is partially resolved.

C: The result after 7 days of thrombolytic treatment is shown. The right lower lobe artery still shows a perfusion defect suggestive for residual thrombus (arrow).

Discussion
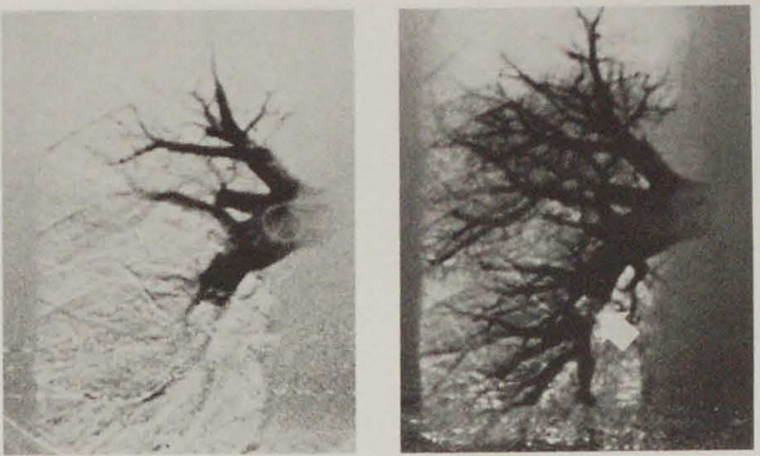

performed at all, because of technical difficulty in placing the catheter in the right side of the heart. Due to a low cardiac output successive intravenous digital angiography performed on a Philips DVI II unit was also considered non diagnostic in that patient. Table 1 summarizes the pressures measured in the pulmonic artery (AP), systemic pressures (RR method) and venous and arterial oxygen saturations. Patients treated with thrombolytic therapy are indicated with an asterix. Three patients were treated with Streptokinase injected selectively through the angiographic catheter after the procedure. One patient was treated with recombinant tissue plasminogen activator (rTPA). The catheter was left in place for continuous pulmonary artery pressure control and control digital subtraction angiography (figure 2 ). In those patients in whom pulmonary embolism was diagnosed oral anticoagulant therapy was instituted and after a mean follow up of 8 months (range 3-14 months) no patient suffered a recurrence of pulmonary embolism.

It was the purpose of these investigations to test a portable video image processor in the diagnosis of pulmonary embolism. Also the pressure on the right side of the heart and in the pulmonary artery were measured in these patients admitted with acute distress at the coronary care unit.

It was not the intention to diagnose abnormalities in pulmonary artery branches of the third degree, although it is evident from segmental and supersegmental injections (figure 3 ) that in selected cases diagnostic information can be obtained. Segmental and selective injections offer several advantages over main pulmonary artery injection: 
Figure 3

$A$ : Subselective injection in the right lower lobe artery. Vessel branches of the third degree are clearly visible. A 9 inch field of view was used with an injection of 10 cc contrast material.

$B$ : Subselective injection of the left pulmonic artery in a case of bronchus tumor, responsible for deviation of the arterial tree (arrow).

Figure 4

$A$ : The left pulmonic artery in which a thrombus completely obstructs the lingula region (arrow) and partially the left lower lobe artery.

B: Taken 3 heartbeats after A, showing lack of perfusion of the lingula region and hypoperfusion of the left lower lobe resulting in a filling defect.

C: After selective streptokinase therapy lysis of the thrombus is seen with a small residual thrombus (arrow).

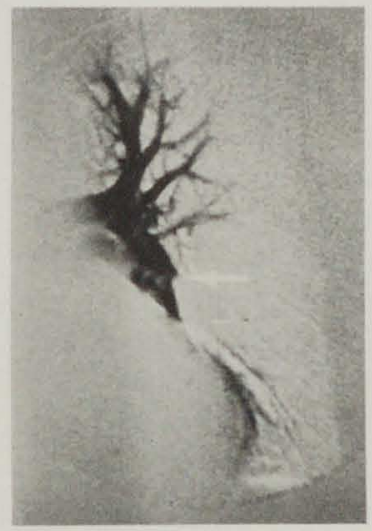

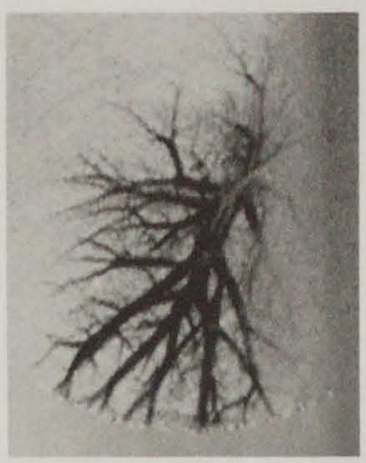

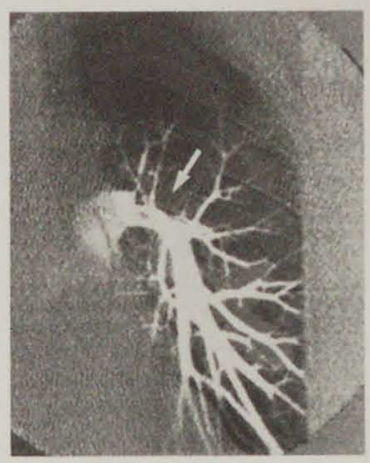

1. There is less dilution of contrast material during cardiac systole.

2. There is no loss of detail by overlapping vessels and

3 . Contrast material is injected directly into the vessel being examined, thereby avoiding diversion from the areas of embolization $(6,15)$.

Continuous digital subtraction angiography using fluoroscopic angiography or cine angiography is found to be superior to cut-film techniques $(6,16,17,18)$. There are only two reliable diagnostic findings in pulmonary arteriography (figure 4): the "cut-off sign" and the "filling defect", if it is assured that these are not due to flow or vessel crossing artefacts (19). In our experience not only the continuous arterial phase but also the venous return pattern is an important aid in diagnosing pulmonary embolism in showing hypoand non-perfusion of segments of the pulmonary vascular tree (figure 5). The pathophysiological consequences of pulmonary embolism are such that no truly
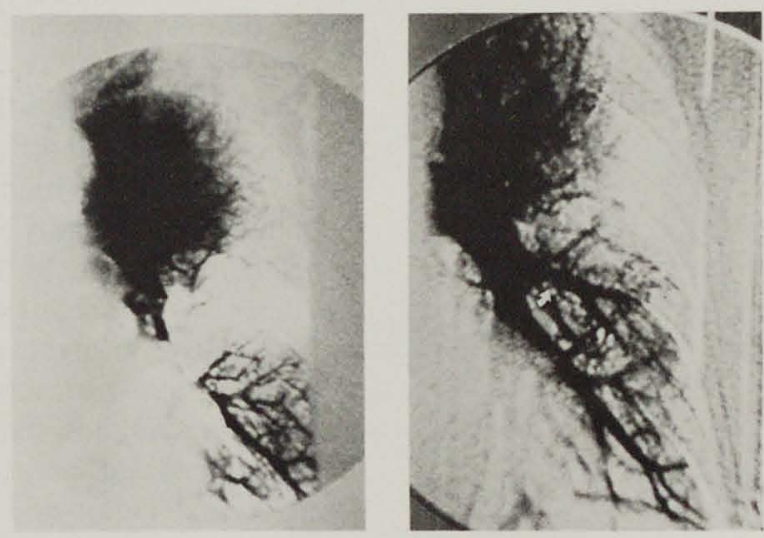


\section{Figure 5}

Example of the venous return pattern in pulmonary embolism. In A an early systolic frame shows massive embolism in the right lung. The venous wash out phase is shown in B. All obstructed areas clearly demonstrate impaired venous return while the one not obstructed vessel is responsible for the segmental venous pattern.
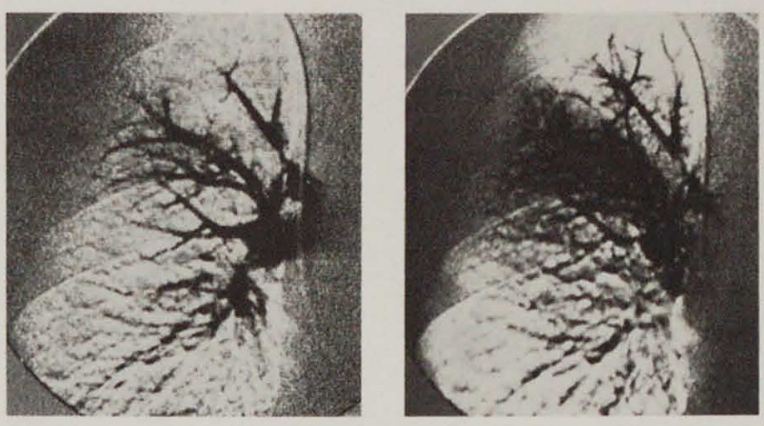

specific historical or physical findings are available upon which a diagnosis can be based firmly. Digital subtraction techniques are extensively used at present to diagnose pulmonary vascular disease. Except for some centers, most investigators use a right atrial or selective pulmonary artery injection technique $(20$, 21). The system we used was an add-on portable video image processor, which we have discussed extensively elsewhere (14). The advantages of a portable device are obvious:

1. it can operate at low costs,

2. as an add-on portable device it is indeed possible to use it "at the bedside", providing appropriate fluoroscopy equipment, and

3 . it allows a fast diagnostic procedure in the coronary care setting.

The disadvantages of the system studied were mainly due to the fact that using fluoroscopic exposure levels a considerable amount of noise was present in the subtraction pictures. This did not influence the diagnostic capability of the images, however, improvement in image quality could be envisioned by using pulsed fluoroscopy techniques.

Pulmonary angiography can be employed as a "forward technique" in an attempt to visualize the large pulmonary veins, left atrium and left ventricle (6). In one of our patients, reported elsewhere (22) digital pulmonary angiography was performed because of suspected embolism. In the levo-phase it was noted that there was severe left ventricular apical hypokinesia, suggestive for myocardial ischemia. The pulmonary angiogram was found to be normal, the Technetium $99 \mathrm{~m}$ pyrophosphate scan showed pathological uptake indicative of myocardial infarction.

The National Heart and Lung Institute Urokinase 
Pulmonary Embolism Trial (UPET) showed an $80 \%$ decrease in mortality if pulmonary embolism was recognized and treated on admission (23). Also long term prognosis is closely related to early detection and institution of adequate therapy $(11,23)$. Pulmonary embolism is a "devil in disguise", often leading to death or a disabling status of the individual in which it stayed unrecognized. This serious illness needs early diagnosis and, if necessary, aggressive treatment. Early digital subtraction angiography seems advantageous as is indicated in our study, however, diagnosis of pulmonary embolism starts with a high level of suspicion.

In the department of cardiology of the State University of Limburg, Maastricht, we are at present evaluating the following flow diagram (Table 2) in case pulmonary embolism is suspected. Characteristic patterns of the intraventricular septum, right ventricular size, the presence of tricuspid or pulmonic valve insufficiency on doppler echocardiography, all indicating right ventricular pressure overload, are ex tremely valuable in diagnosing pulmonary embolism Abnormal perfusion scans, if possible, combined wi* ventilation scans are helpful in detecting pulmonary embolism, and can simultaneously be combined with nuclear scans to localize venous thrombi. Nuclear perfusion scans can be used in the follow-up of treatment.

In severely distressed patients in which thrombolytic treatmentis contraindicated, acute pulmonary embolectomy is the treatment of choice. The development of percutaneously insertable, and removable caval filters make individual tailoring of treatment possible.

Conclusion: The diagnosis of pulmonary embolism is difficult. Short and long term prognosis, however, are related to early diagnosis and treatment. In this study we evaluated the use of a video image processor for on-line subtraction studies of the pulmonary vasculature. We conclude that these subtraction studies seem to be an aid in the early detection of acute pulmonary embolism and we present a flow chart for clinical decision making in case pulmonary embolism is suspected. 
Suspicion P.E. (history, physical cx., ECG)
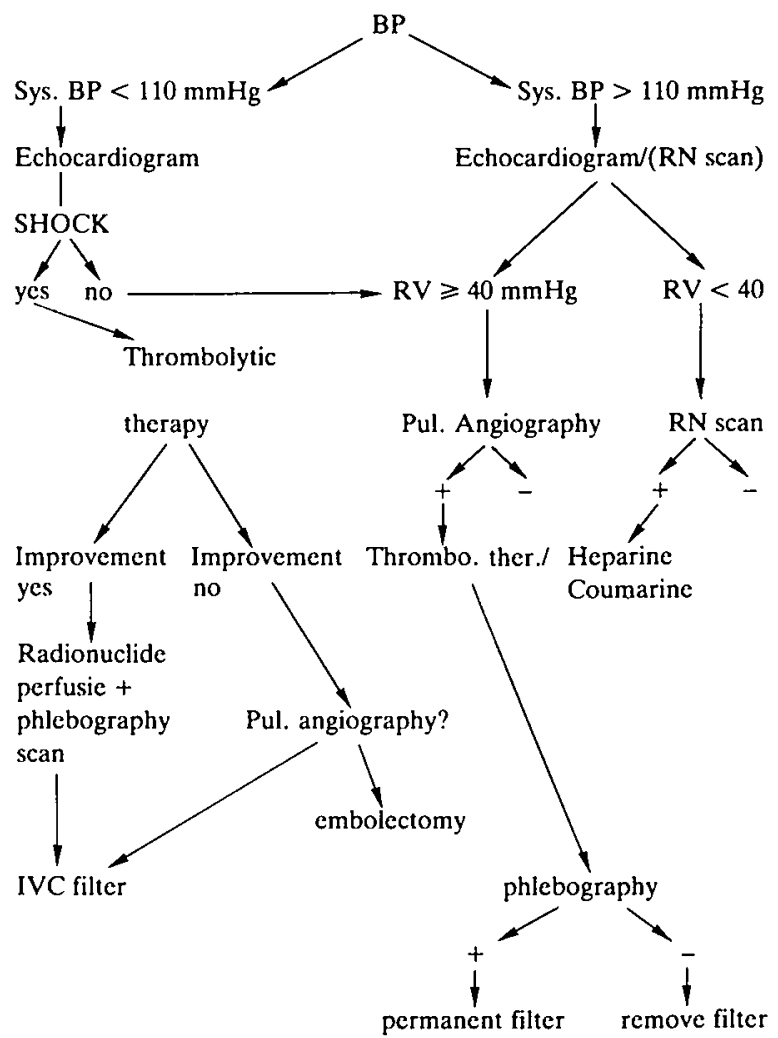

\section{Follow-up}

- ECG

- echocardiogram

- exercise test

- pulmonary function test

Flow chart outlining the workup in diagnosis and treatment of patients with pulmonary embolism.

\section{References}

1. Cournand AF, and Ranges HS: Catheterization of the right auricle in man. Proc Soc Exp Biol Med 46: 462-466, 1941.

2. Denter LE, Haynes FW, Burnell CS, Eppinger EC, Sagerson RR, Evans JM: Studies of congenital heart disease. II: the pres sure and oxygen content of blood in the right auricle, right ventricle, and pulmonary artery, with observations on the oxygen saturation and source of pulmonary "capillary" blood. J Clin Invest 26: 554-560, 1947. 
3. Zimmerman HA, Scott RW, Becker ND: Catheterization of the left side of the heart in man. Circulation 1: 357-359, 1950.

4. Swan HJC, Ganz W: Use of balloon flotation catheters in critically ill patients. Surg Clin N Am 55: 501-520, 1975.

5. Dalen JE: Pulmonary angiography in pulmonary embolism. Bull Physiopathol Respir 6: 45-63, 1970.

6. Grossman W: Cardiac catheterization and angiography. Lea and Febiger, Philadelphia, 1974.

7. Williams JR, Wilcox WC: Pulmonary embolism: Röntgenographic and angiographic considerations. Am J Röntgenol 89: 333-342, 1963.

8. Sasahara AA, Stein M, Simmer M, Littman D: Pulmonary angiography in the diagnosis of thrombo-cmbolic discase. $\mathrm{N}$ Engl J Med 270: 1075-1081, 1964.

9. Szucs HM, Brooks HL, Grossman W, Banas JS, Heister SG, Baxter, L. Dalen JE: Diagnostic sensitivity of laboratory findings in acute pulmonary embolism. Ann Intern Med 74: 161166,1971

10. Linton DS, Bellon EM, Bodic JF, Rejalic AM: Comparison of results of pulmonary arteriography and radioisotope lung scanning in the diagnosis of pulmonary embolism. Am J Röntgenol Radium Ther Nucl Med 112: 745-748, 1971.

11. Rödel M, Stank V, Widnosky J, Prerowskcy: Longterm follow up of patients with pulmonary thrombo-embolism. Chest $81 ; 151-158,1982$.

12. Brugada P, Gorgels AP, Wellens HJJ: The electrocardiogram in pulmonary embolism. In: What's new in clectrocardiography. Wellens HJJ and Kulbertus HE (Eds). Martinus Nijhoff Publishers, p. 366-380, 1981.

13. Yang SS, Bentiroglio LG, Marankaw V, Goldberg H: Cardiac catheterization data to hemodynamic parameters, 2nd ed. Philadelphia, Davis, 1978.

14. Janssen JHA, Ackermans J, Tijdens F, Verstraclen B, de Zwaan $C$, Bär $F$, Brugada P: Bedside digital subtraction angiography in critical care medicine. Critical Care Med 84: 12; 1067-1070, 1984.

15. Bookskin JJ: Segmental arteriography in pulmonary embolism. Radiology 13: 1007-1012, 1969.

16. Panigrahi G, Boudoulas $H$, Ganguly S: Quantitation of pulmonary emboly with pulmonary cineangiography: Preliminary report. Angiology 36, 4: 203, 1985.

17. Schrijen F, Jezek V: Haemodynamics and pulmonary wedge angiography findings in chronic pulmonary disease. Scand J Respir Dis 58: 151-158, 1977.

18. Bowen S, Bookstein J, Johnson A, Peterson H, Moser K: Wedge and subselective pulmonary angiography in pulmonary hypertension secondary to venous obstruction. Radiology 55: $599,1985$.

19. Stein PD, O'Connor JF, Dalen JE, Pur-Shahriani AA, Hoppin FG, Hammond DT, Haynes FW, Fleischer FG, Denter C: The angiographic diagnosis of acute pulmonary embolism: Evaluation of critcria. Am Heart J 73: 730, 1967.

20. Ludwig JW, Verhoeven L, Kerstengen J: Digital subtraction angiography of the pulmonary arteries for the diagnosis of pulmonary embolism. Radiology 197: 639, 1983.

21. Sos TA: Experimental and clinical evaluation of injection 
sides, rates and volumes for DSA studies. Digital Radiography 1984 (Abstract). National Symposium, Miami USA.

22. Janssen JHA, de Zwaan C, Stappers J, Braat S: Intravenous digital angiography in the evaluation of a patient with chest pain. Vascular Medicine 3, 2: 90, 1985.

23. The Urokinase-Strepokinase Pulmonary Embolism Trial: A national cooperative study. JAMA 229: 1606, 1974.

24. Janssen E, Janssen JHA, Cheriex EC, Penn OCKM: Use of a removable caval filter for prevention of recurrent cmbolism following acute pulmonary embolectomy: $A$ flexible approach. In: Prospects and strategies in cardiovascular research. Janssen J, Reneman R, Braat S, de Nollin (eds.), Van Gorcum, Maastricht, page 73, 1988. 


\title{
Low dose ventriculography using a video image processor and fluoroscopic exposure levels
}

\author{
Johan H.A. Janssen, MD \\ Department of Cardiology \\ Academic Hospital Maastricht, University of Lim- \\ burg, The Netherlands
}

Introduction

Methods

With the recent interest in reduction of myocardial damage during the acute phase of a myocardial infarction the assessment of left ventricular wall motion during reperfusion studies is of interest. Since patient survival and patient morbidity is closely related to left ventricular function (1-3) acute determination of the myocardium at risk may have clinical relevance. Because the intraventricular injection of ionic contrast materials can induce toxic effects and substantial hemodynamic derangements $(4,5)$, a practical use of on-line subtraction is in the studies of left ventricular function through intraventricular injection of very small doses of contrast material. The purpose of this study was to study the performance of a video image processor for acquisition of low dose left ventriculograms at fluoroscopic exposure levels.

The video image processor used is a VIP-300 with a $512 * 512$ matrix. As a video signal standard CCIR or EIA signal is used. The video signal from the $\mathrm{X}$-ray TV camera is logarithmically amplified and digitized for storage in each of two $512 * 512 * 8$ bit memories. For digital subtraction left ventriculography, continuous mask mode subtraction is used. The mask frame is stored in a first memory and the subtracted images following contrast enhancement are viewed in real time from the second memory. The subtracted images are recorded on a video tape recorder (Sirecord, Siemens,Erlangen,DDR). The X-ray equipment used was a Pandoros generator with a Siemens Cardioscoop U-arm. A 9 inch image intensifier was used. Left ventriculography was performed using a 7 French pig- 
tail catheter after hemodynamic measurements were recorded. The contrast material used was Hexabrix ${ }^{R}$. Injections were made usig a power injector (Medrad Mark 4) but not ECG triggered. In every patient an injection was made using $40 \mathrm{cc}$ of contrast, followed by two injections with $50 \%$ and $70 \%$ contrast dilution with sterile saline. The injection with $40 \mathrm{cc}$ of contrast was performed with cine left ventriculography and its fluoroscopic image served as the reference for evaluation of the subtracted low dose left ventriculograms. The low dose ventriculograms were recorded during fluoroscopy. Injections were made at using a total volume of $40 \mathrm{cc}$, injected with a speed of $12 \mathrm{cc}$ sec. The patients who participated in the study were admitted for elective, diagnostic catheterization and were not in acute distress.

The obtained left ventriculograms were judged by two cardiologists in a blinded, random fashion. The left ventriculogram was only performed in the 30 degree right anterior oblique projection. The left ventricle in the 30 degree RAO projection was arbitrarily divided in three segments: anterolateral, apical and inferior. The left ventriculogram was judged for the presence of normal wall motion, hypokinesia, akinesia or the presence of one or more dyskinetic segments. Then the results between the two cardiologists were compared.

Results

In the 10 patients studied a total of 90 segments were evaluated. An example is given in figure 1 . The wall motion of the $50 \%$ and $70 \%$ dilution ventriculograms were compared to the wall motion of the ventriculogram obtained with a $0 \%$ dilution $(=40 \mathrm{cc}$ Hexabrix $^{\mathrm{R}}$ ). Between the ventriculograms made with a $50 \%$ dilution and the non-diluted group there was $100 \%$ agreement. The $70 \%$ dilution ventriculograms however, showed a disagreement of $10 \%$. This difference was in all cases due to a different interpretation of the inferior segment (normal versus hypokinesia of this segment).

Discussion

It has been well established that a good correlation exists between digital subtraction ventriculography and conventional ventriculography (6-8). These studies used very sophisticated and expensive systems while we used a relatively simple video image pro- 

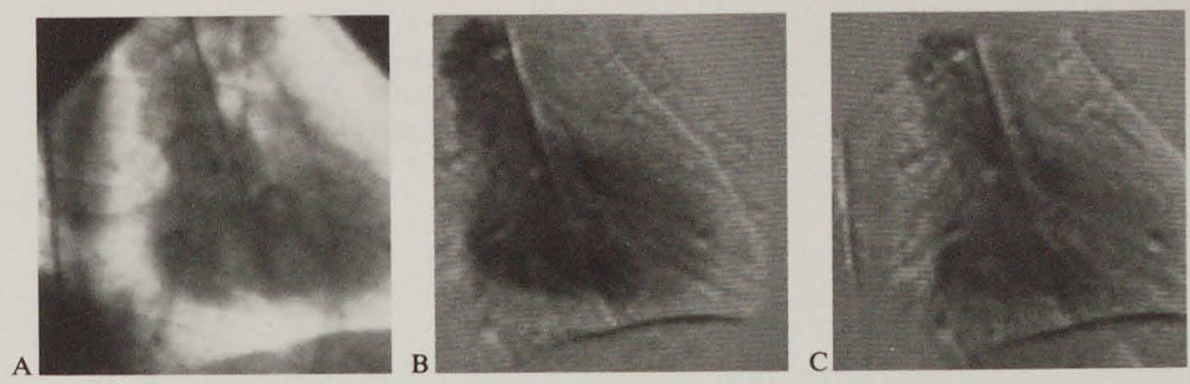

\section{Figure 1}

Panel A shows a cine left ventriculogram in the $30^{\circ}$ RAO projection using $40 \mathrm{cc}$ of Hexabrix ${ }^{R}$. Panels B and $\mathrm{C}$ are showing the left ventricle in the $30^{\circ} \mathrm{RAO}$ projection, obtained with $50 \%$ and $70 \%$ dilution of contrast respectively, during on line mask mode subtraction. Panels $\mathrm{D}$ and $\mathrm{E}$ show a left ventricle during subtraction at fluoroscopic exposure levels (noise!). The definition of the diafragmatic part of the left ventricle is inferior as compared to the apex or anterior wall.
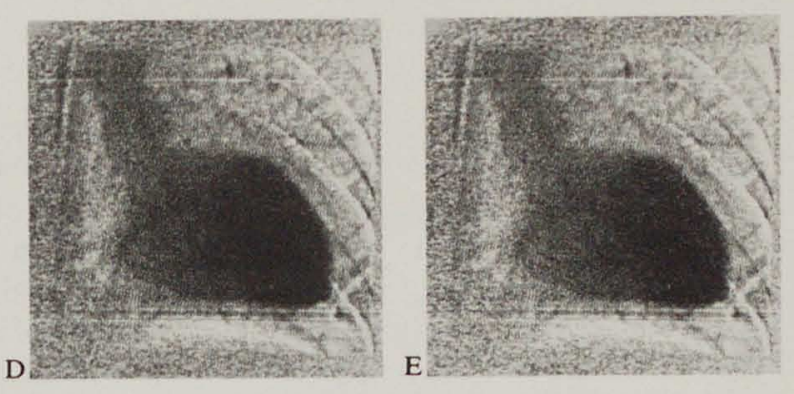

cessor. Another difference is the use in our study of fluoroscopic exposere levels as opposed to exposure levels even exceeding normal cine angiographic exposure levels. Several studies have been performed using small amounts of contrast material and digital subtraction angiography (9-11). They differed with our study in that they included patients with dilated cardiomyopathies and poorly performing left ventricles. The low acquisition rate with these digital systems was another drawback for accurately assessing left ventricular performance. In our study in which we performed on-line, continous subtraction , acquisition rate is sufficient but due to the low energy levels noise is a potentially disturbing factor. Despite the differences of protocols used by us and as mentioned in the literature, it is demonstrated that a consistent lack of hemodynamic pertubations in response to low dose ventriculography exists so that it is anticipated that this application of low dose left ventriculography will allow safer examinations. It should be realized, however, that if one were to use repeated injections with diluted contrast material, the volume load may be detrimental in patients with impaired left ventricular function. It is essential to use the right amount of (diluted) contrast (Table I). In this study we did not evaluate the value of time interval difference sub- 
Table I

The agreement is shown between the segment score during dilution and left ventricular wall motion without the use of diluted contrast. Only during the $70 \%$ dilution ventriculography a misinterpretation of $3 / 10$ segments of the inferior segments occurred.

$\begin{array}{lccc}\text { Dilution \% } & \begin{array}{c}\text { Inferior } \\ \text { segment }\end{array} & \begin{array}{c}\text { Apical } \\ \text { segment }\end{array} & \begin{array}{c}\text { Anterolateral } \\ \text { segment }\end{array} \\ 50 \% & 10 / 10 & 10 / 10 & 10 / 10 \\ 70 \% & 7 / 10 & 10 / 10 & 10 / 10\end{array}$

traction in identifying hypo- or dyskinesia or estimating infarction size. From a practical point of view we advise to use a dilution of $50 \%$. The misinterpretations in the $70 \%$ dilution ventriculograms was in all cases due to a nonoptimal visualization of the mitral valve area. Assessment of left ventricular wall motion is possible using $50 \%$ dilution of contrast and digital subtraction ventriculography at fluoroscopic exposure levels.

\section{References}

1. Simoons ML, Scrruys PW, BrandM vd, et al: Early thrombolysis in acute myocardial infarction: limitation of infarct size and improved survival.JACC 7:729-742, 1986.

2. Kennedy JW, Ritchic JL, Davis KB, et al: Western Washington randomized trial of intracoronary streptokinase in acute myocardial infarction. $\mathrm{N}$ Engl Med 308:1312-1318,1983.

3. Merx MJ, Dorr R, Lambertz H, et al: Successful treatment of acute myocardial infarction shock by combined percutaneous transluminal coronary recanalization and percutancous transluminal coronary angioplasty. Am Heart J 103:132,1982.

4. Higgins CB: Effects of contrast materials on left ventricular function. Invest Radiol 15 (suppl): 220- 31,1980.

5. Mancini GB, Ostrander DR, Slutsky RA et al: Comparative effects of ionic contrast agents injected intravenously or directly into the left ventricle: implications for digital angiography. AJR 140:425-430,1983.

6. Tobis JM, Walcoigh O, Johnston WD, et al: Correlation of digital angiography compared with standard cineangiography. Am Heart J 1: 738-740, 1983.

7. Engels P, Ludwig J, Verhoeven L: Left ventricular cvaluation by digital video subtraction angiography. Radiology, 144: 471474, 1982.

8. Birchlar B, Hess O, Murakami T, Niederer P, Anliker M, Krayenbuchl H: Comparison of intravenous digital subtraction cineangiocardiography with conventional contrast ventriculography for the determination of the left ventricular volumc at rest and each during exercisc. Eur Heart J; 6: 497-509, 1988. 
9. Vas R, Diamond GA, Forrester JS, et al: Computer enhancement of direct and venous-injected left ventricular contrast angiography. Am Heart J 102: 719- 28,1981.

10. Goldberg HL, Borer JS, Moses JW, et al: Digital subtraction intravenous Ieft ventricular angiography: comparison with conventional intraventricular angiography. J Am Coll Cardiol 1:858-862,1983.

11. Sasayama $\mathrm{S}$, Nonogi $\mathrm{H}$, Kawai $\mathrm{C}$, et al: Automated method for left ventricular volume measurement by cineventriculography with minimal doses of contrast medium. Am J Cardiol 48: 746-753,1981. 


\title{
A quantitative analysis of the coronary artery in patients with unstable angina: can we characterize a malignant stenosis?
}

\author{
Johan H.A. Janssen MD, Pedro Brugada MD, \\ Chris de Zwaan MD, Frits W. Bär MD, \\ Hans B. de Swart MD, Vincent van Ommen MD, \\ Frank Vermeer MD, Hein J.J. Wellens MD
}

Department of Cardiology, Academic Hospital Maastricht, University of Limburg, The Netherlands

Introduction

With the introduction of thrombolytic therapy in patients with myocardial infarction and unstable angina pectoris (1), much information has become available on the pathogenesis of the "acute coronary syndrome".

Increasing evidence has been obtained that coronary thrombosis plays an important role in the pathogenesis of unstable angina, acute myocardial infarction and sudden death. The features on coronary angiography suggestive of the formation of thrombus are, however, still being discussed.

By comparing the findings of coronary angiography in patients before and after thrombolytic therapy, we hoped to be able to determine whether coronary angiography could identify lesions prone to the occurrence of an intracoronary thrombus. Possibly, the finding of such lesions on coronary arteriography could have therapeutic consequences.

Methods

The population studied consisted of 41 patients with a clinical diagnosis of unstable angina pectoris. Twentyone were treated with intracoronary streptokinase (group A) and 20 patients with intravenous recombinant tissue-type plasminogen activator (rt-PA, group B). Thrombolytic therapy was instituted after coronary angiography had been performed.

Unstable angina pectoris was defined as angina of 
recent onset, sudden worsening of preexisting angina, or postinfarction angina developing after an asymptomatic period of at least three months. All patients had class $3 / 4$ angina according to the NYHA classification. Acute myocardial infarction was excluded in all these patients by considering the duration of chest pain ( $<20$ minutes) and the absence of electrocardiographic changes suggestive of an evolving myocardial infarction (persistent ST segment elevation on the surface ECG or development of new $Q$ waves).

Coronary angiography was performed as soon as possible after the patient entered the coronary care unit. The first coronary angiogram was performed between 2 and 69 hours (median 9 hours) after onset of the last episode of chest pain. A second coronary angiogram using identical views and an identical position of patient and $\mathrm{X}$-ray equipment, was performed within one day after thrombolytic treatment.

The ischemia-related artery was defined as follows: In patients with significant ( $>50 \%$ diameter narrowing) one vessel disease, this vessel was regarded as the ischaemia related vessel. In all other cases the combination of severity of the stenosis, speed of flow through that artery at the time of the first catheterization and the presence of wall abnormalities during ventriculography in conjunction with other clinical data (e.g the location of ECG abnormalities) were used to determine the ischaemia-related vessel.

Quantitative coronary artery analysis was performed using the computerized Cardiovascular Angiography Analysis System (CAAS, Pie Data Medical) with automated contour detection. This system allows an objective and reproducible quantification of coronary stenosis and has been validated (2). In short, a $35 \mathrm{~mm}$ cineframe is selected in end-diastole and digitized with a charge coupled device camera at high resolution (1330*1770 pixels) and a region of interest encompassing the arterial segment to be analyzed is electronically selected for subsequent analysis by the computer. The contours of the arterial segment are automatically detected on the basis of the first and second derivative functions of the brightness profile, and corrected for pincushion distortion. A calibration factor is derived from a computer processed segment of the angiography catheter used. From the arterial contour data a diameter function is computed. The 
"minimal obstruction diameter", computed after reconstruction of the "original" vessel wall is expressed in millimeters. The severity of the obstruction can also be expressed as percent area stenosis. Assuming circular cross sections at the reference and obstruction site the corresponding luminal area can be calculated. Using the videodensitometric option of the CAAS, background corrected videodensitometric profiles across the vessel image at the "normal" segment compared to the point of greatest narrowing allowed the estimation of area stenosis independent of its crosssectional shape. As also found by other investigators, this densitometrically determined percent area stenosis correlates well with percentage reduction of crosssectional area measured histologically in post-mortem hearts $(r=0.97)(3,4)$.

Using the reconstructed borders of the vessel wall the CAAS calculates a symmetry coefficient for the stenosis: a symmetrical lesion having a value of one and an eccentric lesion having a value of 0 . Symmetry is defined as follows: the distance between the left hand estimated contour of the coronary artery at the site of obstruction is called $\mathrm{dl}$, and similarly for the right hand contour $\mathrm{dr}$. The symmetry measure is then computed as the lowest value for $\mathrm{dl}$ and dr divided by the maximum value of $\mathrm{dl}$ and $\mathrm{dr}$ (figure 1). Validation of CAAS by several investigators could be confirmed in our clinic which revealed an overall error of repeated analysis between $2 \%-5 \%(2,4,5)$.

Analysis of morphology consisted of computer estimation of the eccentricity of the lesion as well as a visual interpretation using the typing of coronary ar-

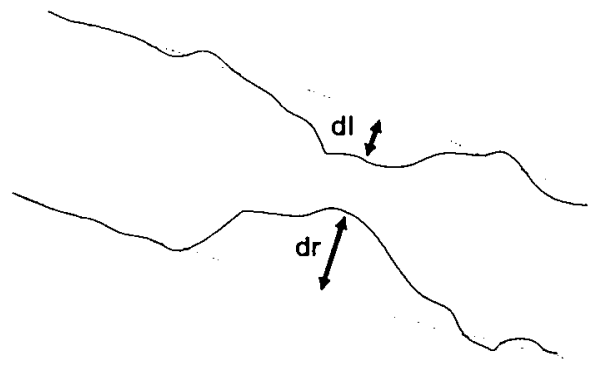

SYMMETRY INDEX $-\frac{\min (d l, d r)}{\max (d l, d r)} \cdot \frac{d l}{d r}$ in this example 
tery lesions as suggested by Ambrose et al (6).

Next to the intraluminal radiolucencies before or after the stenosis (reflected as a dip in the videodensitometric curve of the analysed vessel), ulcerations and irregular scalloped borders of the lesion were noted. A difference in appearance (in radiolucency or changes in percentage stenosis particularly when accompanied by disappearance of escalloped contours of irregular borders) of the lesion after the administration of a thrombolytic agent was thought to reflect the presence of intraluminal thrombus before thrombolytic therapy.

In ten patients a third coronary angiography was performed at a mean of 12 days of the first angiography. Neither diameter nor area stenosis changed significantly between the angiography performed 24 hours after treatment with a thrombolytic agent and the angiography at 12 days. These angiograms will not be considered, however, in further analysis.

Quantitative data of all patients are presented in Table 1 . Because of similar results of treatment with intracoronary streptokinase and intravenous administered rt-PA (7), data after thrombolytic treatment were analyzed together. Before thrombolytic therapy diameter and area stenosis were $80.5 \pm 4.5 \%$ and 93.5 $\pm 4.2 \%$ respectively. After infusion of the thrombolytic agent the coronary anatomy at the second catheterization had significantly improved. The diameter and area stenosis were $62.8 \pm 7.2 \%(\mathrm{p}<0.001)$ and $84.8 \pm 4.5 \%(p<0.01)$ respectively. A typical lesion visualized both before and after thrombolysis is

\section{TABLE I}

Quantitative data of all patients (group $A, n=21$ and $B, n=20$ )

Before $T \quad p$-value After $T$

$D \% \quad 80.5+4.5 \% \quad p<0.001 \quad 62.8 \pm 7,2 \%$

$A \% \quad 93.5 \pm 4.2 \% \quad p<0.01 \quad 84.8 \pm 4.5 \%$

$N^{o} n$-occluded

$\begin{array}{lll}\text { arteries } & 14 & 6\end{array}$

Legends:

$\mathrm{T}=$ thrombolytic therapy

$\mathrm{D} \%=$ percentage diameter stenose

$\mathrm{A} \%=$ percentage area stenose (densitometric) 

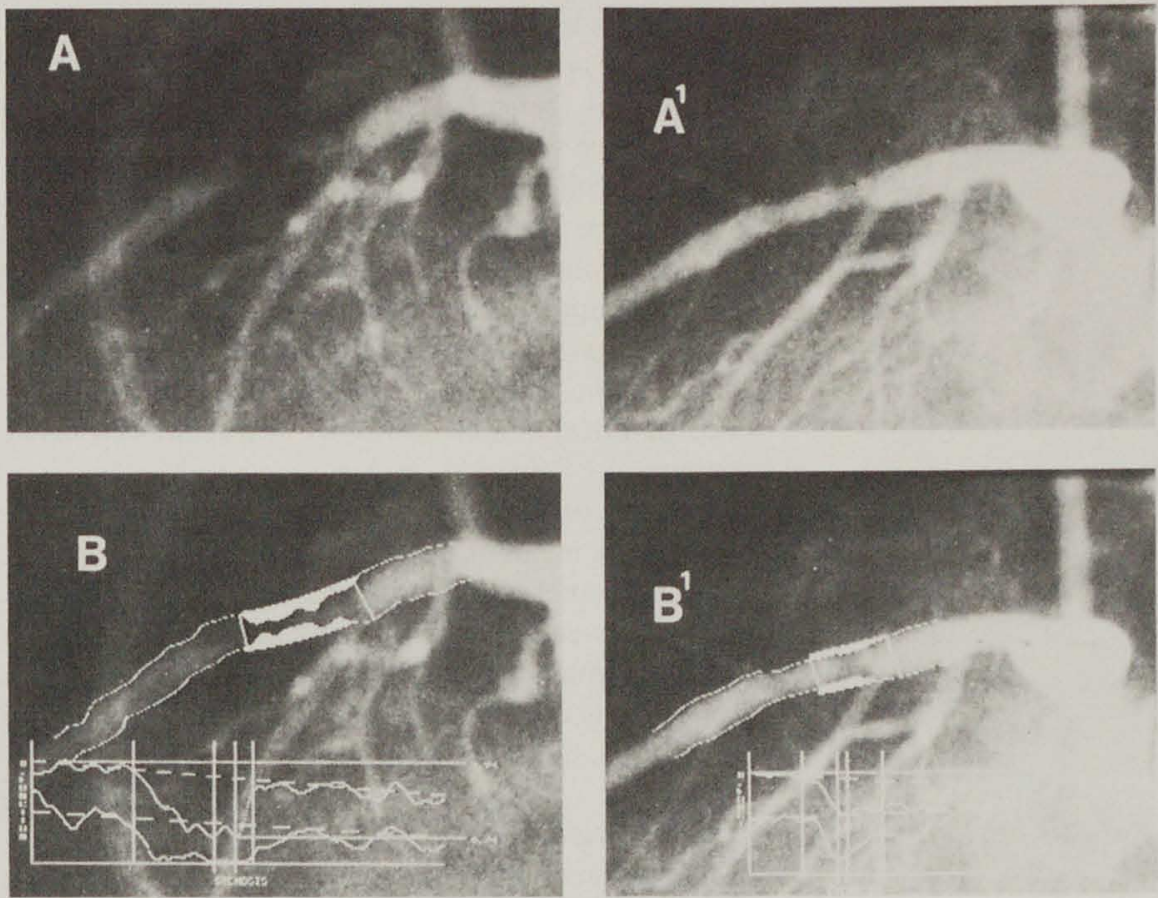

\section{Figure 2}

In $\mathrm{A}$ the left anterior descending coronary artery is visualized with a magnification of 2. After a stenosis a intraluminal defect is seen. In $\mathrm{B}$ analysis of the intraluminal defect is carried out by the CAAS. The upper line between the minimal and maximal diameter of the coronary artery $(0.74$ to $2.69 \mathrm{~mm}$ ) represents the diameter function, the lower line the densitometric analysis. The site of stenosis measurement is indicated. In $A^{\prime}$ and $B^{\prime}$ the results after thrombolysis are shown. During A, plaque area was calculated as $8.37 \mathrm{~mm}^{2}$, $70 \% \mathrm{D}$ and $99 \%$ A. During $\mathrm{A}^{\prime}$, plaque area was reduced to $4.47 \mathrm{~mm}^{2}, \% \mathrm{D}$ to $39 \%$ and $\%$ A to $75 \%$. shown in figure 2 . In the 14 patients with an occluded artery before thrombolysis the angiogram after thrombolysis still showed total occlusion in 6 , while mean diameter and area stenosis in the remaining 8 patients was reduced to $54.8 \pm 4.5 \%$ and $78.1 \pm 7 \%$ respectively. Because of the small size of this group no statistical analysis was performed. However, in patients in whom reopening of a totally occluded coronary artery occurred after thrombolysis, less important stenoses were observed as compared to patients without total occlusion at the first angiography.

The ischaemia-related vessel was the LAD in 20/41 patients, the RCX in $12 / 41$ patients and the RCA in $9 / 41$ patients. The lesion was located in the proximal $1 / 3$ part of the vessel in $9 / 20$ patient with an obstructed LAD. The lesion was proximal to the obtuse marginal branches in 5 patients with a circumflex lesion, while in 2 patients with a RCA lesion the culprit lesion was found in the proximal part. The coronary morphologic findings are listed in Table 2 and figure 3.

The eccentricity score for all vessels analysed was 0.57 $\pm 12 \%$ with a median value of 0.52 . However several 
$10.5 \% \quad 28.9 \% \quad 394 \% \quad 212 \%$

Figure 3

Schematic drawings of the different configurations of coronary stenotic lesions with their occurrence percentage.
Discussion
TABLE 2

Distribution of ischemia related artery in all patients $(n=41)$ related to their eccentricity score.

$\begin{array}{lcc}\text { Coronary artery } & \text { Number Patients } & \text { Eccentricity sco } \\ \text { LAD (proximal) } & 9 & 0.74 \pm 23 \% \\ \text { LAD } & 11 & 0.69 \pm 24 \% \\ \text { RCX (proximal) } & 5 & 0.54 \pm 34 \% \\ \text { RCX } & 7 & 0.58 \pm 36 \% \\ \text { RCA (proximal) } & 2 & 0.41 \pm 7 \% \\ \text { RCA } & 7 & 0.50 \pm 28 \%\end{array}$

subgroups could be distinguished. In patients with proximal LAD lesions the eccentricity score was 0.74 $\pm 23 \%$ with a median of 0.82 , RCA lesions showed an eccentricity score of $0.50 \pm 28 \%$ with a median of 0.37 and lesions in the RCX showed a eccentric score of $0.54 \pm 34 \%$ and a median value of 0.47 .

Clinical follow-up showed a decline of symptoms in $26 / 41$ patients. There was no correlation between improvement of symptoms and reduction of diameter or area stenosis after thrombolytic therapy. During three months follow-up 6 patients underwent PTCA and $13 \mathrm{CABG}$. Also in this group no correlation could be found between angiogram and clinical outcome.

In this study we have evaluated the coronary anatomy of patients who presented with a form of "acute coronary syndrome", clinically diagnosed as "unstable angina pectoris". Coronary angiography was performed as soon as the patient was admitted to the coronary care unit. Admission delay as reflected by the wide range in time difference between onset of complaints and coronary angiography in our group of patients (between 2 and 69 hours) introduced, however, an important variable which unfortunately cannot be controlled, but should not be forgotten. As has been shown by several investigators, presence of thrombus or the ability to detect thrombus in the coronary artery is time dependent $(7,8)$.

The recent studies of Sherman et al with angioscopy illustrate the lack of sensitivity of the coronary angiogram to detect intracoronary thrombus formation (9). To compensate for this lack of sensitivity it may be important to include videodensitometry to analyze intracoronary filling defects and the results of throm- 
bolytic treatment. It is therefore important to define the type of analysis performed on the coronary angiogram when comparing studies in these patients. We used a sophisticated, automated system, able to analyse contours and stenoses of coronary arteries with high resolution which cannot be met by on-line digital systems.

As Ambrose et al, suggested in their studies a typical "type of stenosis" may be identified which predispones to the occurrence of an acute coronary syndrome (10). However, recent information on the role of thrombus in unstable angina pectoris, acute myocardial infarction and sudden death make it difficult to think that a true malignant stenosis can be identified with $100 \%$ sensitivity and specificity.

This study did not assess the functional significance of the stenosis after thrombolytic treatment but only defined coronary anatomy. However it is clear that because patients were admitted with an "acute coronary syndrome" the stenosis in the ischaemia-related vessel was functionally significant at the time of the first angiography. Interesting was our observation that not always the site of the coronary artery with the most severe cross-sectional area reduction was the culprit lesion. It is suggested that the moderate severity of the stenosis and the improvement of subjective complaints as observed in our patients suggest that a significant cross-sectional reduction is not mandatory for provoking an "acute coronary syndrome". It is difficult to understand why a $70 \%$ cross sectional stenosis in a coronary artery is not significant while the $20 \%$ stenosis of the opposite coronary artery may be the site of a total occlusion due to thrombus formation. Although such extreme examples may be rare, in our study, patients with a total occlusion tended to have less severe "rest-stenosis" after succesful thrombolytic treatment as compared to patients with $70 \%$ to $90 \%$ stenosis at their first coronary angiogram.

Can we then define a typical lesion as a "substrate" for this syndrome ? If we distinguish between the three coronary arteries in $49 \%$ of patients the LAD was involved, $29 \%$ the RCX and the RCA in only $22 \%$. Next to an increased incidence of involvement of the LAD, this study showed no significant difference in severity of coronary stenosis after thromboly- 
tic therapy between arteries. However, as can be concluded from Table 2, stenoses in the LAD are less eccentric as compared to stenoses in the RCX $(p<0.05)$ or RCA $(p<0.001)$. Whether mechanical factors play a role in the occurrence of the "acute coronary syndrome" was not studied. For the left coronary artery approximately half the lesions were present in the proximal part of the coronary system as opposed to $22 \%$ proximal lesions in the RCA.

Our data show that in patients with an "acute coronary syndrome", infusion of a thrombolytic agent does change coronary anatomy significantly in many patients. This suggests the presence of some degree of intracoronary thrombosis. Differences in our results compared to others $(5,6,10)$ may be explained by differences in resolution in computer analysis of the coronary artery and differences in time interval between onset of complaints and initiation of thrombolytic treatment. The left coronary system is predominantly involved in this syndrome. In approximately $50 \%$ of the patients a symmetrical lesion was present (mean value 0.57 ).

A combination of abnormalities in coronary anatomy and the presence of "thrombotic factors" is probably the basis for a "malignant" stenosis but at present coronary angiography is unable to identify these accurately.

1. Rentrop P, Blanke H, Karsch KR, Kaiser H, Kostering H, Leitz K.: Selective intracoronary thrombolysis in acute myocardial infarction and unstable angina pectoris. Circulation 1981; 63: 307-317.

2. Reiber J, Kooijman C, Slager C, et al: Computer assisted analysis of the severity of obstructions from coronary cineangiograms: a methodological review. Automedica 1984; 5 : 219-238.

3. Nichols A, Gabrich C, Fenoglio J, Esser P: Quantification of relative coronary arterial stenosis by cinevideodensotometric analysis of coronary arteriograms. Circulation 1984; 69: 512522.

4. Reiber J, Kooijman C, Slager C, et al: Improved densitometric assessment \% Area-stenosis from coronary cineangiograms. Abstr. X World Congress of Cardiology, Washington DC, 1986.

5. Hackett D, Davies G, Chierchia S, Maseri A: Intermittent coronary occlusion in acute myocardial infarction. Value of combined thrombolytic and vasodilator therapy. $\mathrm{N}$ Engl $\mathrm{J}$ Med 1987; 317: 1055-1059. 
6. Ambrose J, Winters S, Stern A et al: Angiographic morphology and the pathogenesis of unstable angina. J Am Coll Cardiol 1985; 5: 609-616.

7. Verstraete M, Bory M, Collen D, et al: Randomised trial of intravenous recombinant tissue type plasminogen activator versus intravenous streptokinase in acute myocardial infarction. Lancet 1985; 1: 842-847.

8. Yusuf S, Collins R, Peto R, et al: Intravenous and intracoronary fibrinolytic therapy in acute myocardial infarction: Overview of results on mortality, reinfarction and side-effects from 33 randomized controlled trials. Eur Heart $]$ 1985; 6: 556-585.

9. Sherman C, Litvak F, Grundfest W, ct al: Fiberoptic coronary angioscopy identifies thrombus in all patients with unstable angina (abstr.). Circulation 1985; 72 (suppl III): III-112.

10. Ambrose J, Hjemdahl-Monsen C, Borrico S, et al: Quantitative and qualitative effects of intracoronary streptokinase in unstable angina and non-q-wave infarction. J Am Coll Cardiol 1987; 9: 1156-1165. 
Johan H.A. Janssen, MD, Chris de Zwaan, MD

Frits Bär MD, Miek Havenith MD* and Hein J.J. Wellens, MD Departments of Cardiology and * Pathology, Academic Hospital Maastricht, University of Limburg, Maastricht, The Netherlands clinical and investigative tool to study coronary artery disease. It has been suggested, however, that the traditional methods of analysis and evaluation of the coronary arteriogram are inadequate, and several investigators have shown that there is considerable intraobserver and interobserver variability (1-3). The results of postmortem studies show a poor correlation between angiographic and anatomic findings (4-6), although that may have been influenced by the methods used (7-8). There is little controversy regarding the usefulness of coronary arteriography in recognizing severe high grade obstructions, however the potential of the coronary arteriogram to predict the hemodynamic significance of angiographically appearing mild to moderate stenoses remains controversial.

In the experimental animal the physiologic significance of artificially produced arterial stenoses has been extensively studied. Gould et al (9) produced varying degrees of coronary narrowing and showed that a short stenosis of more than $50 \%$ reduced coronary vasodilator response in a predictable fashion. Recently, Harrison et al (10) using a pulsed Doppler 


\section{Methods}

Figure 1

The characteristic electrocardiographic pattern of the patients studied. Panel A was recorded on admission. Note the ST segment elevation in leads V2 to V4 with terminal $\mathrm{T}$ wave negativity. Panel B was recorded 24 hours after the last attack of chest pain. Typically symmetrical negative $T$ wave inversion has developed. velocity probe showed a great overlap between abnormal vasodilator response and percent area stenosis in patients who underwent cardiac surgery. In this article we report the degree of percent area stenosis in patients who presented with a clinical picture of unstable angina and having an electrocardiographic pattern suggesting a severe stenosis in the proximal left anterior descending coronary artery (11).

\section{Patient selection}

Seventy patients with a diagnosis of unstable angina pectoris admitted to the coronary care unit of the Academic Hospital of the University of Maastricht were included in this study. All patients showed a characteristic electrocardiographic pattern consisting of initial slight ST-segment elevation in leads V1, V2 followed by the progressive development of marked $\mathrm{T}$-wave inversion in most precordial leads (figure 1). All patients underwent coronary arteriography with contrast left ventriculography within 2 weeks of admission (range 1 hour - 2 weeks, mean 4 days). They received 0,05 mg Fentanyl and 2,5 mg Droperidol before catheterization. Sublingual nitroglycerine ( 0.4 $\mathrm{mg}$ ) was given during the procedure in case of chest pain typical for angina pectoris. The Seldinger approach from the right femoral artery was used. Multiple views of the coronary arteries were obtained. Severity of lesions was quantitatively assessed using a
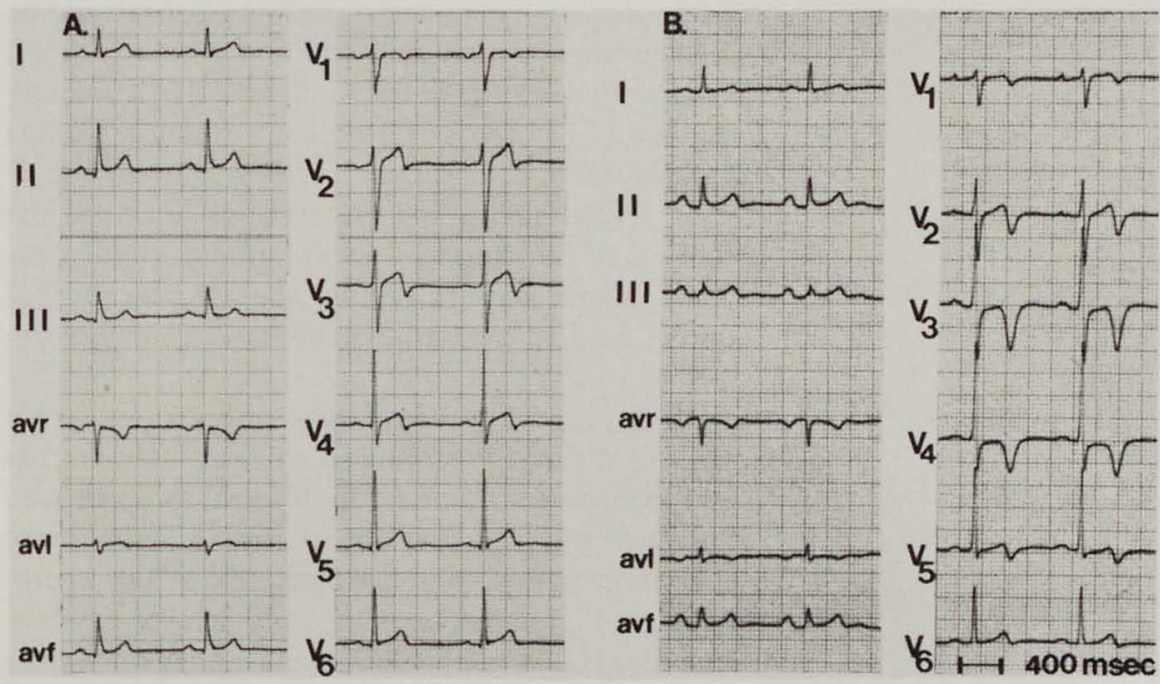
computer assisted measuring device called the Cardiovascular Angiography Analysis System (CAAS) (12).

\section{Quantitative coronary angiography}

Quantitative coronary angiography was performed using the computerized Cardiovascular Angiography Analysis System (CAAS). All steps taken during the measurement have previously been described in detail by Reiber et al (12).

Shortly, a $35 \mathrm{~mm}$ cineframe is selected in end diastole and digitized with a Charge Coupled Device camera at high resolution (1330 x 1770 pixels) and electronically a region of interest encompassing the arterial segment to be analyzed is selected for subsequent analysis by the computer. Contours of the arterial segment are detected automatically on the basis of the first and second derivative functions of the brightness profile, and as mentioned, corrected for pincushsion distortion. A calibration factor is derived from a computer processed segment of the angiography catheters. From the arterial contour data, a diameter function is computed. The minimal obstruction diameter and a reference diameter, estimated by computer after reconstruction of the "original" artery, are expressed in millimeters. The extent of the obstruction is determined from the diameter function on the basis of curvature analysis and expressed in millimeters. The difference in area between the reference and the detached contours over the lesion ("plaque area", in $\mathrm{mm} 2$ ) is a measure of the atherosclerotic plaque (13), which in the setting of unstable angina or acute myocardial infarction may include partially resolved thrombus. The severity of the obstruction can also be expressed as a percentage area obstruction. Assuming circular cross-sections at the obstruction and reference position, corresponding luminal areas are calculated. Using the reconstructed borders of the vessel wall the Cardiovascular Angiography Analysis System (CAAS) calculates a symmetry coefficient for the stenosis. Symmetry is defined as follows: the distance between the left-hand estimated contour at the obstruction position is called $\mathrm{dl}$, and similarly for the right-hand contours dr (see fig. 1, chapter 8 ). Then the symmetry measure is computed as the minimum of $\mathrm{dl}$ and $\mathrm{dr}$ divided by the maximum of $\mathrm{dl}$ and $\mathrm{dr}$. A 
Results

Figure 2

The number of patients are shown with their \% area stenosis at the time of catheterization. Although the range (due to a few patients) is quite large $(41 \%$ $-91 \%$ ), most patients were situated in the $80 \%$ stenosis group. symmetry measure of 1 denotes a concentric obstruction, the number decreasing with increasing asymmetry or eccentricity of the obstruction.

All seventy patients who entered the study underwent angiography. In nine patients the quality of the coronary angiograms was such that quantitative analysis of the film was not possible. This was mainly due to vessel overlap or insufficient density of the coronary artery segments involved. Of 61 patients analysed, 26 had single vessel disease, 18 patients two vessel disease and three vessel disease was found in 17 patients.

\section{Location of the stenosis}

The "culprit" stenosis (in view of the electrocardiographic pattern) was in all patients located in the proximal segment of the left anterior descending artery, the most distal location being at the site of a second diagonal branch.

\section{Severity of the stenosis}

Using quantitative analysis of the left anterior descending artery, mean area stenosis in the 61 pts analysed was $79 \% \pm 15.5 \%$ ( $\mathrm{SD}$, ranging from $41 \%$ $99 \%$ ). A distribution curve of the stenosis is shown in Figure 2. From this graph it can be concluded that in most patients the cross-sectional stenosis exceeded $70 \%$. According to the definition of Ambrose (16) we determined the "type" of stenosis. The used measurement was the degree of symmetry between stenosis and reconstructed vessel wall. Figure 3 is a schematic representation of the four types of stenosis
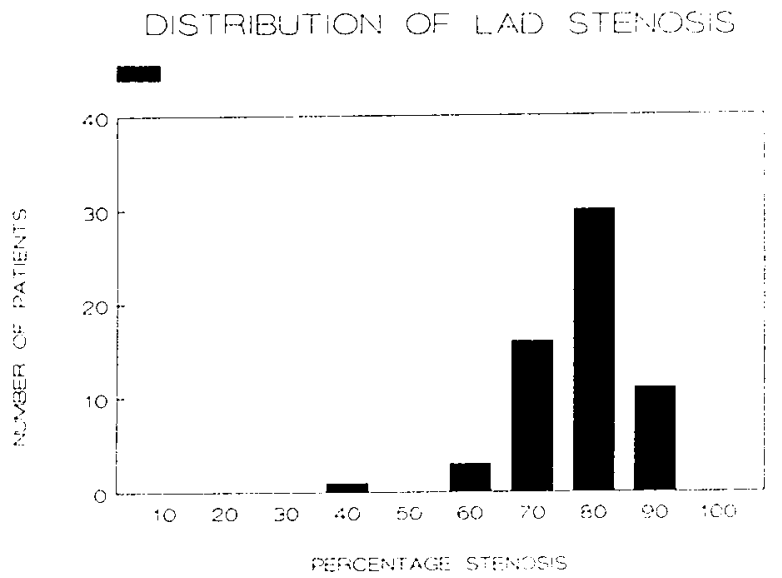
Discussion

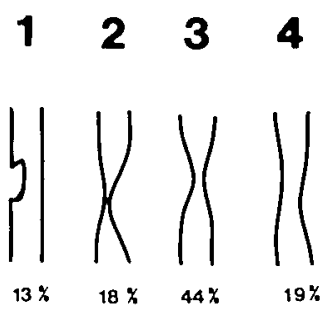

Figure 3

Distribution of the morphologic characteristics as found in the patients analysed with a proximal stenosis in the left anterior descending artery (see text). identified and their symmetry value according to CAAS.

In this series lesions with a mean value of the symmetry coefficient of 0.46 were present in $44 \%$ of cases, $31 \%$ showed lesions with a mean value of 0.14 , while a "smooth" tapering concentric lesion (mean value 0.87 ) was present in $19 \%$. Six percent of lesions could not be classified.

The study of de Zwaan (11) et al showed that approximately $20 \%$ of patients admitted to the coronary care unit because of unstable angina pectoris exhibit typical ECG changes which are combined with a severe lesion of the proximal part of the left anterior descending coronary artery. Patients with unstable angina and an important obstructive lesion of the left anterior descending coronary artery are considered to be at risk for sudden death or imminent myocardial infarction, particularly when the lesion is proximal to the first septal branch (14).

Evidence is increasing that formation of thrombus in a preexistent stenosis may play an important role in the "unstable angina syndrome" $(15,16)$. Our study confirms the observations of Ambrose and one could speculate about the relation between the type of coronary artery stenosis and the presence of coronary thrombosis as the possible cause of the presenting complaints. In two studies Ambrose $(17,18)$ showed that in patients admitted with unstable angina or acute myocardial infarction a characteristic lesion was found. Though the pathologic significance of this eccentric stenosis with a narrow neck is unknown, similar lesions on post mortem angiography have been shown to represent plaque rupture, plaque hemorrhage or a recanalized thrombus (19). Recognition of this subset of patients with unstable angina is therefore important also because of the expected value of PTCA and the possible role of thrombolytic therapy (16).

Mean delay between admission and coronary angiography was 4 days in our series. As already known, spontaneous resolution of thrombus may have been occurred during this period in as much as $40 \%$ of patients (20). Therefore accurate insight into the morphology during the "acute" event is limited. Although 
the value of lesion cross-sectional area determined by quantitative coronary angiography in assessing the physiologic significance of proximal left anterior descending coronary arterial stenosis is questionable (10), this study shows that the clinical-electrocardiographic picture of a proximal left anterior descending stenosis does predict the angiographic findings. We found that in the majority of patients the angiographic findings are within a narrow range and frequently suggestive for the presence of a disrupted atherosclerotic plaque or a partially occlusive or lysed thrombus, or both. However this last statement requires further confirmation. If from the electrocardiogram of this subset of patients with unstable angina the angiographic appearance can be predicted, institution of thrombolytic agents before coronary angiography may be warranted.

Conclusion

Our study shows that patients with unstable angina developing marked $\mathrm{T}$ wave inversion in the precordial leads, will most likely have a $70-100 \%$ stenosis in the proximal LAD. In our study approximately $30 \%$ of patients the morphology of the lesion suggests the presence of a thrombus. Further study is required to establish the true incidence of thrombosis and the possible value of thrombolysis.

References

1. Detre KM, Wright E, Murphy ML, Taharo T: Observer agreement in evaluating coronary angiograms. Circulation, 1975; 52: 979.

2. Zir LM, Miller SW, Dinsmore KE, Gilbert JP, Hawthorne $\mathrm{JW}$ : Interobserver variability in coronary angiography. Circulation 1976; 53: 4.

3. DeRouen TA, Murray JA, Owen W: Variability in the analysis of coronary arteriogram. Circulation 1977; 55: 324.

4. Vlodaver Z, French K, Van Tassel RA, Edwards JE: Correlation of the antemortem coronary arteriogram and the postmortem specimen. Circulation 1973; 47: 162.

5. Grondin CM, Dyrda I, Pasternac A, Campeau L, Bourassa MG, Lesperance J: Discrepancies between cineangiographic and postmortem findings in patients with coronary artery disease and recent myocardial revascularization. Circulation 1981; 49: 703 .

6. Isner JM, Kishel J, Kent KM, Ronan JA Jr., Ross AM, Roberts WC, Accuracy of angiographic determination of left main coronary arterial narrowing. Circulation 1981; 63: 1056.

7. Thomas AC, Davies MJ, Dilly S, Dilly N, Franc F: Potential errors in the estimation of coronary arterial stenosis from clinical arteriography with reference to the shape of the coronary arterial lumen. Br Heart J 1986, 55: 129-39. 
8. Murphy ML, Gatbraith JE, de Soyza W: The reliability of coronary angiogram interpretation: An angiographic-pathologic correlation with a comparison of radiographic vicws. Am Heart Journal May, 1979, vol 97, no. 5, 578-584.

9. Gould KL, Lipscomb K, Hamilton GW: Physiologic basis for assessing critical coronary stenosis: instantancous flow response and regional distribution during coronary hyperemia as measures of coronary flow reserve. Am J Cardiol 1974; 33 : 87.

10. Harrison DG, White CW, Hiratzka LF, Doty DB, Barnes DH, Eastham CL, Marcus ML: The value of lesion crosssectional area determined by quantitative coronary angiog. raphy in assessing the physiologic significance of proximal left anterior descending coronary arterial stenosis. Circulation 1984; 69: 1111.

11. De Zwaan C, Bär FWHM, Wellens HJJ: Characteristic electrocardiographic pattern indicating a critical stenosis high in left anterior descending coronary artery in patients admitted because of impending myocardial infarction. Am Heart $J$ 1982; 103: 730-735.

12. Reiber JHC, Serruys PW, Kooyman CJ et al: Assessment of short-, medium- and longterm variations in arterial dimensions from computer-assisted quantitation of coronary cineangiograms. Circulation 1985; 71:280.

13. Crawford DW, Brooks SH, Silzer RH, Brandt, R, Bechenbach ES, Blankenhorn DH: Computer densitometry for angiographic assessment of arterial cholesterol contents and gross pathology in human atherosclerosis. J Lab clin Med 1977; 89: 378-92.

14. National Cooperative Study Group: Unstable Angina Pectoris: National Cooperative Study Group to compare Medical and Surgical thcrapy IV. Results in patients with Left Anterior Descending Coronary Artery Disease. Am. J. Cardiol. 1985; 48: 517-524.

15. Lawrence JR, Shephard JT, Bone I, Royen AS, Fulton WFM: Fibrinolytic therapy in unstable angina pectoris. A control led clinical trial. Thrombosis research 1980; 17: 767-777.

16. de Zwaan $C$, Bär F, Janssen J, de Swart $H$, Vermeer $F$, Wellens H.J.J: Effects of thrombolytic therapy in unstable angina: clinical and angiographic results. J Am Coll of Cardiol 1988; 12: 301-309.

17. Ambrose JA, Winters SL, Stern A, et al: Angiographic morphology and the pathogenesis of unstable angina pectoris. $J$ Am Coll Cardiol 1985; 5: 609-16.

18. Ambrose J, Hjemdahl-Monsen C, Borrico S, et al: Quantitative and qualitative effects of intracoronary streptokinase in unstable angina and non-q-wave infarction. J Am Coll Cardiol 1987; 9: 1156-1165.

19. Levin DC, Fallon JT: Significance of the angiographic morphology of localized coronary artery stenoses. Histopathological correlations. Circulation 1982; 66:316.

20. Rentrop $\mathrm{K}$, Feit $\mathrm{K}$, Blanche $\mathrm{H}$ et al: Effects of intracoronary streptokinase and intracoronary nitroglycerine infusion on coronary angiographic patterns and mortality in patients with acute myocardial infarction. N Engl J Med 1984; 311: 1457. 


\title{
A critical evaluation of quantitative coronary angiography
}

\author{
Johan Janssen, MD, Pedro Brugada, MD and \\ Hein J.J. Wellens, MD, \\ Department of Cardiology, \\ Academic Hospital Maastricht, \\ University of Limburg, \\ P.O. Box 1918, 6201 BX Maastricht, \\ The Netherlands
}

Introduction

"The idea is to search for basic causes, which after all is what makes medicine a science.... One of my goals is to discover the laws of nature by making objective studies" (29)

Coronary angiography is the accepted gold standard for assessing coronary anatomy in vivo in patients with coronary artery disease. The visual interpretation of $35 \mathrm{~mm}$ coronary cineangiograms, however, is subject to large intra- and inter observer variability $(1,2)$. The recent development of new techniques in the catheterization laboratory such as PTCA, and the need to evaluate the effects of interventions on the regression or progression of coronary artery disease, made it necessary to develop more refined methods of measurement. Manual and digital calipers for measurement of coronary artery stenoses on cineangiograms were implemented $(3,4)$. The most significant improvement, however, was the development of computer assisted techniques to assess absolute coronary arterial dimensions from $35 \mathrm{~mm}$ cineangiograms. Recently, interest has been focussed on the prevention and regression of atherosclerosis by way of changing diet habits or affecting the lipid spectrum with medical intervention $(5,6,7)$. Since large scale investigations are being proposed to study the efficacy of these procedures and government budgets are being reserved for costly interventional programs, it seems essential to critically evaluate the present "gold standard" for study of coronary morphology and disease. 
A commercially available quantitative coronary analysis system (CAAS, Pie Data Medical, Maastricht, The Netherlands) was used for quantitative analysis of cineangiograms. This system has been described extensively by Reiber et al. $(8,9,10)$. Briefly, a $35 \mathrm{~mm}$ cineframe is selected in end diastole and digitized with a Charge Coupled Device camera at high resolution (matrix of the CCD camera is $2800 * 1700$ pixels, of the digitized cineframe $1330^{*} 1770$ pixels). A region of interest encompassing the arterial segment to be analysed is selected electronically for subsequent analysis by the computer. Contours of the arterial segment are detected automatically on the basis of the first and second derivative functions of the brightness profile and corrected for pincushion distortion. A calibration factor correcting for magnification is derived from a computer processed segment of the angiography catheters. A diameter function is computed from the arterial contour data. The minimal obstruction diameter and a reference diameter are estimated by computer after reconstruction of the "original" artery and expressed in millimeters. From the minimal value (Dm) of the diameter function at the site of the obstruction and the mean value (Dr) at a reference position, the percentage diameter reduction is computed as:

$$
\% \text { diameter stenosis }=(1-\mathrm{Dm} / \mathrm{Dr}) * 100 \%
$$

The extent of the obstruction is determined from the diameter function and expressed in millimeters. The CAAS system also computes a densitometric area stenosis $(10,11)$. The basic steps in the densitometric procedure to compute percentage cross-sectional area reduction of a selected lesion can be summarized as follows: The contours of a selected arterial segment are detected as described before. On each scanline perpendicular to the centerline, a profile of brightness values is measured. This profile is transformed into an absorption profile by means of the computed transfer functions. The background contribution is estimated by computing the linear regression line through the background points directly left and right of the detected contours. Subtraction of these background portions from the absorption profile within the arterial contours yields the net cross-sectional absorption pro- 

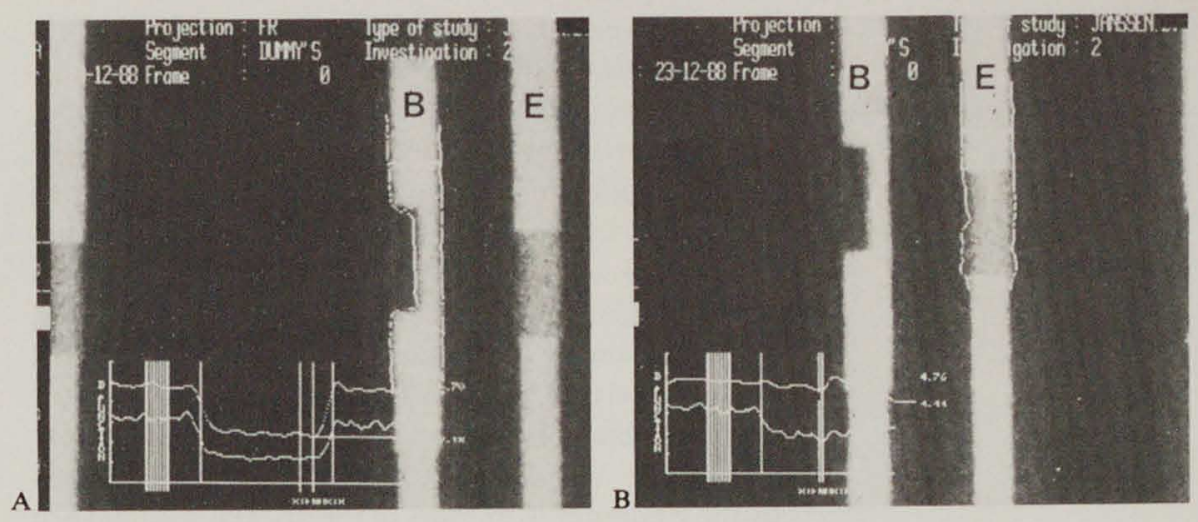

Figure 1

Analysis of one identical pair of the phantom study is shown. B is turned 90 degrees from $\mathrm{E}$. file. Integration of this function results in a measure of the cross-sectional area at the particular scanline. By repeating this procedure for all the scanlines, the cross-sectional area function is obtained. In case of an observer defined reference position comparison of the minimal value at the site of obstruction with the mean value at a selected reference position gives the percentage densitometric area obstruction at that particular site of the analysed vessel. If the observer does not define a reference position the computer will compare the minimal values obtained at the site of obstruction with a reconstructed absorption profile based on all information outside the obstructed segment.

To assess the performance of CAAS and the value of coronary angiography we have conducted four studies.

1. Six acrylate models were constructed. The models were identical two by two but turned 90 degrees from each other as to mimic different angels of visualisation of stenosis. The accuracy of the fabrication of two identical phantoms was within $0.05 \mathrm{~mm}$. Cinefilms of the six models of coronary arteries with their circular cross sections filled with pure contrast medium (Hexabrix $^{\mathrm{R}} 320 \mathrm{mgI} / \mathrm{ml}$, Byk, The Netherlands) were analysed (figure 1).

The phantom was filmed with the X-ray source at 50 $\mathrm{cm}$ from the phantom and the image intensifier at the levels $2 \mathrm{~cm}$ (projection 1), $4 \mathrm{~cm}$ (projection 2), $10 \mathrm{~cm}$ (projection 3 ), and $20 \mathrm{~cm}$ (projection 4) all in the posterior anterior direction. The effect of angulation was tested by both RAO and LAO 20 degrees angulation with an image intensifier height of $20 \mathrm{~cm}$ (projec- 
* The catheter used was a 7 French polyurethane catheter (Cordis Corp., Miami, Florida, USA). tions 5 and 6 , respectively). The orientation of the phantoms was north-south, so that during angulation the axis of the phantom was perpendicular to the $\mathrm{X}$-ray housing. During filming a $2 \mathrm{~cm}$ aluminium filter was used. The pulse width of the X-ray was kept constant at 2 msec. The field of view of the image intensifier was 6 inch. Following the clinical procedures a 7 French catheter* filled with the contrast agent was filmed in the same field of view in order to callibrate the geometric magnification. The $\mathrm{X}$-ray system used was a Siemens Cardioscope U-arm with a Pandoros generator. The relation between iodine volume and X-ray absorption is approximately logarithmic (Lambert Beer's law). Film characteristics, however, influenced by the concentration of the iodine flow in the coronary artery and changing $\mathrm{X}$-ray parameters, influences this relation so we have repeated the study under slightly different circumstances. Using the same model we used Hexabrix $160 \mathrm{mgl} / \mathrm{ml}$ and Iopamiro $370 \mathrm{mgI} / \mathrm{ml}$ ( Dagra, The Netherlands) as contrast agents while body mass was resembled by using a filter of $2 \mathrm{~cm}$ of aluminium and $1 \mathrm{~mm}$ copper. The fantom itself was placed on $8 \mathrm{~cm}$ blank paper. For this study the $\mathrm{X}$-ray setting was identical as in projection 1.

2. In vivo validation was performed as follows: A teflon tube with a length of $1.3 \mathrm{~cm}$, internal diameter of $0.91 \mathrm{~mm}$ and an external diameter of $2 \mathrm{~mm}$, was inserted through an arteriotomy in a coronary marginal branch of a mongrel dog. Over the proximal and distal portion of the cylinder a suture was placed to ensure that no contrast could flow between the vessel wall and outer part of the cylinder. Under stable hemodynamic conditions the chest was closed. Coronary cineangiography was performed (figure 2) using the same system as described above with a 6 inch image intensifier. The contrast used was Hexabrix ${ }^{R}$ $320 \mathrm{mgI} / \mathrm{ml}$, power injected with a volume of $6 \mathrm{ml}$ at a flow rate of $2 \mathrm{ml} / \mathrm{sec}$. Images were acquired at a frame rate of $25 \mathrm{frames} / \mathrm{sec}$. During the whole procedure the dog was treated with Lidocaine, natriumbicarbonate, oxygen and 3000 IU heparine to prevent clotting of the cylinder. The cine film was quantitatively analysed using CAAS. 

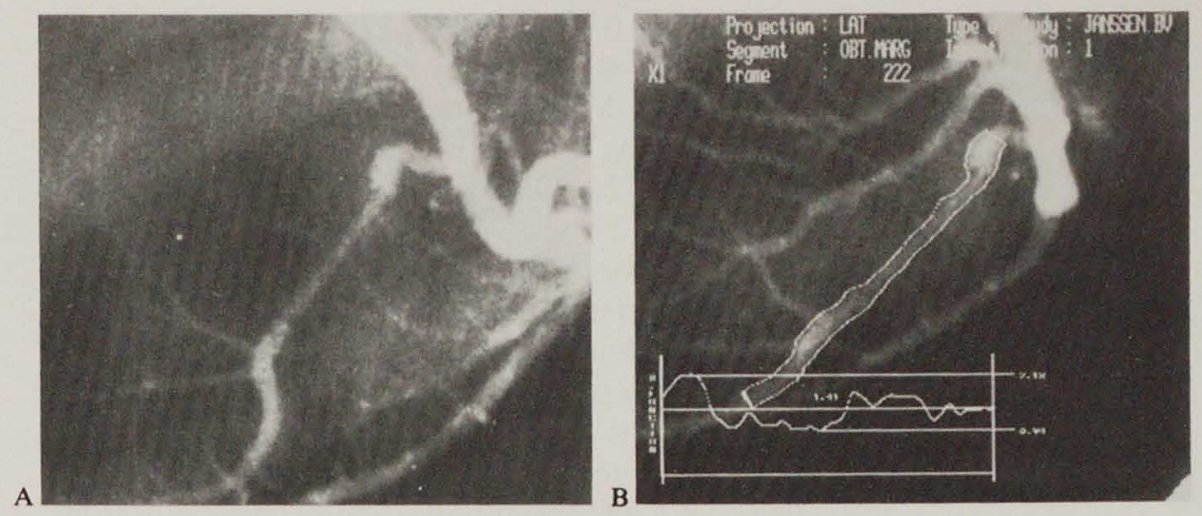

\section{Figure 2}

The left coronary system of the mongrel dog is shown. The teflon tube was inserted in a marginal branch (arrow). Panel $A$ and $B$ is cine angiography, panel $\mathrm{C}$ digital angiography using $512 * 512$ acquisition and twofold magnification.

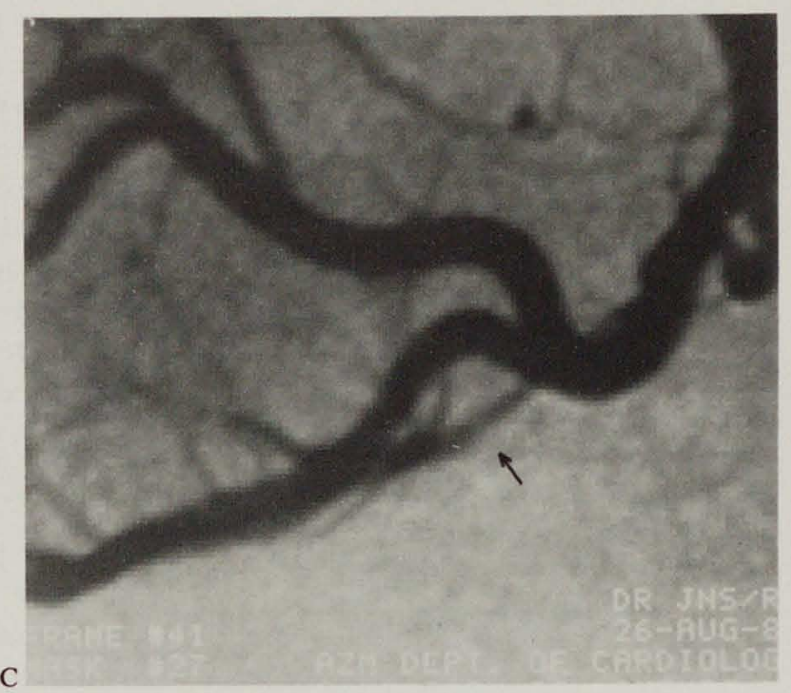

3. Quantitative analysis of the coronary artery from cinefilm and the results of post mortem examination were compared in two patients to assess the accuracy of quantitative coronary angiography in the study of coronary morphology. Patient 1 was a 60 year old male with impending myocardial infarction and severe 3 vessel disease, including a $60 \%$ left main lesion. During the infusion of a thrombolytic agent the patient died of hemorrhagic tamponade. Patient 2 was a 65 year old male admitted with a large anteroseptal myocardial infarction. After intravenous administration of a thrombolytic agent coronary angiography was performed. A hypodensity at the site of the left main coronary artery and proximal left anterior descending coronary artery was interpreted as thrombo- 
sis. During insertion of a balloon pump the patient deterioated and died in pump failure. In both cases post mortem examination was carried out within five hours after the patients died. Since macroscopic visual assessment of the degree of stenosis is inaccurate and not highly reproducible $(12,13,14)$, even under optimal conditions, a modified technique from the one described by Thomas and Davies was used (15). Briefly, the aorta just above the the coronary arteries is cannulated and injected with a warm gelatine solution at a pressure of $\pm 100 \mathrm{mmHg}$. After the ligature around the aorta above the artery is tightened, the heart is frozen and fixed in $10 \%$ formaline for 48 hours. The epicardial right and left coronary arteries are then dissected intact from the heart with surrounding tissue. They are decalcified for at least 24 hours after which the desired segments can be processed for histological examination. The right and left coronary arteries were divided into 41 segments. From each segment a $1 \mathrm{~mm}$ slice was processed for histological examination. Diameter and percent area stenosis was judged by two observers from photographic enlargements after which a morphometric planimetry measurement was performed. Quantitative analysis of the cine film was performed using CAAS and compared with the morphometric measurements. Post mortem flushing with contrast medium and subsequent cinefilming was not possible.

4. In 4 patients with proximal disease of the left descending coronary artery, catheterization was performed using a modified Judkins technique. The left coronary artery was visualized using a 7 French catheter. Nine milliliters of contrast material was injected at a flow rate of $4 \mathrm{ml} / \mathrm{sec}$. Film frame acquisition was performed at 25 frames/sec. Before angiography all patients were on oral nitrates, $b$-blockers and calcium entry blockers. During the investigation all patients received intracoronary administration of nitroglycerine. The coronary artery was filmed in several projections, however, only the projection in which the stenosis was judged visually as most severe was analysed with CAAS. During cineangiography a ECG cinefilmmarker (16) was used to indicate the $\mathrm{R}$-wave of the electrocardiogram on the cinefilm. Frame to frame analysis was performed for two car- 
Results

TABLE la

\begin{tabular}{|c|c|c|c|c|c|c|c|c|}
\hline \multicolumn{2}{|c|}{ Projection } & 1 & 2 & 3 & 4 & & 6 & Mean + SD \\
\hline \multicolumn{9}{|c|}{ Phantom } \\
\hline \multirow[t]{2}{*}{ A } & $\% \mathrm{D}$ & 60 & 59 & 58 & 57 & 60 & 54 & $58.0 \pm 2.3$ \\
\hline & $\% \mathrm{~A}$ & 52 & 62 & 63 & 53 & 61 & 48 & $56 . \pm 6.2$ \\
\hline \multirow[t]{2}{*}{ B } & $\% D$ & 57 & 58 & 52 & 53 & 52 & 58 & $55.0 \pm 2.9$ \\
\hline & $\% \mathrm{~A}$ & 61 & 65 & 64 & 47 & 50 & 50 & $56.1 \pm 8.0$ \\
\hline \multirow[t]{2}{*}{$\mathrm{C}$} & $\% \mathrm{D}$ & 62 & 56 & 58 & 56 & 56 & 58 & $57.6 \pm 2.3$ \\
\hline & $\% \mathrm{~A}$ & 71 & 74 & 75 & 64 & 74 & 71 & $71.5 \pm 4.0$ \\
\hline \multirow[t]{2}{*}{$\mathrm{D}$} & $\% D$ & 48 & 46 & 42 & 42 & 44 & 62 & $45.6 \pm 3.8$ \\
\hline & $\% A$ & 46 & 60 & 57 & 49 & 55 & 53 & $53.3 \pm 5.1$ \\
\hline \multirow[t]{2}{*}{ E } & $\% D$ & 10 & 7 & 12 & 10 & 7 & 0 & $7.6 \pm 4.2$ \\
\hline & $\% \mathrm{~A}$ & 37 & 32 & 41 & 38 & 41 & 37 & $37.6 \pm 3.3$ \\
\hline \multirow[t]{2}{*}{$\mathrm{F}$} & $\% \mathrm{D}$ & 58 & 57 & 78 & 59 & 58 & 57 & $57.8 \pm 0.7$ \\
\hline & $\% \mathrm{~A}$ & 69 & 79 & 75 & 75 & 77 & 72 & $74.5 \pm 3.5$ \\
\hline
\end{tabular}
pared within each model. For diameter stenosis, with- diac cycles in each patient. CAAS determined the diameter function of the vessel of each separate frame. The diameter of the coronary artery at the $\mathrm{R}$ wave frame indicated by the ECG marker was compared to the mean diameter of the analysed segment.

1. The result of CAAS analysis of the phantoms studied are given in Table 1. Diameter stenosis and the densitometric determined area stenosis were comin a model a mean difference of $10.6 \% \pm 5.7$ (SD) with a range of $6 \%-20 \%$ was observed. For densitometric determined area stenosis variation within a model was found to have a mean difference of $12.8 \%$ \pm 3.43 (SD) with a range of $9 \%-18 \%$. Analysis of two identical phantoms revealed no statistical difference between $A$ and $D$ or $C$ and $F$. Comparison of phantom $B$ and $E$, however, revealed a significant difference $(p<0.01)$ between both the diameter stenosis as well as the densitometric determined area stenosis. Influence of angulation alone of the image intensifier (projections 5 and 6 ) on the quantitative measurements are represented by the mean difference for diameter stenosis of $6.6 \% \pm 6.0(\mathrm{SD})$, range $1 \%-18 \%$ and for the densitometric determined area stenosis by the

Phantom $\mathrm{A}=\mathrm{D}, \mathrm{B}=\mathrm{E}$ and $\mathrm{C}=\mathrm{F}, \% \mathrm{D}=$ percent diameter stenosis,

$\% A=$ densitometric area stenosis. For explanation of projections $1-6$ see text. 


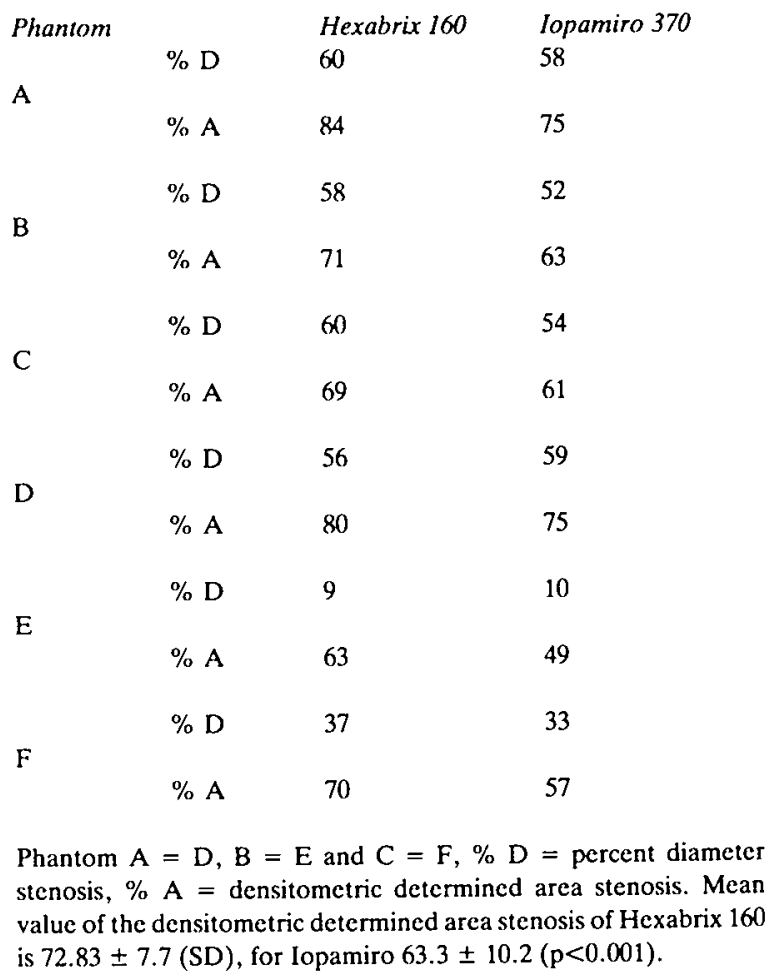

mean difference of $4.5 \% \pm 4.3(\mathrm{SD})$ with a range of $0 \%-13 \%$ (Table $1 \mathrm{~A}$ ). Table $1 \mathrm{~B}$ shows the results of the phantom analysis with low contrast and $\mathrm{Al} / \mathrm{Co}$ / paper filtering of the X-ray beam.

Between Hexabrix $160 \mathrm{mgI} / \mathrm{ml}$ and Iopamiro $370 \mathrm{mgV} /$ $\mathrm{ml}$ no significant difference exists as CAAS uses only diameter functions for determination of stenosis. For the densitometry, however, there does exist a significant difference in analysis $(p<0.001)$. It can be concluded that although Lambert Beer's law can be applied the discussed influencing parameters ( film development etc) are critical.

2. The results of the in vivo validation are shown in figure 3 . The internal diameter of the teflon tube is $0.91 \mathrm{~mm}$, the outer diameter $2.00 \mathrm{~mm}$. The minimal diameter as determined by CAAS is $0.88 \mathrm{~mm} \pm 0.05$ 
Figure 3

Quantitative analysis using CAAS of the diameter of the lumen of the teflon tube (figure 2) over one cardiac cycle as compared to the real luminal diameter of the teflon tube.
Variation in diameter of tefion tube during cardiac cycle.

- segment 2-..-segment 2 Tube minimal $D$ mean $D$ minimal $D$

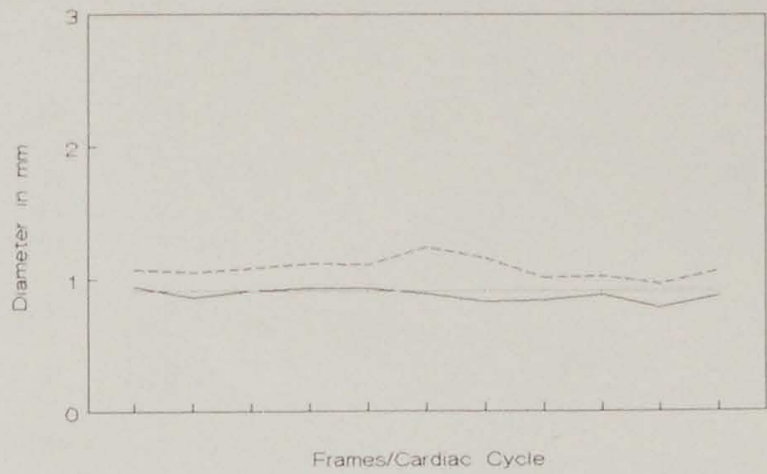

(SD), while the mean diameter was calculated by CAAS as $1.08 \pm 0.08$ (SD). Irrespective of degrading factors such as veiling glare, focus of the X-ray, development factors involving cine film development, the accuracy of CAAS to determine in vivo diameters is within the range of $0.1 \mathrm{~mm}$ as previously found by Reiber et al (8). Note, however, the absence of diameter variation in the teflon model during frame to frame analysis as opposed to the analysis of coronary arteries in man (study 4).

3. The results of the comparison of quantitative measurement of the left descending coronary artery in vivo and in vitro, as well as the estimation of coronary disease from in vivo measurements as compared to post mortem examination are presented in figures 4 and 5. Figure 4 represents the obtained values for minimal, mean and maximal determined diameter by CAAS $(1.91 \mathrm{~mm} \pm 0.37 ; 2.48 \mathrm{~mm} \pm 0.53 ; 3.09 \pm$ 0.81 ) and the maximal diameter as it was obtained from morphometric examination of the post mortem specimen $(2.25 \mathrm{~mm} \pm 0.76)$. The mean deviation of CAAS from post mortem analysis was $0.33 \mathrm{~mm}$ for the minimal CAAS value, $0.06 \mathrm{~mm}$ for the mean and 0.84 for the maximal CAAS determined diameter.

Using morphometric technique the actual lumen of the coronary artery was measured and compared to the atherosclerotic plaque. The atherosclerotic plaque was expressed as percentage obstruction of the 
acutal lumen over the length of the left descending coronary artery. The corresponding diameter function of the left descending coronary artery as determined by CAAS was used to compute an area stenosis assuming a circular lumen of the coronary artery. This was then compared with the morphometric determined percentage obstruction. It is demonstrated that there exists no close relation between the extent of the atherosclerotic plaque and the diameter function or area reduction of the lumen of the coronary artery.

4. Frame to frame analysis of the left descending coronary artery was performed during one cardiac cycle. The cardiac cycle was determined by an ECG triggered cinefilm marker. In 4 patients two cardiac cycles were analysed. The result of such an analysis is shown in figure 6 . Frame number 1 and 27 are the frames identified by the ECG trigger. The difference in diameter ( in $\mathrm{mm}$ ) between frame 1 and 27 was computed as percentage of the mean diameter of all analyzed frames. The results of all patients combined are presented in Tables 2 and 3. From these data it is concluded that during the heart cycle the diameter of the coronary vessel can variate with $7.5 \%$ to $46.8 \%$ depending on the measured segment. At end diastole (as marked by the ECG triggered marker) a variation in diameter measurement can occur ranging $0 \%$ to $29.9 \%$ compared to the mean diameter of the coronary artery during the cardiac cycle.

Figure $4 \mathrm{~A}$

The correlation is shown between in vivo measurement of the proximal left coronary system with CAAS, and morphometric determined diameter of the post mortem specimen.
Caas/min …... Caas/max -.- Caas/mean Post mort

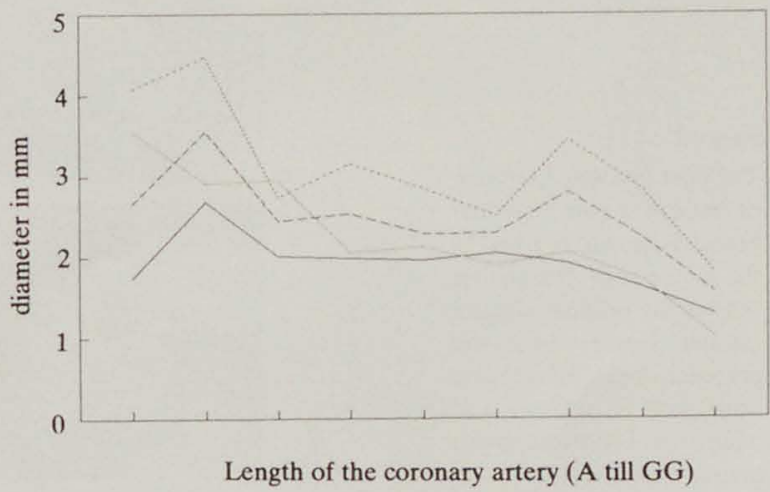




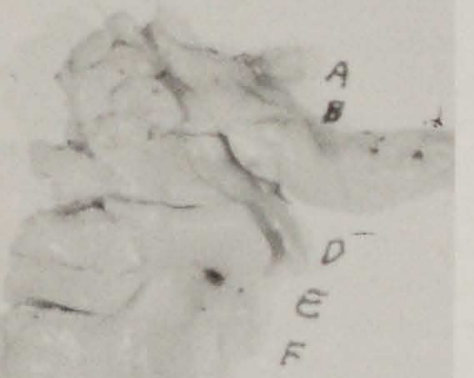

A
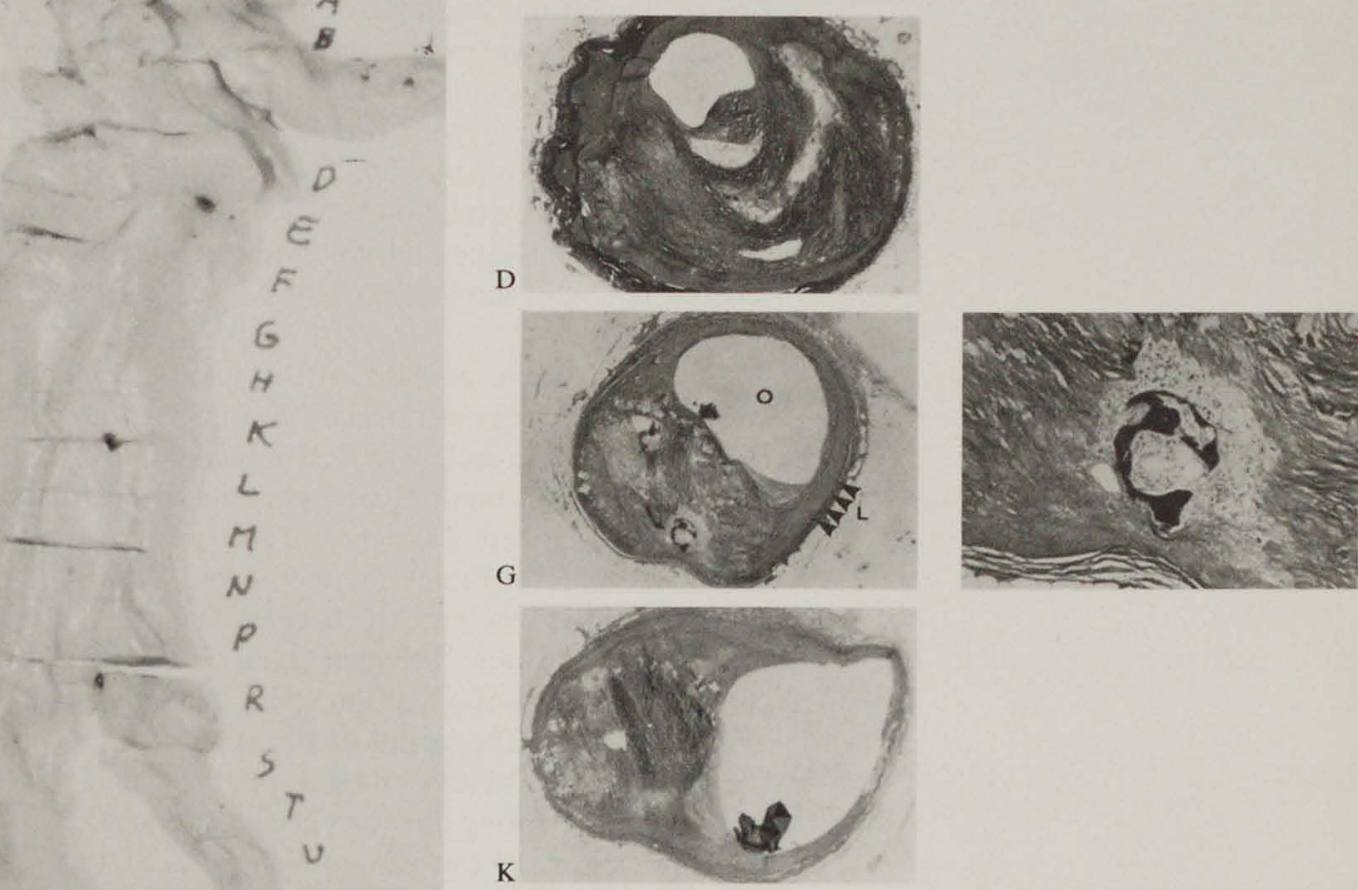

W

Figure $4 B$

The post mortem specimen of the LAD and Diagonal branch is shown. In panel $G$ the lumen is $\mathrm{O}$, the arrows outline the original elastica interna. Interesting is the presence of metaplastic bone with fatty tissue and haematopoetic tissue in the plaque (see inlay).
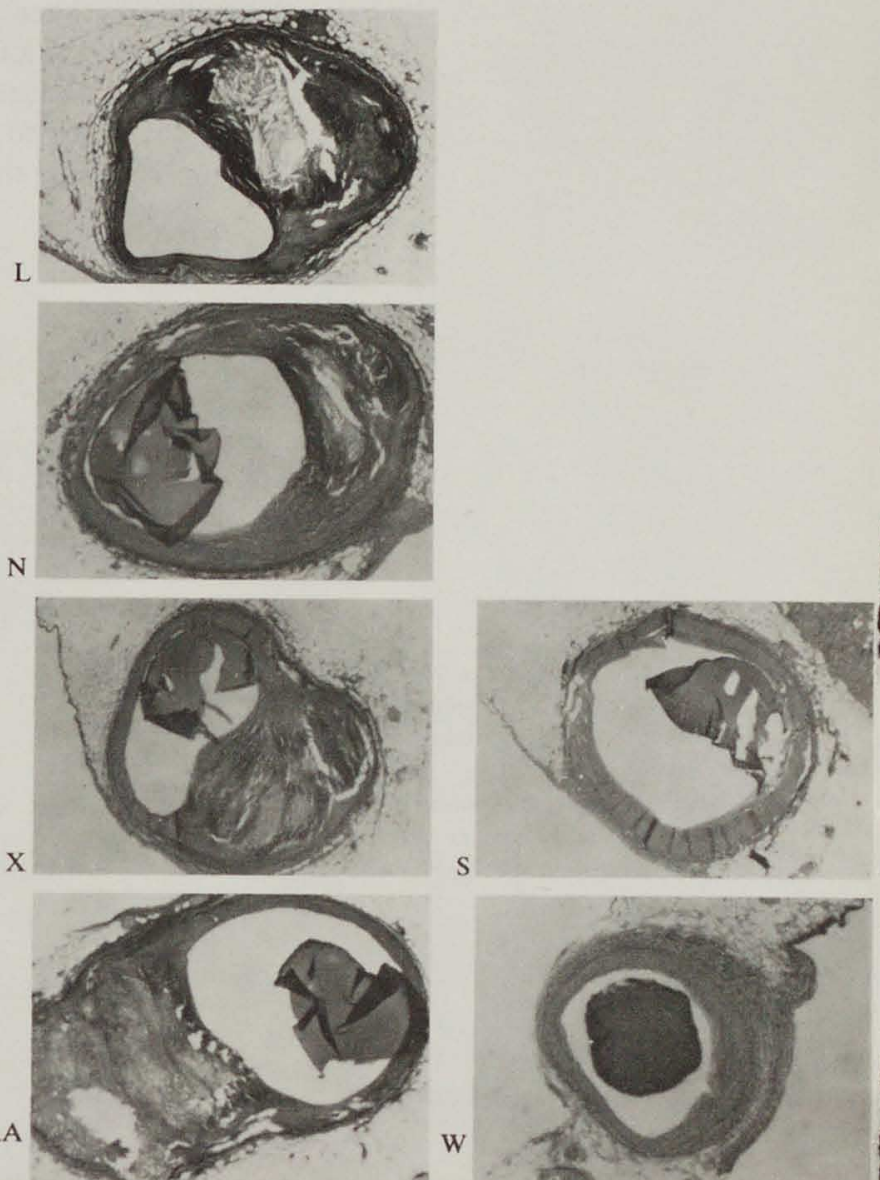


\section{TABLE 3}

Percent difference from the mean diameter $( \pm S D)$ at end-diastole

$\begin{array}{lr}\text { Pt. number } & \text { Mean } \pm S D \\ 1 & 23.09 \pm 19.75 \\ 2 & 14.48 \pm 12.16 \\ 3 & 7.54 \pm 9.53 \\ 4 & 46.83 \pm 5.93\end{array}$

Figure 5

The morphometric determined percent atherosclerotic plaque as compared to the original elastica interna is shown, and compared with the quantitative determined diameter function (see also figure 4). There exists no close correlation between distribution or severity of the atherosclerosis and the observed luminal diameter of the coronary artery.

\section{Figure 6}

Frame to frame analyses of the left anterior descending coronary artery over one cardiac cycle is shown. Frame 1 and 27 were identified by the ECG trigger.
TABLE 2

$\begin{array}{lllllll}\begin{array}{l}\text { Segment } \\ \text { Patient }\end{array} & 1 & 2 & 3 & 4 & 5 & \text { Mean }+S D \\ 1 & 13.29 & 6.4 & 3.6 & 8.3 & 5.17 & 7.35 \pm 3.7 \\ 2 & 10.31 & 0.0 & 7.4 & 11.8 & 5.1 & 6.92 \pm 4.6 \\ 3 & 19.67 & 29.9 & 9.4 & 13.2 & 31.9 & 20.4 \pm 10.5 \\ 4 & 9.09 & 7.49 & 6.8 & 1.14 & 13.6 & 7.62 \pm 4.4\end{array}$

Of each coronary segment ( 1 to 5 ) of the 4 studied patients the maximal percentage deviation occurring in one cycle is given. The value mean \pm SD refers to the average deviation over the whole arterial segment in one patient. post-mortem

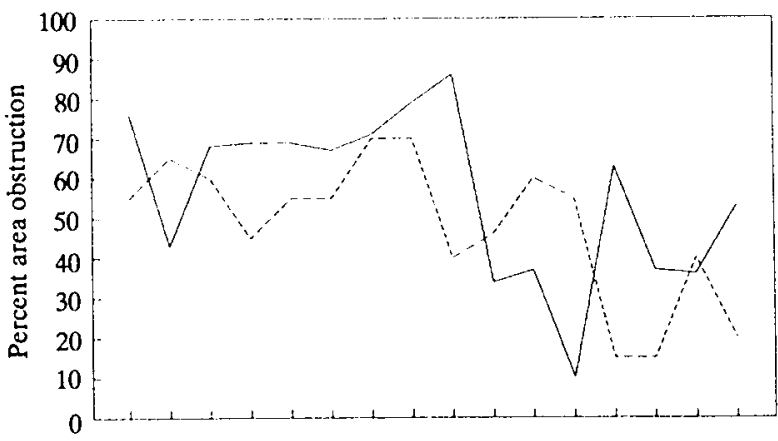

Length of the analysed segments LAD
- SEGMENT 5 pre-treat

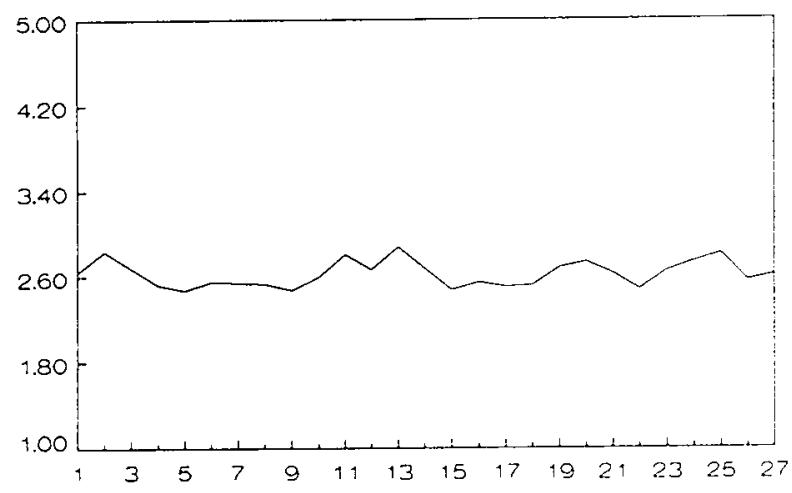



nosis may underestimate or overestimate the degree of narrowing as is shown in several investigations $(2,3,4)$. To cope with this inaccuracy of visual interpretation, quantitative coronary angiography was advocated as a step forward to more precise and reproducible measurements. Digitized cine angiograms have the advantage of high resolution as compared to on-line digital systems.

We conducted four studies to determine the 1) variation in quantitative measurements on an acrylate model, due to slight alterations in distance and angulation of the X-ray system 2) the in vivo validation of the CAAS, to evaluate the random effects of the $\mathrm{X}$-ray equipment (scatter, veiling glare etc.), 3 ) the relation between the quantitative assessed lumen of the coronary artery and actual (post mortem) assessment of coronary atherosclerosis and 4) analysis of variation in diameter of coronary arteries in man. What did we learn?

The phantom studies confirm earlier studies by Reiber et al (8) in which it is shown that diameter assessment of coronary artery lumen dimensions are reproducible and accurate. Within $0.1 \mathrm{~mm}$ the CAAS system is able to correctly identify the lumen of the coronary artery. In this study, however, we were not interested in the absolute measurement of the diameter of the phantom. We wanted to study the reproducibility of the measurement with varing the orientation of the phantom towards the X-ray beam, and identify a possible influence on the measurements by slight variation of the position of the image intensifier towards the phantom. It is shown that within a model the variations in stenosis measurements are minimal .The densitometric evaluation, however, did not always correlate as well as compared to the diameter function with the actual lumen of the coronary artery. As is demonstrated in table 1 densitometric estimation of "coronary stenosis" did not differ significantly from diameter function assessment of stenosis in the same model, while turning the phantom 90 degrees did result in significant changes between the pairs of identical models. A possible explanation for this result may be the occurence of veiling glare and focus unsharpness but an incorrect positioning (not exactly perpendicular to the $\mathrm{X}$-ray) of the phantoms is not 
excluded. Lambert-Beer's absorption law predicts proportionality between a layer of thickness of contrast medium inside the coronary artery (d) and the resulting logarithmic attenuation of the concerned $\mathrm{X}$-ray beam element:

$$
\log (\mathrm{I} \text { incident })-\log (I \text { transmitted }(t))=\bar{a} \times d
$$

where I is the intensity of the beam element; a represents a constant factor related to the tissue characteristics. Several investigators, however, have shown that this relationship is actually not always linear $(17,18)$. In fact, our results indicate that the densitometric analysis of coronary artery stenosis is not only inaccurate, but also that there exist a dependence on orientation of the stenosis towards the X-ray beam and concentration of iodine in the contrast used. Others believe that also the diameter of the coronary artery and the size and shape of the stenotic lumen are determinants of the inaccurate behavior of conventional densitometry (18). Also the occurence of beam hardening due to more absorption of the $\mathrm{X}$-ray when higher concentrations of iodine are used influences the Lambert-Beer relationship and thus the results. It must be noted, however, that in our study we could not account for differences in visual shortening and differences in film characteristics (saturation) and development.

Assuming optimal conditions, densitometry has as a single parameter the best definition of the actual lumen of the coronary artery ( figure 7). The question which raises is whether the densitometrically constructed arteries and myocardial outline represent true (inadequate) filling of the artery due to atherosclerotic plaque or whether it is caused by "system noise". If from coronary angiograms morphologic features are to be determined, associated with ruptured plaques, ulceration or subintimal hemorrhage (19-23) these findings may have a significant impact on the way quantitative coronary angiography (including densitometry) has to be performed and interpreted.

In man, X-ray parameters and cine development procedures may interfere with the detection of the actual diameter function of the coronary artery. We con- 


\section{Figure 7}

A digital angiogram of the left coronary system is shown. In panel A the circumflex artery is within the region of interest. The detected iodine is related to the volume that passed through the lumen of the circumflex artery at that particular time (second cardiac cycle).

One cycle later the contrast entered the myocardium (B) and perfused it (C).

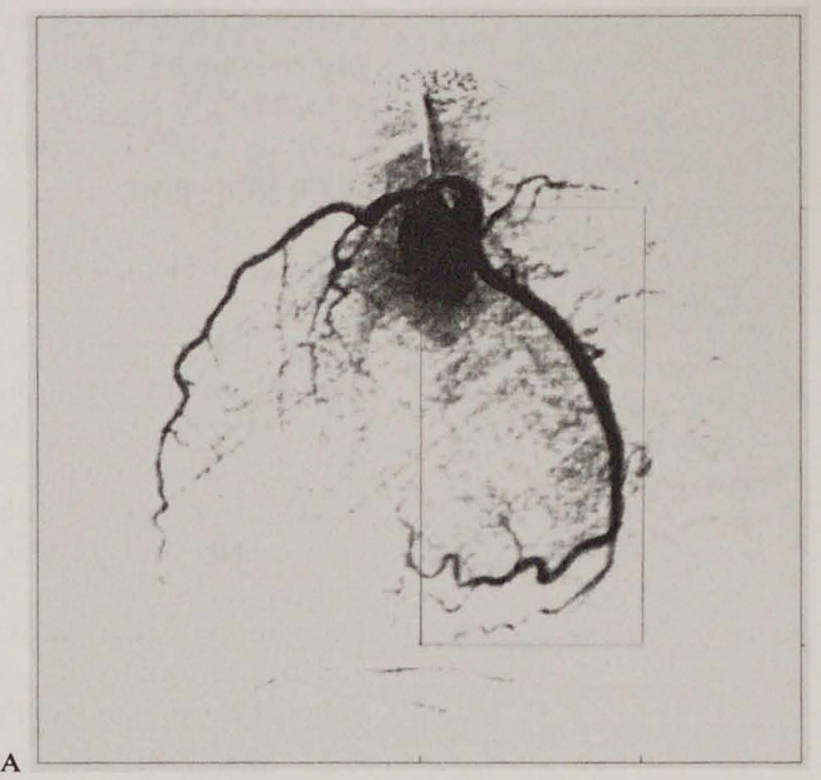

C

ORg800367. IMG

Inage 4 Hask 2

xrange - 256 - 405

$\mathrm{npx}:$

$n p x=1$
sinorg: -418

anxorg $=62$

$=\sin =8$
$\operatorname{sox}=-418$

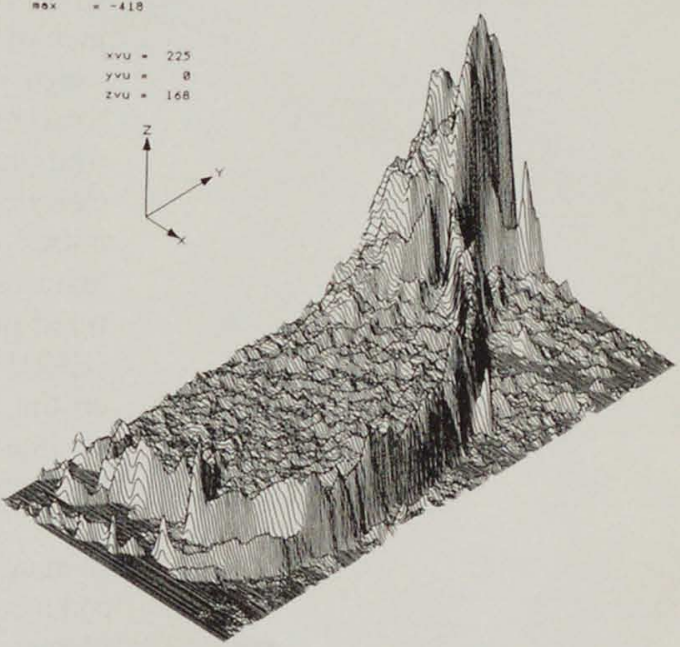


ducted the second study to evaluate CAAS including these factors. It can be concluded that irrespective of the above mentioned influences, the accuracy of CAAS in detecting the diameter function of the "coronary artery" (teflon tube) stays good within the 0.1 mm range. A second observation can be made in this study. The minimal variation in diameter of the teflon tube as compared to the variations observed in man (see study four) may exclude pulsatile flow or insufficient mixing of the contrast agent with the blood in the coronary vessel as the major determinant of this variation. It is postulated that coronary vasomotor tone may play an important role in the frame to frame variation of the coronary artery dimension (24).

The third study provides a clear perspective of the limitations of coronary arteriography. Others have documented the limitations of coronary arteriography as currently practised, using other techniques $(25,26)$. Our study indicates that variations of atherosclerosis, shape of the lumen, presence of intraluminal thrombosis etc. may be undetected by the angiography since the lumen may present itself differently in the different projections analysed. This variation cannot be detected unless different techniques are applied aiming at visual inspection (27) or functional significance (28). This suggests that quantitative coronary angiography alone may not be sufficient for the study of changes in stenosis of coronary arteries over time.

The fourth study addresses the problem of beat to beat variation and variation within a cardiac cycle of the coronary artery due to beating and rotation of the heart, respiration, pulsatile flow, blood pressure, position, central nerve influence, medication, intrinsic vasomotor tone, sludging of contrast, etc. If we can conclude from study one and two that analysis by CAAS is accurate although dependent on parameters such as identical position of the patient, concentration of iodine in the contrast material used, identical X-ray parameters etc, then the variations as observed seemed to be caused by instrinsic vessel movement and may as such disclose the amount of arteriosclerosis. For comparative studies of coronary morphology and disease this may mean that frame to frame analysis during one cardiac cycle is compulsatory next to 
Conclusion

References study of functional behavior of the coronary system investigated. Above all, it is crucial to define the methods used when reporting study results and great care should be taken in proper standarization of procedures.

From the above mentioned studies we can conclude that the bottomline for clinicians is to critically analyse all arteriograms, which must include multiple angles of view, and to be as certain as possible that it all fits with the individual patient. In a research setting, however, quantitative coronary angiography is critical to assess coronary morphology and study coronary artery disease in man. From the validation studies in man, however, it seems that the "gold" standard of coronary arteriography is "bronze" at best. Quantitative analysis including frame to frame analysis as well as the adjuvance of the determination of functional capacity of the coronary system may be necessary to upgrade the standard to "silver".

1. Detre KM, Wright E, Murphy ML, Takaro T: Observer agrecment in cvaluating coronary angiograms. Circulation, 1975; 52: 979.

2. Zir LM, Miller SW, Diwsmore KE, Gilbert JP, Hawthrone JW: Interobscrver variability in coronary angiography. Circulation, 1976; 53: 4.

3. Feldman RL, Pepine CJ, Curry RC, Conti CR: Quantitative coronary angiography using $105 \mathrm{~mm}$ photospot angiography and an optical magnifying device. Cath Cardiovasc Diagn, 1979; 5 : 195.

4. Scoblionko DP, Brown S, Mitlen S, Caldwell JH, Kennedy W, Bolson EL, Dodge HT: A new digital electronic caliper for measurement of coronary arterial stenosis: comparison with visual estimates and computer-assisted measurements. Am J Cardiol 1984; 53: 689 .

5. Arntzenius A, Kromhout D, Barth J, Reiber J, Brüschke A, Buis B, Gent C, Kempen-Voogd N, Strikwerda S, Velden E: Diet, lipoproteins and the progression of coronary atherosclerosis. The Leiden Intervention Trial. N Engl J Med 1985; 312 : 805-811.

6. Schwartz L, Bourassa M, Lespérance J, Aldrigde H, Farouk K,Salvatori V, Henderson M, Bonan R, David P: Aspirin and Dipyridamol in the prevention of restenosis after percutaneous transluminal coronary angioplasty. $N$ Engl J Med 1988; 318: 1714-1719.

7. Sigwart U, Puel J, Mirkovitch V, Joffre F, Kappenberger L: Intravascular stents to prevent occlusion and restenosis after transluminal angioplasty. N Engl J Med 1987; 316: 701-706.

8. Reiber JHC, Serruys PW, Kooijman CJ, Wijns W, Slager CJ, Gerbrands JJ, Schuurbiers JCH, den Boer A, Hugenholtz 
PG: Assessment of short-, medium-, and long-term variations in arterial dimensions from computer assisted quantitations of coronary cineangiograms. Circulation, 1985; 280-288.

9. Reiber JHC, Scrruys PW, Kooijman CJ, Slager CJ, Schuurbier JCH, den Bocr A: Approaches towards standardization in acquisition and quantitation of arterial dimensions from cineangiograms. In: State of the art in quantitative coronary arteriography. JHC Reiber and PW Serruys (eds), Martinus Nijhoff Publishers, 1986.

10. Reiber JHC: Morphologic and densitometric analysis of coronary arterics. In: Progress in digital angiocardiography. PM Heintzen and JH Bürsch (eds), Kluwer Academic Publishers, 1988.

11. Reiber JHC, Kooijman CJ, Slager C: Improved densitometric assessment of percent area stenosis from coronary cineangiograms. Abstract X World Congress of Cardiology. Washington DC, 1986.

12. Vlodaver Z, French K, Van Tassel RA, Edwards JE: Correlation of the antemortem coronary arteriogram and the post mortem specimen. Circulation 1973; 47: 162 .

13. Frondin CM, Dyrda I, Pasternac A, Campean L, Bourassa MG, Lesperance J: Discrepancies between cineangiographic and post mortem findings in patients with coronary artery disease and recent myocardial revascularization. Circulation, 1981: 49: 703.

14. Isner JM, Kistul J, Kent KM, Ronan Jr. JA, Ross AM, Roberts WC: Accuracy of angiographic determination of left main coronary arterial narrowing. Circulation, 1981; 63: 1056.

15. Thomas AC, Davies MJ, Dilly S, Dilly N, France F: Potential errors in the estimation of coronary arterial stenosis from clinical arteriography with reference to the shape of the coronary arterial lumen. Br Heart J, 1986; 55: 129-139.

16. Janssen JHA, Ackermans S, Mulkens G, Winter R: A modified ECG-triggered cine film marker unit for DSA studies of the heart and great vessels. Angiology, 1986, 37; 9: 654-657.

17. Bürsch J, Joh SR, Heintzen P: Validity of Lambert-Becr's law in Roentgen densitometry of contrast material (urografin) using continous radiation. In: Heintzen P (ed). Roentgen-, cine- and videodensitometry. George Thieme Verlag, Stuttgart 1971; pp. $81-84$.

18. Doriot $P$, Pochon $Y$, Welz R, Rutishauser W: Nonlinearity by densitometric measurements of coronary arteries. In: Heintzen P, Bursch JH (eds). Progress in digital angiocardiography. Kluwer Academic Publishers, Dordrecht 1988; pp. 173-180.

19. Levin DC, Gardiner GA: Complex and simple coronary artery stenoses: A new way to interprete coronary angiograms based on morphologic features of lesions. Radiology, 1987; 164: 675-680.

20. Frink RJ, Rooney Jr. P, Trowbridge J, Rose J: Coronary thrombosis and platelet film microemboly in death associated with acute myocardial infarction. $\mathrm{Br}$ Heart J, 1988; 59: 156200.

21. Ambrose J, Winters S, Slem A ct al: Angiographic morphology and the pathogenesis of unstable angina. J Am Coll Cardiol, 1985; 5: 609-616.

22. Ambrose J, Hjemdahl-Monsen C, Borrico S et al: Quantita- 
tive and qualitative effects of intracoronary streptokinase in unstable angina and non-Q wave infarction. J Am Coll Cardiol, 1987; 9: 1156-1165.

23. Williams A, Frecman M, Chioholm K, Patt N, Armstrong P: Angiographic morphology in unstable angina pectoris. Am J Cardiol, 1988; 62: 1024-1027.

24. Hori $M$, Inouc $M$, Shimazu $T$, Mishima $M$ et al: Clinical assessment of coronary arterial elastic properties by the image processing of coronary arteriograms. Comp Cardiol, 1983: 393-395.

25. Mancini G, Vogel R: Coronary arteriography, stress test and coronary flow reserve measurements: Comparative studies. In: Progress in digital angiocardiography. Heintzen $P$ and Bürsch J (eds), Kluwer Academic Publishers, Dordrecht, The Netherlands, 1988; 293-304.

26. Gould K: Functional and anatomic assessment of coronary artery stenosis. In: Progress in digital angiocardiography. Heintzen P and Bürsch J (eds), Kluwer Academic Publishers, Dordrecht, The Netherlands, 1988; 305-326.

27. Sherman C, Litvack F, Grundvest W, Lee M, Hickey A, Chaux A, Kass K, Blanche C, Matloff J, Morgenstern L, Ganz W, Swan H, Forrester J: Coronary angioscopy in patients with unstable angina pectoris. N Engl J Med 1986; 315: 913-919.

28. Marcus M, White C, Kirchner P: Isn't time to reevaluate the sensitivity of non-invasive approaches for the diagnosis of coronary heart disease? JACC 1986; 8: 1033-1034.

29. Ariyoshi S: The Doctor's Wife. Tokyo, New York: Kodansha International Ltd., 1978. 


\section{Samenvatting}

In dit proefschrift worden nieuwe methoden beschreven met betrekking tot het gebruik van video beelden bij de angiografie van het hart. $\mathrm{Na}$ een historisch overzicht van opname technieken in de cardiologie wordt in hoofdstuk twee nader ingegaan op de in Maastricht gebezigde methodiek. Een apparaat om nauwkeurig het electrocardiogram op de cinefilm van het angiogram aan te geven wordt beschreven in hoofdstuk 3. Hierdoor wordt het mogelijk om zo nauwkeurig mogelijk te subtraheren vanaf cinefilm. Tegelijkertijd wordt onderzocht welke de variatie in diameter van de kransslagader voor een invloed heeft op de nauwkeurigheid en reproduceerbaarheid van de meting. In de hoofdstukken 4 en 5 wordt beschreven hoe de röntgendosis belangrijk kan worden gereduceerd door gebruik te maken van digitale technieken. Enerzijds kan een reductie tijdens doorlichten worden verkregen door met behulp van bewerking (filtering) van videobeelden de beeldkwaliteit te verbeteren, anderzijds kan tijdens cineangiografie de opnamesnelheid van de beeldjes met ruim $50 \%$ worden gereduceerd, waarbij de geinduceerde hinderlijke flikkering van het beeld teniet gedaan wordt door een zogenaamde gapfiller. De klinische toepassing van het gebruik van bewerkte videobeelden wordt in de volgende hoofdstukken besproken. Het gebruik van de digitale subtractie techniek bij de diagnose en behandeling van de acute longembolie wordt gedemonstreerd in hoofdstuk 6 . Deze ernstige aandoening die helaas dikwijls wordt miskend, kan uitstekend worden aangetoond met behulp van digitale subtractie angiografie (DSA). Deze techniek kan ook worden gebruikt om het resultaat van thrombolytische therapie na te gaan. Hoofdstuk 7 gaat in op onze ervaring met linker hartkamer (ventrikel) an- 
giografie bij patienten met een acuut hartinfarct. Door het verlagen van de hoeveelheid contrast en het behoud (m.b.v. digitale techniek) van de benodigde informatie is het risico van de procedure voor de patient beperkt. Er bestaan bij het beoordelen van vernauwingen van kransslagaders (coronairvaten) aanzienlijke verschillen tussen verschillende waarnemers. Zelfs wanneer dezelfde waarnemer een film meerdere malen moet beoordelen bestaat er een significante variabiliteit. Om deze verschillen te verminderen en om te onderzoeken of door quantificering van de vernauwingen in kransslagader groepen hoge risicopatienten herkend kunnen worden is exacte meting van de vernauwing wenselijk. In de hoofdstukken 8 en 9 worden de resultaten beschreven van quantitatieve analyse van kransslagadervernauwing met behulp van het Cardiovascular Angiography Analysis Systems (CAAS) systeem bij patienten met instabiele angina pectoris of een dreigend hartinfarct. De laatste jaren wordt er in toenemende mate aandacht besteed aan de preventie van hart- en vaatlijden. Naast preventie wordt nu ook een regressie van kransslagaderlijden vermoed door maatregelen als het verlagen van het serum cholesterol. Daar het coronair angiogram wordt beschouwd als de "gouden standaard" voor bestudering van de kransslagader in de levende mens wordt deze standaard kritisch geëvalueerd in hoofdstuk 10. Daarbij blijkt dat deze "gouden standaard" op z'n best "brons" genoemd mag worden. 


\section{Summary}

In this dissertation new applications of video image processing in cardiovascular angiology are described. After a historical overview in chapter one, the digital techniques used in the catheterisation laboratory of the University Hospital of Mastricht, The Netherlands is discussed in chapter two. In chapter 3 the construction of an ECG triggered cinefilm marker is reported which permits correct identification of the $\mathrm{R}$-wave of the electrocardiogram on the cinefilm. This makes it possible to obtain high quality subtraction studies from cinefilms. Variation in coronary diameter and its influence on reproducible measurements is also investigated. As shown in chapter 4 the X-ray dose can be markedly reduced during fluoroscopy procedures by the application of image enhancement and filtering techniques; the resulting images still have sufficient image quality for diagnostic purposes. Chapter 5 describes the possibilities of reducing radiation by reducing the film-speed. However, acquiring images at low frequency introduces a flicker, which can interfere with the diagnostic capacity of the film. The use of gap-filling and last image hold techniques will diminish this problem significantly, so that an optimal balance between radiation used and image quality is obtained. The clinical application of video image processing is shown in the following chapters. Pulmonary embolism which often presents a diagnostic problem can be diagnosed using subtraction techniques. The use of this technique in patients presenting with acute symptoms of dyspnea is discussed in chapter 6 . During acute revascularization procedures in patients with myocardial infarction, repeated left ventriculography, using contrast material, may be an unwanted burden on left ventricular performance. In chapter 7 our experience is described with low dose contrast ventriculography. It is shown that contrast 
which is diluted up to $70 \%$ can still be diagnostic in $90 \%$ of cases.

In judging the severity of coronary artery disease from coronary angiograms there exists considerable interand intra observer variability. In an effort to reduce these variations and to investigate whether quantitative analysis of coronary arteries can be of help in the stratification of patients at risk, we undertook several investigations. Chapter 8 reports our results in patients with unstable angina and shows that there is a wide variation in degree of stenosis, presence of thrombus and morphology of the stenosis. This indicates that in these patients it is not yet possible by quantitative coronary analysis alone to determine those at risk to develop an acute coronary syndrome. However, in chapter 9 , our study of patients presenting with acute chest pain and a typical pattern on the ECG, previously described by de Zwaan et al. (1), shows that in all these patients the coronary angiogram most likely reveals a $70-100 \%$ stenosis in the proximal left anterior descending coronary artery. also, in approximately $30 \%$ of the patients, the morphology of this lesion suggests the presence of a thrombus. Quantitative coronary angiography allows the objective assessment of the severity of a coronary artery lesion and might be a key in predicting "the malignancy" of coronary artery stenosis.

Chapter 10 addresses the variability in analysis of coronary artery disease. Cine Coronary Angiography, however, being regarded as the gold standard must be carefully approached. "Bronze" would probably be a more justified definition of the method and in chapter 10 we suggest frame to frame analysis as one way to cope with the variations observed.

Reference

1. De Zwaan C, Bär FWHM, Wellens HJJ: Characteristic electrocardiographic pattern indicating a critical stenosis high in left anterior descending coronary artery in patients admitted because of impending myocardial infarction. Am Heart $\mathrm{J}$. 1982; 103: 730-735. 


\section{Subject index}

ADC. Sec Analog-to digital converter

Algorithms 30

Amplification 26

Analog-to digital converter $21,23,25,62$

Angina pectoris 2, 88

Arrival time 31,45

Arterial blood flow 33, 46

Artifacts 37,42

Athcrosclerosis 39, 49, 50, 99, 112

Atrial pacing 36

Atrial septal defect 46

Automated contour detection 89

Beam hardening 117

Bit 23, 24, 25

Breath holding 38

Brightness 23, 26, 99

\section{Calipers 104}

Callibration 89

Cardiac output, and contrast administration 6,37 , 76

Cardiovascular Angiography Analysis System (CAAS) 21, 24, 33, 36, 40, 50, 89, 100, 105

Cardiac cineangiography $33,37,40,68$

Cardiac digital angiography 37

Catheter Cook 37, 40

Catheter Cordis 40, 107

Charge-coupled device (CCD) camera 21, 105

Cine film, costs $21,51,71$

Cine pulse marker 2, 20, 51

Contrast $5,16,27,36,64$

Contrast dilution $16,17,40,85$

Contrast materials $6,31,34,37,40,47$

Coronary arteriography, quantitative 49

Coronary artery 7,22

Coronary artery disease 1, 29

Coronary carc unit 78

Coronary flow reserve (CFR) 20, 33, 45, 46

Densitometry $16,34,35,43,44,46,50,90,106$

Diagnosis of coronary artery disease 88

Diagnosis of pulmonary cmbolism 79, 80

Diagnosis of unstable angina pectoris 2, 49, 88, 97

Digital angiography $1,16,25$

Digital fluoroscopy $15,16,59$
Digital subtraction angiography $20,26,76$

Digital disks 25, 36

Dosimetry index 59

Dual energy imaging 29

Edge detection 89

EIA 22, 74, 83

Ejcction fraction 86

Electrocardiogram $5,28,29,36,38,43,51,56,74$, $89,98,113$

Echocardiography 79

Electrophysiology 59

Embolectomy 79, 80

Encrgy subtraction 27, 29

End-diastole, acquisition of frames $29,32,50,54$

Equipment 20

\section{Field 69}

Filter $61,75,111$

Film subtraction 28

Filter, pulmonary 75,79

Fluoroscopy 59, 68, 83

Focal spot 116

Frame 29, 42, 69, 109

Frame rate $36,40,42,69$

Functional imaging $16,17,29,30,32,120$

Gated interval difference subtraction $27,29,31$ Gap filling 70

Gray levels 24, 32

Grid 55

Heart rate 42,119

Hexabrix 40, 45, 51, 107

\section{ICRP 11}

Imaging chain 21,23

Image intensifier 21, 83, 107

Image processor 16

Image quality 46.59

Intervention cardiology 38,66

Intra-arterial digital subtraction angiography 37

Intravenous digital subtraction angiography 36,39

Iodine 26

Ionizing radiation 1,9

Iopamiro 107, 111 
Lambert- Beer 117

Lag 63

LED 51

Left ventricle 6

Lipids 50

Linear density profile 117

Logarithmic amplification 21

Logarithmic relation 117

Mask mode substraction $27,74,83$

Matrix size 22, 25, 33

Medrad Mark IV 40

Modulation transfer function (MTF) 23, 25

Morphology 92, 104, 112, 119

Myocardial infarction 49, 66

Myocardial ischacmia 49,78

Myocardial perfusion 31,34

Noise 55, 61

Nuclear medicine 79

Nuclear powcr 9

Occupational exposure 59

Off-line 21, 23, 33

On-line 1, 21, 25, 29, 32, 33, 44, 73, 79, 83

Operator 74

\section{Papaverine 45}

Parametric imaging 30, 32

Patient motion 36

Percutaneous transluminal coronary angioplasty

$$
1,50,59
$$

Pincushion distortion 105

Pixel 20, 22, 23, 27, 31, 33, 62, 74

Post mortem 49, 101, 108, 114

Post processing 29

Processor 14

Projections 110

PSI 41

Pulmonary artery 44, 46, 73

Pulmonary embolism 2, 73

Pulmonary flow 47

Pulsed fluoroscopy 78

Quantitative analysis $49,50,89,97,104,116$

Quantum mottle 61
Radiation 7, 11, 59,64, 68, 83

Radiation, biological effects 10

Radioactivity 7, 73

Recombinant tissuc plasminogen activator 75,88

Recursive filtering 60

Region of interest (ROI) 35

Remasking 74

Renal disease 37

Resolution 16, 23, 24, 36

Röntgen Wilhelm C 3, 4

Rose model 23

Shunt 46

Sievert 10

Signal-to-noise ratio 65

Spatial resolution 16

Streptokinase 73, 88

Stenosis, coronary 50,88

Stent 1, 50

Subtraction $15,16,28,75$

Tagarno 33,83

Television camera 22,83

Temporal subtraction 27

Tetralogy of Fallot 47

Threshold 33

Thrombolyquine 38

Thrombolytic therapy $49,75,91,108$

Time interval difference $31,60,85$

Time intensity curves $29,32,33$

UNSCEAR 19

UPET 79

Veiling glare 112

Vena cava 75

Ventriculography 5, 6, 33, 40, 71, 83, 98

Video image processor 14, 33, 40, 60, 68

Video densitometry 90

Wall motion 86

$\mathrm{X}$-ray $1,3,5,7,8,16,25,28,43,46,66,71,107$, 117

Ziedses des Plantes, BG 26, 28 


\title{
Curriculum vitae
}

\author{
J.H.A. Janssen
}

18 december 1954 (Geboren te Geleen) 1967-1974 Atheneum-B, St. Michiellyceum te Geleen 1974-1980 Geneeskunde, Rijksuniversiteit Limburg 1980-1985 Opleiding tot cardioloog, opleider Prof. H.J.J. Wellens

Werkzaam als cardioloog bij de vakgroep

Cardiologie in het Academisch Ziekenhuis Maastricht 